\title{
Validade e confiabilidade do peso, estatura e IMC auto- referidos obtidos em entrevistas telefônicas
}

ALESSANDRA LUCCA

Tese apresentada ao Programa de PósGraduação em Saúde Pública para obtenção do título de Doutor em Saúde Pública.

Área de concentração: Nutrição.

Orientador: Prof. Dr. Carlos Augusto Monteiro

\section{São Paulo}

2006

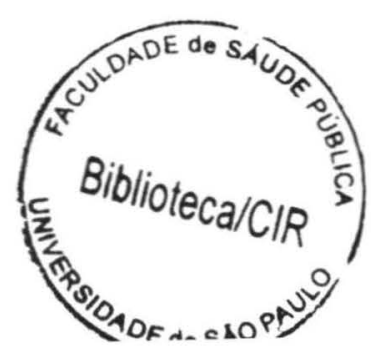


É expressamente proibida a comercialização deste documento, tanto na sua forma impressa como eletrônica. Sua reprodução total ou parcial é permitida exclusivamente para fins acadêmicos e científicos, desde que na reprodução figure a identificação do autor, título, instituição e ano da tese/dissertação.

4780712006 doc 


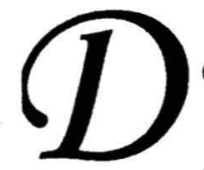

edico este trabalho à minha querida mãe, Amelia Lucca (in memorian).

Uma mulher singular, forte, generosa, que num gesto de amor incondicional, transformou-me em sua "filha do coração" quando eu ainda nem me entendia por gente e sempre fez questão de dizer, a quem quer fosse, que eu era seu orgulho e uma das alegrias de sua vida.

Uma pessoa que mesmo não tendo oportunidade de concluir os estudos, sempre o valorizou e nunca poupou esforços para que eu o fizesse.

Infelizmente, por desígnios do destino, não pôde realizar seu sonho de ver a filha tornando-se doutora. Entretanto, tenho certeza, de que onde quer que esteja, continua me iluminando e motivando para que eu siga meu caminho.

Não poderia deixar de falar, também, do meu querido pai, Indalécio Lucca (in memorian), que apesar da breve passagem de dezessete anos pela minha vida, é uma referência de doçura e paciência. Minha gratidão eterna. 
o Eduardo, meu querido companheiro, que com muito amor, carinho e paciência, esteve sempre ao meu lado durante todo o doutorado, me apoiando nos momentos bons e ruins e tornando, sem dúvida, minha jornada mais prazerosa. Eu dedico este trabalho e a minha vida. 


\section{AGRADECIMENTOS}

Agradeço a Deus pela vida e por iluminar meu caminho, dando-me forças para continuar diariamente.

Ao professor Dr. Carlos Augusto Monteiro pela oportunidade, confiança e valorosas contribuiçōes neste trabalho. Minha admiração e respeito.

À Faculdade de Saúde Pública, pela oportunidade de realização do curso de doutorado.

Aos professores da banca examinadora: Prof. Dr. Eduardo Faerstein, Prof ${ }^{a} r^{a}$ Erly Catarina de Moura, Prof. Dr. José Maria Pacheco de Souza e Prof ${ }^{a}$ Dr $^{a}$ Patrícia Constante Jaime pelas críticas e sugestões que tanto enriqueceram o trabalho.

À coordenadora do Projeto Platino na América Latina, $\mathrm{Dr}^{\mathrm{a}}$ Ana Baptista de Menezes e ao coordenador de campo em São Paulo, Dr. José Roberto Jardim, por terem cedido as fichas de controle viabilizando, assim, o contato telefônico com os participantes.

À Prof ${ }^{\circ} \mathrm{Dr}^{\mathrm{a}}$ Maria de Jesus Mendes da Fonseca e à coordenação do Estudo Pró-Saúde (prof $\mathrm{Dr}^{\mathrm{a}}$ Claudia Lopes, prof ${ }^{\mathrm{a}} \mathrm{Dr}^{\mathrm{a}}$ Dóra Chor; Prof. Dr. Eduardo Faerstein e Prof. Dr. Guilherme Werneck) pelo envio do banco de dados.

A todos os participantes que concordaram em informar seus dados antropométricos por telefone, sem os quais este trabalho não seria possivel.

Ao professor Dr. Wolney Conde pelas preciosas e atualizadas indicações de literatura no início do processo, que enriqueceram sobremaneira este trabalho e, ainda, pela paciência em sanar algumas dúvidas.

À bibliotecária Maria Lúcia E. F. Ferraz, da Biblioteca da Faculdade de Saúde Pública pelo auxílio no levantamento bibliográfico.

Aos funcionários da Faculdade de Saúde Pública em especial à Alessandra Blaya Frutuoso e Regina Rodrigues pela paciência e por mostrarem-se sempre prestativas, e à Maria Aparecida Mendes - "Cidinha" - do Serviço de Aprimoramento pela simpatia.

Aos funcionários da Biblioteca da Faculdade de Saúde Pública e aos funcionários do "xerox do Angelino" pela constante colaboração.

À Ângela Tavares Paes pela elaboração e revisão de algumas análises estatísticas.

À toda minha família, minha irmã Isabel e meus sobrinhos Daniela e Tiago, que sempre me apoiaram e que tiveram que conviver com minhas ausências. 
À minha sogra Hortência, Mirley, Henrique, Paulo, Leidiane e Felipe pelo carinho e torcida constante.

Aos amigos e colegas do doutorado, em especial Lili e Iramaia, pela convivência durante o curso e pelas singelas contribuições do dia-a-dia.

$E$, finalmente, a todos que direta ou indiretamente colaboraram para a realização deste estudo e que não foram aqui mencionados. O meu sincero agradecimento pelo apoio e carinho. 
Não diga "eu achei a verdade", mas sim "eu achei uma verdade".

Kahlil Gibran - escritor sírio 


\section{RESUMO}

Lucca A. Validade e confiabilidade do peso, estatura e IMC auto-referidos obtidos em entrevistas telefônicas [Tese de doutorado]. São Paulo: Faculdade de Saúde Pública da USP; 2006.

Introdução - O peso e a estatura auto-referidos são amplamente utilizados em estudos epidemiológicos, principalmente por favorecer a economia de recursos e a simplificação do trabalho de campo, no entanto, apesar de mais convenientes do que as medidas diretas, estas medidas podem ser inacuradas. Objetivo - Avaliar a validade e confiabilidade do peso, estatura e IMC auto-referidos obtidos por entrevista telefônica $\mathrm{e}$ investigar os fatores associados com a validade das medidas antropométricas referidas. Métodos - Estudou-se 726 adultos residentes na área metropolitana de São Paulo, participantes de um estudo multicêntrico cuja amostra era representativa da população adulta com 40 ou mais anos de idade. 0 peso e estatura auto-referidos foram coletados por entrevista telefônica e as aferições foram realizadas até 14 dias após esta entrevista. Para avaliar as diferenças nos parâmetros aferidos e referidos, utilizou-se o teste t pareado de Student, gráficos de Bland e Altman (1986) coeficiente de correlação intraclasse (CCIC) e coeficiente de correlação de concordância (CCC) de Lin (1989). Estimaram-se a sensibilidade e a especificidade das várias categorias do IMC e equações de predição para o peso e estatura aferidos. Resultados - Houve tendência de superestimação da estatura em ambos os sexos, subestimação do peso no caso das mulheres e superestimação no caso dos homens. A sensibilidade $(71 \%)$ e especificidade $(96 \%)$ do diagnóstico de obesidade foram altas. $O$ peso e o IMC referidos apresentaram boa concordância quando comparados às suas respectivas aferições $(C C C=0,94$ para peso e $C C C=0,86$ para $I M C)$; a estatura autoreferida, entretanto, mostrou-se menos confiável ( $C C C=0,75$ para homens e $C C C=0,60$ para mulheres). Os modelos de regressão apresentaram desempenho apenas razoável quando aplicados em população diferente daquela que gerou os modelos (Pró-Saúde). Porém, as equações preditivas desenvolvidas em metade da amostra (PLATINO), quando aplicadas no restante da amostra, foram úteis em aproximar a prevalência de obesidade referida da real prevalência de obesidade, bem como em melhorar a sensibilidade do diagnóstico de obesidade. Conclusões - A obtenção da informação 
do peso e estatura por entrevista telefônica é um método válido para estimar a prevalência da obesidade nesta população. Entretanto, devido aos vieses sistemáticos encontrados, o pesquisador deve estar ciente da necessidade de corrigir estes erros e, se possivel, testar equações de calibração em subamostra da população a ser estudada.

Descritores: Validade; Confiabilidade; Peso e Estatura Auto-referidos; IMC; Obesidade; Entrevista Telefônica. 


\section{ABSTRACT}

Lucca A. Validade e confiabilidade do peso, estatura e IMC auto-referidos obtidos por entrevista telefônica/ Validity and reliability of self-reported weight, height and Body Mass Index from telephone interview [Thesis]. São Paulo (BR): Faculdade de Saúde Pública da Universidade de São Paulo; 2006.

Background - For practical and economic reasons, self-reports of height and weight are widely used in epidemiologic surveys, however, although more convenient than objective measurement, may be inaccurate. Obesity extension and probably the continuing rise in prevalence show the relevance of efforts to monitor the population's BMI. Objective - To assess the validity and reliability of self-reported weight, height and body mass index from telephone interview and to examine factors associated with validity of self-reported anthropometrics measures. Methods - Self-reported weight and height were collected by telephone interview from 726 adults living in metropolitan area of São Paulo, who had participated in multicentric survey which representative sample of adults aged 40 years or more. The objectives measures were done 14 days after telephone interview. In order to evaluate the differences between the measured and the reported parameters Student's paired test, Bland e Altman (1986) graphs, the intraclass correlation coefficient (ICC) and the concordance correlation coefficient (CCC) by Lin (1989) were used. The sensitivity and specificity of the various BMI categories and weight and height prediction equation were estimated. Results - There was a trend toward height overestimation in both sexes, however weight underestimation in women and weight overestimation in men. The sensitivity (71\%) and specificity (96\%) to diagnose obesity were high. There was good agreement between measured and selfreported weight and $\mathrm{BMI}(\mathrm{CCC}=0,94$ for weight and $\mathrm{CCC}=0,86$ for $\mathrm{BMI})$, however selfreported height was less reliable ( $C C C=0,75$ for men and $C C C=0,60$ for women). The linear prediction equations have been only reasonable when tested in different population from those who originated the models (Pró-Saúde). However, the weight and height prediction equations developed in sample half (PLATINO), when applied in remainder half, were useful in to approximate the self-reported obesity prevalence from real obesity prevalence, as well as improve the sensitivity to diagnosis obesity. Conclusions - Self-reported weight and height obtained from telephone interview is 
valid to estimate the obesity prevalence in this population. However, due to systematic bias found, researchers should be aware of the need to correct this bias and, if possible, to test the predictive equations in a random sub sample.

Descriptors: Validity; Reliability; Self-reported Weight and Height; BMI; Obesity; Telephone Interview. 


\section{ÍNDICE}

1. INTRODUÇÃO 17

1.1. Obesidade: Relevância do Problema 17

1.2. A ocorrência de obesidade no mundo 21

1.3. A ocorrência de obesidade no Brasil 24

1.4. Medidas de Sobrepeso e Obesidade: O Índice de Massa Corporal

1.5. Peso e Estatura Referidos: Avaliação da qualidade da informação

1.5.1. Validade (Acurácia) $\quad 30$

1.5.2. Confiabilidade (Precisão) 31

1.5.3. Controvérsia sobre a validade e confiabilidade das informaçōes referidas de peso e estatura 33

1.5.4. Validade e confiabilidade dos dados obtidos por telefone 44

2. OBJETIVOS 65

3. MATERIAL E MÉTODOS 66

3.1. Amostragem 66

3.2. Coleta de dados 67

3.3. Variáveis de estudo 68

3.4. Análise dos dados 69

4. RESULTADOS 76

4.1. Análise das diferenças entre peso referido e aferido 78

4.2. Análise das diferenças entre estatura referida e aferida $\quad 81$

4.3. Análise das diferenças entre o IMC referido e aferido 84

4.4. Estudo do impacto dos erros de medidas auto-referidas na aferição da magnitude da obesidade e do excesso de peso 88

4.5. Confiabilidade das medidas auto-referidas 92

4.5.1. Coeficiente de Correlação de Pearson 92

4.5.2. Coeficiente de Correlação Intraclasse (CCIC) 93

4.5.3. Coeficiente de Correlação de Concordância (CCC) 95

4.6. Modelos para correção de medidas referidas - I 103

4.7. Aplicação dos modelos de correção para peso e estatura referidos em população distinta daquela que deu origem aos modelos (População do Estudo Pró-Saúde) 
4.8. Modelos para correção de medidas referidas - II

4.9. Aplicação dos modelos de correção para peso e estatura referidos, elaborados a partir de metade da amostra, em metade restante da amostra

5. DISCUSSÃO

5.1. Validade do diagnóstico de obesidade

5.2. Desempenho dos modelos para correção das medidas referidas

5.3. Diferenças entre entrevista telefônica e entrevista pessoal ou questionário de auto-preenchimento

5.4. Limitações do estudo

5.4.1. Validade interna

5.4.2. Validade externa

5.5. Implicações dos resultados 


\section{Lista de Tabelas}

Tabela 1 - Características e conclusōes de estudos nacionais e internacionais que utilizaram informaçōes auto-referidas de peso e estatura.

Tabela 2 - Distribuição da população adulta com 40 ou mais anos de idade da área metropolitana de São Paulo (2003), segundo variáveis sócio-demográficas, por sexo.

Tabela 3 - Média (e desvio-padrão) de peso, estatura e índice de massa corporal (IMC) segundo medidas aferidas e referidas, por sexo. População adulta com 40 ou mais anos de idade da área metropolitana de São Paulo, 2003.

Tabela 4 - Médias das diferenças entre peso referido e aferido, segundo faixa etária, escolaridade, grupo étnico, quartis de peso e estatura aferidos e categorias de índice de massa corporal (IMC) aferido, por sexo. População adulta com 40 ou mais anos de idade da área metropolitana de São Paulo, 2003.

Tabela 5 - Médias das diferenças entre estatura referida e aferida, por sexo, segundo faixa etária, escolaridade, grupo étnico, quartis de peso e estatura aferidos e categorias de índice de massa corporal (IMC) aferido. População adulta com 40 ou mais anos de idade da área metropolitana de São Paulo, 2003.

Tabela 6 - Médias das diferenças entre o indice de massa corporal (IMC) calculado com base nos valores referidos e aferidos, por sexo, segundo faixa etária, escolaridade, grupo étnico, quartis de peso e estatura aferidos e categorias de IMC aferido. População adulta com 40 ou mais anos de idade da área metropolitana de São Paulo, 2003.

Tabela 7 - Distribuição da população adulta com 40 ou mais anos de idade da área metropolitana de São Paulo (2003) segundo estado nutricional baseado no peso e estatura aferidos e referidos, por sexo.

Tabela 8 - Sensibilidade (\%) e Especificidade (\%) do diagnóstico de obesidade (IMC $\geq$ $30 \mathrm{~kg} / \mathrm{m}^{2}$ ) com base em medidas referidas, por sexo, segundo faixa etária e escolaridade. População adulta com 40 ou mais anos de idade da área metropolitana de São Paulo, 2003.

Tabela 9 - Sensibilidade (\%) e Especificidade (\%) do diagnóstico de excesso de peso (IMC $\geq 25 \mathrm{~kg} / \mathrm{m}^{2}$ ) com base em medidas referidas, por sexo, segundo faixa etária e escolaridade. População adulta com $\mathbf{4 0}$ ou mais anos de idade da área metropolitana de São Paulo, 2003. 
Tabela 10 - Valor Preditivo Positivo (\%), Valor Preditivo Negativo (\%) e Eficiência do teste (\%) do diagnóstico de obesidade (IMC $\geq 30 \mathrm{~kg} / \mathrm{m}^{2}$ ) e de excesso de peso (IMC $\geq 25 \mathrm{~kg} / \mathrm{m}^{2}$ ) com base em medidas referidas, por sexo. População adulta com 40 ou mais anos de idade da área metropolitana de São Paulo, 2003.

Tabela 11 - Coeficiente de correlação de Pearson entre medidas referidas e aferidas, por sexo, segundo variáveis sócio-demográficas. População adulta com 40 ou mais anos de idade da área metropolitana de São Paulo, 2003.

Tabela 12 - Coeficiente de correlação intraclasse (CCIC) entre medidas referidas e aferidas, segundo variáveis sócio-demográficas, por sexo. População adulta com 40 ou mais anos de idade da área metropolitana de São Paulo, 2003.

Tabela 13 - Coeficiente de correlação de concordância (CCC) entre medidas referidas e aferidas, segundo variáveis sócio-demográficas, por sexo. População adulta com 40 ou mais anos de idade da área metropolitana de São Paulo, 2003.

Tabela 14 - Coeficientes de Pearson, correlação intraclasse e correlação de concordância entre medidas referidas e aferidas, por sexo. População adulta com 40 ou mais anos de idade da área metropolitana de São Paulo, 2003.

Tabela 15 - Resultados de modelos de regressão para correção do peso referido. População adulta com 40 ou mais anos de idade da área metropolitana de São Paulo, 2003.

Tabela 16 - Resultados de modelos de regressão para correção da estatura referida. População adulta com $\mathbf{4 0}$ ou mais anos de idade da área metropolitana de São Paulo, 2003.

Tabela 17 - Média (e desvio-padrão) de peso, estatura e índice de massa corporal (IMC) segundo medidas aferidas e referidas, por sexo. Adultos com 40 ou mais anos de idade do Estudo Pró-Saúde, 2003.

Tabela 18 - Média (e desvio-padrão) de peso, estatura e índice de massa corporal (IMC) segundo medidas aferidas e referidas/ajustadas, por sexo. Adultos com 40 ou mais anos de idade do Estudo Pró-Saúde, 2003.

Tabela 19 - Distribuição segundo categorias de IMC calculado a partir de medidas aferidas, referidas e referidas/ajustadas, por sexo. População adulta com 40 ou mais anos de idade do Estudo Pró-Saúde, 2003. 
Tabela 20 - Sensibilidade (\%) e Especificidade (\%) do diagnóstico de obesidade (IMC $\geq$ $30 \mathrm{~kg} / \mathrm{m}^{2}$ ) com base em medidas referidas com e sem ajuste, segundo faixa etária e escolaridade, por sexo. População adulta com 40 ou mais anos de idade do Estudo Pró-Saúde, 2003.

Tabela 21 - Valor Preditivo Positivo (\%), Valor Preditivo Negativo (\%) e Eficiência do teste $(\%)$ do diagnóstico da obesidade (IMC $\geq 30 \mathrm{~kg} / \mathrm{m}^{2}$ ) com base em medidas referidas com e sem ajuste, por sexo. Adultos com 40 ou mais anos de idade do Estudo Pró-Saúde, 2003.

Tabela 22 - Sensibilidade (\%) e Especificidade (\%) do diagnóstico de excesso de peso (IMC $\geq 25 \mathrm{~kg} / \mathrm{m}^{2}$ ) com base em medidas referidas com e sem ajuste, segundo faixa etária e escolaridade, por sexo. Adultos com 40 ou mais anos de idade do Estudo Pró-Saúde, 2003.

Tabela 23 - Valor Preditivo Positivo (\%), Valor Preditivo Negativo (\%) e Eficiência do teste (\%) do diagnóstico de excesso de peso $\left(\mathrm{IMC} \geq 25 \mathrm{~kg} / \mathrm{m}^{2}\right)$ com base em medidas referidas com e sem ajuste, por sexo. Adultos com 40 ou mais anos de idade do Estudo Pró-Saúde, 2003.

Tabela 24 - Coeficientes de correlação de concordância para peso, estatura e IMC aferidos e referidos, e aferidos e referidos/ajustados. Adultos com 40 ou mais anos de idade do Estudo Pró-Saúde, 2003.

Tabela 25 - Resultados de modelos de regressão para correção do peso referido. População adulta com 40 ou mais anos de idade da área metropolitana de São Paulo, 2003.

Tabela 26 - Resultados de modelos de regressão para correção da estatura referida. População adulta com 40 ou mais anos de idade da área metropolitana de São Paulo, 2003.

Tabela 27 - Distribuição da população adulta com 40 ou mais anos de idade da área metropolitana de São Paulo, (2003) segundo categorias de IMC calculado a partir de medidas aferidas, referidas e referidas/ajustadas, por sexo.

Tabela 28 - Sensibilidade (\%) e Especificidade (\%) do diagnóstico de obesidade (IMC $\geq$ $30 \mathrm{~kg} / \mathrm{m}^{2}$ ) com base em medidas referidas com e sem ajuste, segundo faixa etária e escolaridade, por sexo. População adulta com 40 ou mais anos de idade da área metropolitana de São Paulo, 2003. 
Tabela 29 - Valor Preditivo Positivo (\%), Valor Preditivo Negativo (\%) e Eficiência do teste (\%) do diagnóstico de obesidade (IMC $\geq 30 \mathrm{~kg} / \mathrm{m}^{2}$ ) com base em medidas referidas com e sem ajuste, por sexo. População adulta com 40 ou mais anos de idade da área metropolitana de São Paulo, 2003.

Tabela 30 - Sensibilidade (\%) e Especificidade (\%) do diagnóstico de excesso de peso (IMC $\geq 25 \mathrm{~kg} / \mathrm{m}^{2}$ ) com base em medidas referidas com e sem ajuste, segundo faixa etária e escolaridade, por sexo. População adulta com 40 ou mais anos de idade da área metropolitana de São Paulo, 2003.

Tabela 31 - Valor Preditivo Positivo (\%), Valor Preditivo Negativo (\%) e Eficiência do teste (\%) do diagnóstico do excesso de peso $\left(\mathrm{IMC} \geq 25 \mathrm{~kg} / \mathrm{m}^{2}\right) \mathrm{com}$ base em medidas referidas com e sem ajuste, por sexo. População adulta com 40 ou mais anos de idade da área metropolitana de São Paulo, 2003. 


\section{Lista de Figuras}

Figura 1 - Diferenças entre peso referido e aferido por sexo. População adulta com 40 ou mais anos de idade da área metropolitana de São Paulo, 2003.

Figura 2 - Diferenças entre peso aferido e referido segundo o valor médio desses pesos e limites de concordância de $95 \%$ (LC). População adulta masculina e feminina com 40 ou mais anos de idade da área metropolitana de São Paulo, 2003.

Figura 3 - Diferenças entre estatura referida e aferida por sexo. População adulta com 40 ou mais anos de idade da área metropolitana de São Paulo, 2003.

Figura 4 - Diferenças entre estatura aferida e a estatura referida segundo o valor médio dessas estaturas e limites de concordância de $95 \%$ (LC). População adulta masculina e feminina com 40 ou mais anos de idade da área metropolitana de São Paulo, 2003.

Figura 5 - Diferenças entre o índice de massa corporal (IMC) calculado a partir dos valores referidos e aferidos por sexo. População adulta com 40 ou mais anos de idade da área metropolitana de São Paulo, 2003.

Figura 6 - Diferenças entre o índice de massa corporal (IMC) aferido e referido segundo o valor médio desses IMCs e limites de concordância de $95 \%$ (LC). População adulta masculina e feminina com 40 ou mais anos de idade da área metropolitana de São Paulo, 2003.

Figura 7 - Gráficos de concordância e coeficientes de correlação de concordância entre peso referido e aferido, por sexo. População adulta com 40 ou mais anos de idade da área metropolitana de São Paulo, 2003.

Figura 8 - Gráficos de concordância e coeficientes de correlação de concordância entre estatura referida e aferida, por sexo. População adulta com 40 ou mais anos de idade da área metropolitana de São Paulo, 2003.

Figura 9 - Gráficos de concordância e coeficientes de correlação de concordância entre índice de massa corporal (IMC) referido e aferido, por sexo. População adulta com 40 ou mais anos de idade da área metropolitana de São Paulo, 2003. 


\section{INTRODUÇÃO}

\subsection{Obesidade: Relevância do Problema}

A obesidade, definida como um acúmulo excessivo de tecido adiposo no organismo que traz prejuízo à saúde do indivíduo (NIHC, 1985), é, indiscutivelmente, o maior desafio entre as epidemias que o mundo enfrenta e vem crescendo tanto nos países desenvolvidos como naqueles em desenvolvimento. Nenhum dos países tem ainda pistas no sentido de atenuar ou reverter esta epidemia (SWINBURN et al., 2004), cujas conseqüências à saúde são muitas e variadas, levando a um aumento do risco de mortes prematuras e inúmeras condições incapacitantes não-fatais, porém com influências negativas na qualidade de vida (WHO, 2000).

A obesidade é considerada um agravo integrante do grupo de doenças não transmissíveis, não-infecciosas ou crônico-degenerativas. Tais terminologias são usadas para definir grupos de patologias caracterizados pela ausência de microorganismos no modelo epidemiológico, pela irreversibilidade, pela não transmissibilidade, pelo longo curso clínico em geral lento, prolongado e assintomático (LESSA, 1998).

Além de a obesidade ser em si uma doença, ela também é um fator de risco para outras doenças não transmissíveis (DNTs) altamente debilitantes. Estudos prospectivos têm demonstrado que sua ocorrência aumenta de forma significativa a morbi-mortalidade por diversas DNTs, incluindo o diabetes não insulino-dependente (tipo 2), a hipertensão arterial, a doença cardíaca (SEIDELL, 1997), alguns tipos de câncer (cólon, mama, endométrio e próstata), a hipercolesterolemia (SOLOMON e MANSON, 1997; BURTON et al., 1985), doenças da vesícula biliar, doenças do aparelho locomotor, distúrbios 
metabólicos e endócrinos, apnéia do sono, osteoartrite e vários problemas psico-sociais (WHO, 2000).

Estudos epidemiológicos transversais e prospectivos têm comprovado à exaustão a forte associação que fatores de risco nutricionais como obesidade, sedentarismo e dietas de composição inadequada mantêm com as doenças não transmissíveis (WHO/FAO, 2003). Com base nesses estudos, a OMS estimou recentemente a fração da carga global de DNTs que poderia ser atribuída a fatores de risco nutricionais. O sobrepeso e a obesidade responderiam por $58 \%$ da carga de doença relativa ao diabetes mellitus não insulino dependente, $39 \%$ no caso da doença hipertensiva, $23 \%$ para isquemia cerebral, $21 \%$ para doença isquêmica do coração, $13 \%$ para osteoartrite, $12 \%$ para os cânceres de cólon e reto e $8 \%$ para o câncer de mama (WHO, 2002).

Em relação às causas de mortes no mundo, o fato mais notável nas últimas décadas tem sido a queda acentuada dos óbitos decorrentes de doenças infecciosas e desnutrição e o grande crescimento das DNTs, processo denominado Transição Epidemiológica (POPKIN, 1998). O aumento da vida média e $\circ$ envelhecimento populacional aumentam a probabilidade de acometimento de DNTs, normalmente associadas com idades mais avançadas (PINHEIRO et al., 2004). A Transição Demográfica caracteriza-se pela mudança de um padrão de alta fertilidade e mortalidade (típico de países menos desenvolvidos em meados do século XX e da Europa do século XVIII) para um de baixa fertilidade e mortalidade (comum nas nações modernas industrializadas) (POPKIN, 1998).

Integra os processos de Transição Demográfica e Epidemiológica a Transição Nutricional cujo conceito engloba mudanças consideráveis no perfil nutricional de populações humanas diretamente relacionadas à adoção de um 
estilo de vida mais sedentário e à mudança de um padrão dietético tradicional para um padrão "ocidental" (POPKIN, 1994). Tais alteraçōes, verificadas particularmente nas últimas duas décadas do século $\mathrm{XX}$, são basicamente determinadas pela interação de mudanças socioeconômicas, demográficas, ambientais e culturais (POPKIN, 1993) e, no que tange aos indivíduos, podem se refletir em modificações na composição corporal, na média da estatura e elevação dos níveis de obesidade e doenças não transmissíveis relacionadas à dieta (MARTORELL et al., 2000). Entender a rapidez destas mudanças e seus fatores subjacentes em nível global, nacional e regional é importante para prevenir doenças e sustentar a saúde e a integridade humana (POPKIN, 2005).

Em todas as nações, as principais mudanças dietéticas que caracterizam a transição nutricional contemporânea incluem alterações na estrutura da dieta, tanto quali quanto quantitativamente, direcionadas a uma maior densidade energética e baixo conteúdo de nutrientes (POPKIN et al., 2002); aumento da ingestão de alimentos de origem animal, principalmente nos países de baixa renda (POPKIN, 2003); redução na ingestão de carboidratos complexos e fibras dietéticas; pobre consumo de vegetais e frutas frescas (WHO, 1990); maior ingestão de gordura e gorduras saturadas; alto consumo de carboidratos refinados e açúcares de adição (POPKIN, 1994); aumento da ingestão de óleo comestivel, fatores observados especialmente na Ásia, África e Oriente Médio (DREWNOWSKI e POPKIN, 1997); alto consumo de bebidas alcoólicas (POPKIN, 1998); maior disponibilidade e crescimento das ações de marketing das indústrias de alimentos; aumento no tamanho das porções de alimentos, especialmente em restaurantes do tipo fast food (PENA e BACALLAO, 2000; POPKIN, 1998; PEREIRA et al., 2005).

Dentro deste quadro, POPKIN (2005) aponta modificações no padrão de atividade física e de composição corporal que podem contribuir para o aumento 
da obesidade no globo. Dentre as principais mudanças que afetam o padrão de atividade física são citadas: transferência do mercado de trabalho (da agricultura e outras ocupações com gasto de energia intenso) para o setor de serviços (POPKIN, 1998); redução do nível de atividade física dentro de cada ocupação ou predomínio crescente das ocupações que demandam menor esforço físico (POPKIN, 1998; PAERATAKUL et al., 1998); o uso cada vez maior de transporte automotor e padrões de atividade física associadas ao lazer que refletem uma redução no gasto de energia (BELL et al., 2002); mecanização de todas as atividades relacionadas à produção doméstica (LANNINGHAM-FOSTER et al., 2003); redução do tempo de preparo dos alimentos pela metade - de 2 a 3 horas por dia para menos do que 1 hora por dia - bem como maior ingestão de refeições consumidas fora de casa, especialmente nos países de maior renda (NIELSEN et al, 2002); uso de elevadores e escadas rolantes; redução de atividade física nas escolas; maior utilização de computadores e aumento do tempo gasto em frente à televisão (JEFFERY, 2001).

Mudanças na composição corporal têm levado a um rápido crescimento da obesidade no mundo todo, porém a uma taxa mais rápida nos países de baixa renda (POPKIN, 2003) onde se observa declínio da desnutrição à medida que a obesidade aumenta (MONTEIRO et al., 2002) e predominância da obesidade em relação ao baixo peso entre mulheres em idade reprodutiva, tanto na área urbana como rural (MENDEZ et al., 2005); verifica-se o aumento da obesidade infantil globalmente, porém, aparentemente, em níveis menores do que em adultos (WANG et al., 2002).

Identificar a etiologia da obesidade não é tarefa simples e nem objetiva. Em termos gerais, a obesidade é o produto de um balanço energético positivo, resultante do gasto energético relativamente baixo, consumo energético 
relativamente alto ou a combinação destes fatores, promovendo um aumento nas reservas de energia e peso corporal. $O$ consumo energético é dependente da quantidade de alimentos ingeridos e da composição da dieta, principalmente em relação à proporção de gorduras. $\mathrm{O}$ gasto energético inclui tanto a energia utilizada no metabolismo basal, como aquela associada à ingestão de alimentos e também a necessária para a atividade física. $O$ consumo e o gasto energético são influenciados não só pela suscetibilidade individual determinada por fatores genéticos e biológicos, como também por fatores ambientais, sociais psicológicos, culturais e comportamentais. O papel desses componentes na determinação da obesidade é bastante complexo, pois acredita-se que 0 aumento da obesidade seja produto da interação entre estes fatores, e não só da influência isolada de um deles (WHO, 1995; 2000).

Nos países industrializados ou desenvolvidos, inquéritos antropométricos são realizados com freqüência, possibilitando verificar a prevalência e tendências da obesidade na população. Nos países em desenvolvimento, os inquéritos antropométricos são mais escassos, impedindo que se tenha uma idéia mais precisa da magnitude e tendência do problema.

\subsection{A ocorrência de obesidade no mundo}

Os problemas nutricionais relacionados ao excesso alimentar vêm crescendo a passos tão largos que as estatísticas de prevalência tornam-se rapidamente obsoletas (PRENTICE, 2006).

Um inquérito nacional com objetivo de examinar a tendência na prevalência de sobrepeso e IMC nos Estados Unidos, avaliou dados de 6.000 a 13.000 adultos com idades entre 20 e 74 anos de idade, entre 1960 a 1991 (KUCZMARSKI et al., 1994). A comparação das estimativas de prevalência de sobrepeso com dados de pesquisas anteriores, no período de 1988 a 1991, 
indicou um aumento dramático do sobrepeso em todos os grupos de idade e sexo. Durante o período de 1976 a 1991, o IMC médio aumentou de $25,3 \mathrm{~kg} / \mathrm{m}^{2}$ para $26,3 \mathrm{~kg} / \mathrm{m}^{2}$ e o ganho médio de peso foi de $3,6 \mathrm{~kg}$. O aumento na prevalência da obesidade (ajustada para a idade) previamente observada no período de 1988-1994 (22,9\%, p<0,001) (FLEGAL et al., 1998) continuou em $1999-2000(30,5 \%)$, entre homens e mulheres, em todos os grupos de idade, $\mathrm{e}$ em todos os grupos raciais (FLEGAL et al., 2002).

Em paises europeus, a prevalência da obesidade vem aumentando nos últimos anos e apresenta índices altos, porém com notáveis contrastes: por exemplo, $21 \%$ dos alemães são obesos comparados com $5 \%$ dos noruegueses (PRENTICE, 2005). Na Inglaterra a prevalência da obesidade aumentou de $7 \%$ em 1980 para 16\% em 1995 (WHO, 2000); na Espanha, cresceu de 7,6\% para $12,2 \%$ e de $8,9 \%$ para $12,1 \%$ em homens e mulheres, respectivamente (GUTIÉRREZ-FISAC et al., 2000). Na Suécia, durante os anos 80 , foi encontrado um aumento de $19 \%$ na prevalência de obesidade (IMC > $28,6 \mathrm{~kg} / \mathrm{m}^{2}$ ) na população feminina e de $19 \%$ na prevalência de sobrepeso combinado com obesidade (IMC $>25 \mathrm{~kg} / \mathrm{m}^{2}$ ) na população masculina, após ajustes para variáveis demográficas (KUSKOWSKA-WOLK e BERGSTRÖM 1993a; KUSKOWSKA-WOLK e BERGSTRÖM, 1993b).

Outros países europeus têm índices de obesidade menores como a Holanda, cujas estimativas passaram de $5 \%$ em 1980 para $8 \%$ em 1997 (SEIDELL, 1999). A Suíça apresentou taxas de obesidade de $6 \%$ e $7 \%$ (SCHUTZ e WORINGER, 2002) e França, 6,5\% e 7\% (MAILLARD et al., 1999), para homens e mulheres, respectivamente.

As maiores prevalências têm sido encontradas em países do leste Europeu como Eslovênia, Croácia e Grécia (SCHUTZ e WORINGER, 2002). Na 
Tchecoslováquia, no período de 1985-1988, a proporção de homens obesos com faixa etária entre 25 a 64 anos aumentou de $18,5 \%$ para $23,9 \%$ e de $30,2 \%$ para $33,2 \%$ no caso das mulheres (SKODOVA et al., 1991).

Em alguns países do Oriente Médio, embora haja uma considerável heterogeneidade, a obesidade parece ser um problema comum entre os adultos. $\mathrm{O}$ Irã, por exemplo, tem $10 \%$ dos adultos obesos enquanto que Bahrain tem 29\%; Egito, $25 \%$ e Arábia Saudita, $17 \%$ (PRENTICE, 2005). A prevalência de obesidade na Jordânia também é muito alta, atingindo quase $60 \%$ das mulheres e $33 \%$ dos homens (AJLOUNI et al., 1998).

Alguns dos maiores índices de prevalência de obesidade no mundo foram encontradas em várias ilhas do Pacífico com taxa recorde em Nauru onde, em 1994, 79\% dos adultos foram apontados como obesos (IMC > $30 \mathrm{~kg} / \mathrm{m}^{2}$ ) (PRENTICE, 2005). A prevalência na Nova Zelândia, em meados de 1990, era de $65 \%-70 \%$ (WHO, 2000). Na Austrália, a prevalência era de $19 \%$ na população masculina e $18 \%$ na feminina (Australian Bureau of Statistics citado por JACKSON et al., 2001).

No continente asiático, o Japão apresenta taxas de obesidade de 1,8\% e $2,9 \%$ para homens e mulheres, respectivamente (YOSHIKE et al., 1998). Índices reduzidos de obesidade também são encontrados em países pouco desenvolvidos do continente tais como a Índia, onde a prevalência de obesidade é de apenas 0,5\%; as Filipinas, 3\% e Singapura, 6\% (PRENTICE, 2005). Na China, nos últimos 10 anos, a proporção de homens chineses com sobrepeso (IMC $>25 \mathrm{~kg} / \mathrm{m}^{2}$ ) triplicou de $4 \%$ para $15 \%$ e em mulheres dobrou de $10 \%$ para $20 \%$ (BELL et al., 2001). 
As taxas da África são muito variáveis e refletem o estágio de transição de cada país, aumentando com a melhora das condições sócio-econômicas, urbanização e queda nos níveis de atividade física. Gana, por exemplo, apresenta índices de obesidade de 3\% enquanto que na África do Sul estes índices atingem $21 \%$. $\mathrm{Na}$ Cidade do Cabo, o aumento tem sido pequeno (8\%) na população masculina, porém entre as mulheres o aumento foi de $34 \%$, um nivel similar às mulheres negras americanas (WALKER et al., 2001).

Na maioria dos países da América Latina, a prevalência de obesidade é maior nas áreas urbanas do que nas áreas rurais (com exceção da Colômbia) (FILOZOF et al., 2001). Na Guatemala, a prevalência de obesidade entre as mulheres tem aumentado rapidamente passando de 8,1\% em 1995 para 16,2\% em 2000 (MARINI e GRAGNOLATI, 2003).

\subsection{A ocorrência de obesidade no Brasil}

Os problemas nutricionais relacionados ao excesso alimentar não ocorrem exclusivamente nos países desenvolvidos. Há evidências de que a pandemia da obesidade vem aumentando nas últimas décadas em inúmeros países e esteja atingindo as nações mais pobres do globo (SWINBURN et al., 2004).

No Brasil, de acordo com os dados da Pesquisa Nacional sobre Saúde e Nutrição (PNSN - 1989), na população adulta, cerca de $32 \%$ apresentavam algum grau de excesso de peso (IMC $\geq 25 \mathrm{~kg} / \mathrm{m}^{2}$ ). Destes, aproximadamente $8,3 \%$ apresentavam obesidade (IMC $\geq 30,0 \mathrm{~kg} / \mathrm{m}^{2}$ ), sendo $4,8 \%$ entre os homens e $11,7 \%$ entre as mulheres. Além disso, a maior prevalência de excesso de peso foi estimada para o grupo etário entre 45 e 54 anos de idade, 
no qual $37 \%$ dos homens e $55 \%$ das mulheres apresentaram peso acima dos limites normais (COITINHO et al., 1991).

Quando comparados com o Estudo Nacional de Despesa Familiar (ENDEF) 1974/75, uma situação preocupante é revelada: no período compreendido entre os dois inquéritos nacionais (1975-1989), houve aumento de $100 \%$ na prevalência da obesidade entre os homens e de $70 \%$ entre as mulheres, abrangendo todas as faixas etárias (COITINHO et al., 1991).

Na Pesquisa de Padrão de Vida (PPV) realizada cerca de dez anos depois pelo IBGE, restrita às regiões Nordeste e Sudeste onde estão concentrados mais de $70 \%$ da população brasileira, estimou-se que cerca de $29 \%$ da população adulta estava acima do peso ideal (IMC $\geq 25 \mathrm{~kg} / \mathrm{m}^{2}$ ) (IBGE, 1998 citado por FONSECA et al., 2003). De acordo com MONTEIRO et al. (2000), a prevalência de obesidade na população adulta que vive na região Nordeste e Sudeste do Brasil, nos anos de 1989 e 1997, aumentou quase 50\% entre os homens (4,7\% para $6,9 \%)$; entre as mulheres o aumento foi reduzido (12\% para $12,5 \%)$.

Mudanças no padrão de prevalência da obesidade podem ser vistas em alguns países que têm monitorado as taxas de prevalência durante o período de transição econômica (MONTEIRO et al., 2001). O aumento da renda per capita tem sido associado com as mudanças para uma dieta com alta densidade energética e atividade física reduzida (POPKIN, 2005). Os estudos de MONTEIRO et al. (1995; 2000; 2002 e 2004b) têm documentado que 0 aumento da prevalência da obesidade, apesar de estar distribuído em todas as regiões do país e nos diferentes estratos socioeconômicos da população, é proporcionalmente mais elevado entre as famílias de baixa renda (MONTEIRO et al., 1995). 
Uma revisão exaustiva dos estudos anteriores a 1989 identificou relações fortemente positivas entre status socioeconômico e obesidade entre homens, mulheres e crianças em $90 \%$ dos estudos conduzidos nos países em desenvolvimento e nenhum dos estudos apresentava relação inversa (MONTEIRO et al., 2004a).

Nos países em desenvolvimento, a obesidade, que inicialmente predominava nas classes econômicas de maior renda, vem apresentando uma evolução temporal com predominância nas populações mais pobres, principalmente entre as mulheres e entre aqueles que vivem em áreas urbanas (PINHEIRO et al. 2004). Nos países mais ricos, a obesidade está mais associada com menor status socioeconômico, especialmente mulheres e comunidades rurais (PENA e BACALLAO, 2000).

No caso do Brasil, dentre as regiões do País, a Sul apresenta as maiores prevalências de obesidade, sendo essas semelhantes e, até mesmo superiores, a de países desenvolvidos. Em Pelotas em 1994, um estudo transversal realizado numa amostra representativa da população adulta $(n=1035)$ residente na zona urbana, revelou uma prevalência de obesidade de $21 \%$, enquanto que quase $40 \%$ da amostra apresentou sobrepeso. A proporção de obesidade entre as mulheres foi maior $(25 \%)$ que a observada entre os homens (15\%). A proporção da obesidade estimada foi cerca de 4 vezes mais elevada no grupo com mais de 40 anos de idade do que no grupo de 20 e 29 anos de idade (GIGANTE et al., 1997).

No Rio de Janeiro, foram encontradas prevalências de obesidade sistematicamente mais elevadas entre as mulheres $(20 \%)$ do que entre os homens $(13 \%)$, com diferenças significativas entre 46 e 60 anos de idade. A 
prevalência de sobrepeso foi similar entre homens e mulheres, com exceção da faixa etária entre 26 e 45 anos de idade na qual $35 \%$ dos homens e $23 \%$ das mulheres foram classificados nesta categoria (PEREIRA, 1998).

De acordo com a Organização Mundial da Saúde, o rápido aumento global da prevalência de obesidade tem ocorrido num período tão curto de tempo, que seria imprudente atribuí-lo somente às mudanças genéticas ocorridas na população, sugerindo, portanto, que a causa primária do aumento possa ser investigada nas mudanças ambientais e sociais que afetam uma grande proporção da população mundial (WHO, 2000).

Os resultados acima descritos indicam um aumento progressivo na prevalência de sobrepeso e obesidade na maioria dos paises, sendo, portanto, crescente a importância da obesidade como tema de investigação científica. Entretanto, somente recentemente a obesidade passou a ser reconhecida como epidemia global (WHO, 1998a).

A extensão e a possível continuidade no aumento da prevalência da obesidade, bem como o risco que esta condição apresenta para patologias importantes, mostram a importância dos esforços em monitorar o peso dos indivíduos e minimizar ganhos futuros.

\subsection{Medidas de Sobrepeso e Obesidade: $O$ Índice de Massa Corporal.}

A antropometria é um método de avaliação nutricional facilmente aplicado e não-invasivo. As medidas antropométricas são valiosas em avaliações do estado de saúde em adultos por serem fortes preditores de danos funcionais, morbidade e mortalidade (WHO, 1998b). 
Em estudos epidemiológicos que têm como objeto de investigação a obesidade e/ou excesso de peso em adultos, medidas antropométricas simples e que apresentem grande reprodutibilidade têm sido recomendadas (GARROW e WEBSTER, 1985). Nesse sentido, o método que tem sido mais utilizado é o índice de massa corporal (IMC).

O IMC ou Índice de Quetelet, usado em estudos de epidemiologia descritiva e aplicações clínicas, é uma medida popular e aceitável de obesidade, definido como razão do peso (em quilos) pelo quadrado da estatura (em metros), classificando os indivíduos em desnutridos, eutróficos, com sobrepeso ou obesos.

Contudo, existem algumas limitações do IMC como medida de gordura corporal: dependência da idade, pois o IMC falha em detectar a "conversão" de massa magra para tecido gorduroso que acompanha o envelhecimento, na mensuração da gordura corporal em atletas e menor validade nos valores extremos de estatura (WILLET, 1998; HORTOBAGYI et al., 1994). Além disso, não distingue massa magra, massa gorda e edema (BURTON et al., 1985). No entanto, apesar destas limitações, O IMC apresenta alta correlação com medidas de gordura corpórea (CHOR et al., 1999; ANJOS, 1992), sendo considerado uma medida confiável (GARROW e WEBSTER, 1985). Outra vantagem do IMC seria sua relativa independência da estatura (WILLET, 1998), normalmente " $r$ " em torno de 0,10 , o que é uma característica desejável em se tratando de um indicador de massa corporal, não sendo superado por outro índice quando o grau de correlação com medidas diretas de obesidade é considerado (KEYS et al., 1972). De acordo com ANJOS (1992), o IMC parece ser um índice válido para medir o estado nutricional em grupos populacionais $\mathrm{e}$ tem sido muito utilizado por sua facilidade de cálculo e também porque o 
significado de suas categorias permite comparabilidade entre os estudos (WILLET, 1998).

A maioria dos estudos distingue obesidade e sobrepeso através do IMC, cujos pontos de corte são independentes da idade e do sexo, entre os adultos (ANJOS, 1992). O critério de obesidade (IMC $\geq 30 \mathrm{~kg} / \mathrm{m}^{2}$ ) foi selecionado devido à forte relação entre IMC e a mortalidade, sendo que neste ponto de corte o risco de mortalidade aumenta aproximadamente $30 \%$ e acima de $40 \mathrm{~kg} / \mathrm{m}^{2}$ o aumento é de $100 \%$ (MANSON et al., 1995).

A Organização Mundial da Saúde recomenda a classificação de sobrepeso (ou pré-obesos) para adultos com IMC entre 25 e 29,9 kg/m 2 e de obesos para aqueles com IMC igual ou superior a $30 \mathrm{~kg} / \mathrm{m}^{2}$ (obesidade grau I: 30-34,9; grau II: 35-39,9 e grau III: maior ou igual a $\left.40 \mathrm{~kg} / \mathrm{m}^{2}\right)$ (WHO, 1995). Esta definição padrão de sobrepeso e obesidade é derivada principalmente de populações com descendência européia (WHO, 2000a). Contudo, em populações com maior compleição, como os polinésios, tem sido usado pontos de cortes maiores (SWINBURN et al., 1999) e um ponto de corte menor tem sido proposto em populações com menor compleição, como a população chinesa (WHO, 2000b).

\subsection{Peso e Estatura Referidos: Avaliação da qualidade da informação}

A mensuração de qualquer fenômeno sempre apresenta possibilidade de erro. Segundo CARMINES e ZELLER (1979) "a meta de medições livres de erro, apesar de almejada, nunca é alcançada, em qualquer área de investigação científica". Assim, duas seqüências de medições da mesma característica 
realizadas no mesmo indivíduo, nunca irão produzir exatamente os mesmos resultados.

Em estudos epidemiológicos, a acurácia dos métodos de aferição das variáveis do estudo é fundamental pela demonstração de que a medida de aferição utilizada é capaz de avaliar o que foi planejado. Assim, é sempre importante avaliar a qualidade da informação obtida em pesquisas epidemiológicas, seja por medição direta, questionário ou qualquer outro método.

$O$ desempenho de qualquer instrumento de medida pode ser avaliado quanto a dois aspectos fundamentais: a validade (validity) e a confiabilidade (reliability), e embora estejam intimamente relacionados, são conceitos distintos. A validade e viés estão relacionados a quanto um teste mede o que ele tem que medir e refletem o quanto o teste está correto. Confiabilidade e precisão estão relacionados à possibilidade de repetição de medições por um mesmo observador ou por observadores diferentes (BERGAMASCHI, 1999; CARMINES e ZELLER, 1979).

\subsubsection{Validade (Acurácia)}

Tem-se uma observação válida quando esta corresponde ao estado verdadeiro do fenômeno que está sendo medido (FLETCHER et al., 1991). A melhor forma de avaliar a validade é por comparação com uma medida de referência que se sabe ser válida (padrão-ouro). A validade pode ser dividida em três grandes grupos:

Validade do conteúdo: refere-se ao grau que uma escala ou índice abrange os significados incluídos no conceito que tenta representar. 
Validade de constructo: baseia-se na maneira como uma medida se relaciona com outras variáveis em um sistema de relações teóricas.

Validade de critério: definida pelo grau com que um instrumento de medida produz resultados semelhantes ou próximos ao verdadeiro valor chamado "padrão ouro" (ABRAMSON, 1984).

Em estudos epidemiológicos, a validade de critério é geralmente analisada utilizando-se os indicadores de sensibilidade e especificidade, que indicam a proporção de identificações corretas em relação a um padrão e são inerentes ao instrumento de medida. Este estudo realizou a análise da validade de critério, comparando as informações referidas de peso e estatura com peso e estatura aferidos (padrão ouro).

\subsubsection{Confiabilidade (Precisão)}

Fundamentalmente, confiabilidade (reliability) refere-se à extensão na qual um experimento, teste ou qualquer procedimento de medida produz os mesmos resultados, caso este seja repetido, sob condições experimentais semelhantes (CARMINES e ZELLER, 1979).

Dados confiáveis não são necessariamente válidos. Se um equipamento produz resultados afastados do verdadeiro valor (por exemplo, uma balança que consistentemente mede o peso um quilo acima do verdadeiro valor), diz-se que o equipamento não é acurado (válido), pois produz dados viciados ou viesados (neste exemplo, não produziu uma indicação válida do peso). Entretanto, o erro de um quilo não afeta a confiabilidade, uma vez que este equipamento pode produzir resultados semelhantes (consistentes e estáveis) 
sempre que for utilizado com um mesmo indivíduo, portanto, diz-se que ele é preciso (confiável) (FLETCHER et al., 1991).

A confiabilidade está, assim, relacionada ao grau de concordância entre observações repetidas, realizadas para um mesmo indivíduo. Se os resultados obtidos apresentarem o mesmo valor, pode-se dizer que os dados são repetíveis ou reprodutíveis. Apesar da semelhança dos conceitos de repetibilidade e reprodutibilidade, suas aplicações são distintas. Repetibilidade (repeatability) é utilizada em situações homogêneas, e está relacionada ao grau de concordância entre resultados sucessivos, obtidos mediante o uso de um mesmo método, em material de teste idêntico, sob as mesmas condições experimentais. O conceito de reprodutibilidade (reproducibility) é aplicado em situações heterogêneas que envolvem medições realizadas em laboratórios diferentes, ou com operadores que usam equipamentos, ou até mesmo métodos, diferentes (BERGAMASCHI, 1999).

A confiabilidade é definida como a reprodutibilidade (reproducibility) dos resultados fornecidos por um instrumento específico, isto é, a consistência de resultados quando utilizado por diferentes observadores (confiabilidade interobservador) ou quando replicada em distintos momentos de tempo, nos mesmos participantes (confiabilidade intra-observador) (ABRAMSON, 1984). Assim, o que se deseja de um instrumento, em termos de confiabilidade, é a obtenção de uma medida precisa e estável, pouco influenciada por fatores do observador, dos participantes ou do ambiente.

A confiabilidade inter-observador mede o grau de concordância entre dois ou mais observadores na classificação de todos os indivíduos do grupo (CARMINES e ZELLER, 1979). Ela é testada por meio da comparação dos 
resultados de diferentes avaliadores de um mesmo exame sobre o mesmo indivíduo, ou seja, por meio da comparação entre medidas repetidas.

\subsubsection{Controvérsia sobre a validade e confiabilidade das informações referidas de peso e estatura}

Embora medidas diretas de peso e estatura possam ser facilmente obtidas, estas nem sempre são coletadas. $O$ exame físico de saúde requer uma complexa infra-estrutura e, conseqüentemente, um alto custo. Além disso, a validade das medidas é freqüentemente limitada às taxas de baixa participação, característica comum das pesquisas domiciliares (PACCAUD et al., 2001).

Em países desenvolvidos, tem sido observada a freqüente utilização de peso e estatura auto-referidos em estudos epidemiológicos, tanto em questionários administrados (NIEDHAMMER et al., 2000), questionários autopreenchidos (KUCZMARSKI et al., 2001; SPENCER et al., 2002), quanto em entrevistas por telefone (DEL PRETE et al., 1992; TELL et al., 1987; BOWLIN et al., 1993; FLOOD et al., 2000; PACCAUD et al., 2001).

Em muitas circunstâncias, as informações do indivíduo sobre seu peso e estatura podem ser os únicos dados disponíveis em estudos epidemiológicos, e seu uso tem sido feito principalmente por favorecer a economia de recursos e a simplificação do trabalho de campo (CHOR et al., 1999; JALKANEN et al., 1987, WILLET, 1998). Embora as medidas referidas sejam mais convenientes do que as medidas diretas, esta informação pode ser inacurada, fato que tem levado muitos pesquisadores a estudar a qualidade dos dados fornecidos, ou seja, a validade (PALTA et al., 1982; STUNKARD e ALBAUM, 1981; WEAVER et al., 1996; JALKANEN et al., 1987; SCHMIDT et al., 1993; KUCZMARSKI et al., 2001) e a confiabilidade destas medidas (CHOR et al., 1999; 
FORTENBERRY, 1992; HIMES e FARICY, 2001; NAKAMURA et al., 1999; STEWART 1982).

De acordo com os resultados de alguns estudos, o peso e a estatura declarados são indicadores válidos, com níveis aceitáveis de validade, até mesmo entre os obesos, que poderiam apresentar maior tendência de subestimação do peso referido (WEAVER et al., 1996), e entre grupos com baixa escolaridade (SCHMIDT et al., 1993).

Apesar da alta concordância entre informação referida e medida direta, KUSKOWSKA-WOLK et al. (1989) alertaram para a ocorrência da síndrome de "flat slope", na qual indivíduos mais altos e com maior peso tendem a subestimar o peso e estatura referidos, da mesma forma que o contrário é verdadeiro para os indivíduos mais baixos e de menor peso. Este viés atua na mesma direção, porém sua magnitude pode variar com gênero e idade (PACCAUD et al., 2001).

A validade da informação auto-referida pode se alterar conforme a idade, sendo esta, portanto, um importante fator na classificação do peso, estatura, IMC e sobrepeso proveniente de dados referidos (KUCZMARSKI et al., 2001). Os estudos sugerem que as pessoas mais idosas subestimam seu peso em comparação com pessoas mais jovens, de ambos os sexos e apresentam, em geral, as maiores diferenças entre os valores referidos e a aferição (JALKANEN et al., 1987; QUILES-IZQUIERDO e VIOQUE, 1996).

Usando dados de uma amostra representativa da população adulta americana ( $n=16.573$ ), KUCZMARSKI et al. (2001) examinaram o efeito da idade na classificação do IMC calculado a partir dos dados antropométricos referidos, em comparação com os mesmos valores aferidos diretamente. Os 
autores concluíram que, especialmente em pessoas com 60 anos ou mais, o uso do peso e estatura referidos ao invés das medidas aferidas resultou em erros significativos na classificação do IMC. A prevalência de sobrepeso calculada a partir dos valores aferidos foi superior àquela calculada com base nos valores referidos em $6 \%$, no caso dos homens e $11 \%$, no caso das mulheres.

No caso de crianças e adolescentes, os resultados de um estudo transversal realizado na Arábia Saudita, cuja amostra era representativa de estudantes com idades entre 9 e 21 anos $(n=2860)$, apontam menor acurácia nas informações de peso e estatura auto-referidos. $O$ estudo de validade utilizou-se de subamostra $(n=84)$ da referida população e verificou que pouco mais de $50 \%$ das crianças não tinham consciência do seu peso e estatura, resultando num IMC desconhecido em aproximadamente $60 \%$ dos casos. Entre os $40 \%$ restantes que informaram seu peso e estatura, a subestimação média do peso foi cerca de $2,7 \mathrm{~kg}$, principalmente em meninas de $16-21$ anos, com alto nível sócio-econômico e nascidas de mães com maior escolaridade. A estatura foi informada, em média, $4 \mathrm{~cm}$ acima daquela medida, principalmente entre indivíduos com sobrepeso, obesos, meninas e por aqueles com pelo menos 16 anos. A sensibilidade do diagnóstico da obesidade obtida por meio do peso e estatura referidos foi baixa, especialmente entre meninas com pelo menos 16 anos, enquanto a especificidade foi maior entre os homens e melhorou com o aumento da idade (ABALKHAIL et al., 2002).

Outro estudo realizado com 1635 jovens americanos com idades entre 12 e 17 anos não obteve a informação do peso em $40 \%$ dos jovens com 12 anos e $25 \%$ dos que tinham 13 anos. Aqueles que se recusaram ou foram incapazes de fornecer o peso eram mais jovens, mais baixos, e de menor peso do que aqueles que informaram. $O$ estudo concluiu que peso e estatura auto- 
referidos não são recomendados como substitutos das medidas aferidas em jovens com menos de 14 anos de idade (HIMES e FARICY, 2001).

WANG et al. (2002) também recomendam cautela na utilização de peso e estatura referidos por adolescentes. 0 estudo comparou dados antropométricos referidos e aferidos de $\mathbf{5 7 2}$ adolescentes australianos com idades entre 15 e 19 anos. A porcentagem de erro na classificação de sobrepeso e obesidade proveniente de dados auto-referidos, considerando a subestimativa de peso e superestimativa de estatura, foi de $31 \%$ para meninos e $30 \%$ para meninas.

TROY et al. (1995) compararam os dados da estatura atual auto-referida e do peso recordado aos 18 anos por 118 mulheres jovens (entre 25 e 42 anos) participantes de uma coorte americana (Nurse's Health Study II) com os registros de exames físicos quando as mesmas tinham 18 anos. O coeficiente de correlação (Spearman) entre o peso recordado e o aferido no passado foi de 0,87 e entre a estatura atual referida e a aferida aos 18 anos foi de 0,94 . O valor do IMC médio calculado com base no peso recordado e estatura atual foi $21,6 \mathrm{~kg} / \mathrm{m}^{2}$ e $22,1 \mathrm{~kg} / \mathrm{m}^{2}$ para aquele calculado com base no peso contido nos registros médicos, com correlação de 0,84 . O estudo concluiu que mulheres jovens (entre 25 e 42 anos) podem fornecer informações antropométricas altamente válidas da época em que tinham 18 anos. Assim, um simples questionário de avaliação pode ser usado para investigar o impacto do peso e do IMC em idades mais jovens num subseqüente risco de doenças.

Outros estudos que também utilizaram o peso recordado de muitos anos antes sugerem alta validade das informaçōes recordadas, embora a magnitude do erro destas informações tenha sido maior do que a das informações autoreferidas. STEVENS et al. (1990) que estudaram uma população idosa ( $\geq 62$ 
anos), encontraram correlações entre o peso referido e aferido de 0,98 para peso atual, 0,93 e 0,82 para pesos recordados 4 e 28 anos antes, respectivamente. $O$ erro em referir o peso aumentou inversamente com a escolaridade e positivamente com a idade. Da mesma forma, PERRY et al. (1995) compararam o peso medido durante um exame inicial (1971-1975) com o peso referido recordado de 1971-1975 durante entrevista (1982-1984) com 1931 adultos americanos. $O$ peso recordado de 10 anos antes foi fortemente correlacionado com o peso aferido previamente $(r=0,73$ para homens e $r=0,74$ para mulheres). Influenciaram a acurácia da informação o sexo (homens superestimaram e mulheres subestimaram seu peso passado), grupo étnico (negros subestimaram mais o peso passado), IMC atual (positivamente associado com subestimativa do peso passado) e peso ganho ao longo dos 10 anos do exame inicial (indivíduos com ganho maior de $6,8 \mathrm{~kg}$ recordaram melhor do que aqueles com ganhos até $6,8 \mathrm{~kg}$ ).

A validade da informação auto-referida também pode se alterar conforme o gênero. De modo geral, a mulher refere seu peso mais corretamente que o homem (JALKANEN et al., 1987), observa-se subestimação do peso referido de modo mais marcante entre as mulheres e maior superestimação da estatura referida entre os homens (SCHMIDT et al., 1993; PALTA et al., 1982).

PALTA et al. (1982) encontraram erros na informação de peso e estatura de pequena magnitude, entre homens e mulheres adultos americanos. $O$ peso foi subestimado por $1,6 \%$ dos homens e $3,1 \%$ das mulheres; a estatura foi superestimada por $1,3 \%$ dos homens e $0,6 \%$ das mulheres.

Na população britânica, um estudo realizado numa amostra de 4808 adultos com idades entre 35 e 76 anos mostrou que estatura referida foi superestimada em maior grau por mulheres e homens mais velhos, homens 
mais baixos e mulheres com maior peso (em média $1,23 \mathrm{~cm}$ em homens e 0,60 $\mathrm{cm}$ em mulheres). A extensão da subestimação do peso referido foi maior em mulheres e homens com maior peso, porém não variou com a idade e estatura aferida (em média, $-1,85 \mathrm{~kg}$ em homens e $-1,40 \mathrm{~kg}$ em mulheres) (SPENCER et al., 2002).

NIEDHAMMER et al. (2000) estudaram a validade do peso e estatura referidos por carta em relação aos mesmos valores contidos em registros médicos e suas conseqüências no IMC, em uma coorte de 7350 adultos. Encontraram uma forte correlação entre os valores aferidos e referidos, porém este último apresentou erros sistemáticos significativos. $O$ peso foi significativamente subestimado por homens e mulheres $(0,54 \mathrm{~kg}$ e $0,85 \mathrm{~kg}$, respectivamente) e a estatura foi superestimada por ambos os sexos $(0,38 \mathrm{~cm}$ para homens e $0,40 \mathrm{~cm}$ para mulheres). A prevalência do sobrepeso foi subestimada por $13 \%$ dos homens e $17 \%$ das mulheres. Os cinco fatores associados ao viés do peso e estatura referidos foram: idade (maior subestimativa do peso entre os homens mais velhos), escolaridade (no caso dos homens, negativamente associada com superestimativa da estatura e no caso das mulheres, positivamente associada), ocupação (quanto maior o grau de ocupação maiores foram as diferenças entre estatura medida e aferida), nivel de sobrepeso (IMC associado positivamente com subestimativa do peso) e preferência por dígitos que terminam em zero ou cinco (tendência de superestimativa entre homens e mulheres que arredondam a estatura e maior probabilidade de subestimativa entre aquelas que arredondam o peso).

Os preditores do grau de discrepância no peso (diferença entre peso referido e peso aferido) podem ser específicos de cada sexo. No estudo de VILLANUEVA (2001), o modelo de regressão logística mostrou que a idade (positivamente associada com discrepâncias), grupo étnico (negros e 
mexicanos foram $66 \%$ e $16 \%$, respectivamente, mais prováveis de superestimar o peso quando comparados aos brancos americanos; no caso das mulheres, as mexicanas e as mulheres de outras raças foram, respectivamente, $17 \%$ e $29 \%$ mais prováveis de superestimar peso), escolaridade (superestimação do peso era 1,36 vezes mais provável nos indivíduos com educação primária do que naqueles com educação terciária) e IMC (associação positiva) estavam associados com o grau de discrepância no peso, em ambos os sexos. Em homens, os preditores adicionais foram: tabagismo (associado com aumento da chance de $27 \%$ de superestimar peso) e o desejo de mudar de peso (associado com o dobro de probabilidade de superestimar peso). Em mulheres, foram importantes o estado civil (viúvas apresentaram maior erro no peso), renda (positivamente associada com chance de subestimar o peso), nível de atividade física (mais ativas tiveram 1,18 vezes mais chances de superestimar peso) e 0 número de meses passados desde a última visita ao médico (o acréscimo de um ano desde a última visita foi associado com aumento de $3 \%$ na probabilidade de subestimar o peso).

Os niveis de sobrepeso e obesidade também podem influenciar a validade do peso e estatura auto-referidos. Um estudo realizado na Espanha com 1387 adultos apontou maior prevalência de obesidade entre aqueles que não declararam seu peso elou estatura em comparação com aqueles que o fizeram - 27,9\% versus 13,1\%, respectivamente (QUILEZ-IZQUIERDO e VIOQUE, 1996).

Fatores socioeconômicos também podem influenciar a qualidade das medidas antropométricas auto-referidas. Em relação ao peso, um estudo finlandês ( $n=11.880$ ) mostrou que homens cuja renda familiar anual era mais baixa, subestimavam mais seu peso em relação àqueles com renda superior. Mulheres com maior renda familiar anual ou cujas visitas ao médico eram mais 
freqüentes tinham maior consciência do peso atual do que aquelas com menor renda anual ou que tinham menos visitas ao médico (JALKANEN et al., 1987). Em relação à estatura, os indivíduos com menor escolaridade tendiam a superestimá-la numa magnitude maior do que aqueles cujo nível educacional era superior (PALTA et al., 1982). Estes dois estudos realizados em países desenvolvidos indicam, portanto, que o maior status socioeconômico teve influência positiva na qualidade das informações de peso e estatura autoreferidas.

BOSTRÖM e DIDERICHSEN (1997) analisaram os erros provenientes dos dados auto-referidos sobre peso, estatura e IMC obtidos de questionários enviados pelo correio, e sua dependência dos fatores socioeconômicos. Cerca de 3208 indivíduos com idades entre 18 e 84 anos, residentes em Estocolmo, forneceram informações sobre peso e estatura e após um período de 4 a 6 meses tiveram suas medidas aferidas em exame clínico. Mulheres obesas e homens com IMC inferior a $20 \mathrm{~kg} / \mathrm{m}^{2}$ subestimaram seu peso. A estatura foi mais superestimada por homens, homens mais baixos, idosos e trabalhadores manuais de ambos os sexos. O IMC calculado a partir das medidas referidas foi subestimado em todos os grupos socioeconômicos, principalmente pelas mulheres, obesos e idosos de ambos os sexos, trabalhadores não manuais do sexo masculino e trabalhadoras manuais. Quando se utilizou o IMC calculado com base nos dados referidos, somente $61 \%$ dos homens e $55 \%$ das mulheres obesas foram identificados.

Como o IMC é derivado somente do peso e estatura dos indivíduos, os achados sugerem cautela ao se utilizar estas medidas antropométricas autoreferidas, pois o efeito combinado da superestimação da estatura e subestimação do peso no cálculo do IMC pode ser substancial, resultando em subestimação da real prevalência de sobrepeso e obesidade. Erros de 
classificação que afetam a distribuição populacional do IMC podem interferir na associação entre obesidade e morbidades, especialmente em certos segmentos da população como mulheres e indivíduos idosos (NIEDHAMMER et al., 2000; KUSKOWSKA-WOLK et al., 1989; FLOOD et al., 2000; KUCZMARSKI et al., 2001; SCHMIDT et al., 1993; JALKANEN et al., 1987; MILLAR, 1986; HILL e ROBERTS, 1998).

Uma solução "inovadora" para melhorar significativamente a validade do peso auto-referido foi sugerida por um estudo americano que recrutou 223 indivíduos com idades entre 18 e 82 anos através de um anúncio em área de grande circulação de pessoas (shopping). Os participantes foram separados em dois grupos: 1 grupo era informado de que seria pesado $(n=113)$ e recebia 1 questionário incluindo 6 questões sobre seu peso (instrução para referir peso atual, período do dia que se pesa, quantidade de roupas, etc.) e o segundo grupo $(n=110)$ recebia apenas a orientação de como referir o peso atual, porém não tinha conhecimento de que seria pesado. Logo após o preenchimento dos questionários, todos os participantes tiveram seu peso medido. Os autores concluíram que o grupo não informado tendia a referir o peso com menos acurácia $(-1,32 \mathrm{~kg})$ do que o grupo informado $(-0,85 \mathrm{~kg})$, sendo que este último referiu o peso com igual acurácia, independentemente da faixa de peso. Este estudo foi o primeiro a indicar que o peso referido pode ser usado como um substituto válido do peso medido sem necessidade de ajustes estatísticos, desde que os indivíduos recebam a informação de que serão pesados, recebam instrução de como referir o peso e respondam questões simples pertinentes ao seu histórico de peso. A solução, de fato, é inovadora e simples de ser aplicada, no entanto, tal procedimento é questionável do ponto de vista ético, pois, no momento da adesão à pesquisa, é fornecida uma informação não verídica aos participantes (BLACK et al., 1998). 
A utilização do peso e estatura referidos é uma prática pouco freqüente no Brasil, possivelmente devido à carência de estudos nacionais e de base populacional analisando a validade de tais informações. O levantamento da literatura nacional nos últimos 20 anos revelou apenas 4 estudos (SCHMIDT et al., 1993; CHOR et al., 1999, FONSECA et al., 2004 e SILVEIRA et al., 2005) que investigaram a validade do peso e/ou estatura referidos na população brasileira. Estas investigações sugeriram alta validade, principalmente em grupos populacionais com alto nível de escolaridade e maior acesso a serviços de saúde.

SCHMIDT et al. (1993) compararam os valores do peso referido com o peso diretamente aferido, ambos obtidos em domicílio durante a mesma entrevista, numa amostra de 659 adultos residentes em Porto Alegre, RS, entre 1986 e 1987. A correlação entre o peso referido e medido foi alta $(r=0,97)$ e a média destas diferenças pequena $(-0,06$ e $3,16 \mathrm{~kg}$, média e desvio padrão, respectivamente). Referiram o peso com erro inferior a 2 quilos, $62 \%$ dos participantes; inferior a 4 quilos, $87 \%$ e inferior a 6 quilos, $95 \%$ da população estudada. Indivíduos com baixo peso superestimaram seu peso, o oposto ocorrendo com indivíduos obesos e mulheres. A prevalência de obesidade (IMC $\geq 30 \mathrm{~kg} / \mathrm{m}^{2}$ ) obtida pelo peso referido (10\%) foi semelhante daquela obtida através do peso-aferido (11\%). Os autores concluíram que a validade do peso auto-referido foi aceitável para inquéritos de prevalência realizados em contextos similares.

No estudo realizado por CHOR et al. (1999), com funcionários de um banco estatal no Rio de Janeiro, homens e mulheres tenderam a subestimar o peso referido, sendo este comportamento mais marcante entre homens com peso igual ou maior do que 80 quilos. Em relação à estatura, as diferenças encontradas entre informação e aferição foram pouco relevantes. $O$ estudo 
concluiu que grupos populacionais específicos podem fornecer informação confiável e barata para estudos epidemiológicos relacionados à obesidade.

No estudo de FONSECA (2003), no Rio de Janeiro, houve alta concordância e validade entre a aferição e a informação do peso e da estatura dos 4030 funcionários de uma universidade pública. Em ambos os sexos, houve tendência leve e uniforme à subestimação do peso referido e à superestimação da estatura referida, tendência que não se acentuou entre os indivíduos com maior peso ou menor estatura. $\mathrm{O}$ estudo sugere que em populações similares, em que se disponha de recursos escassos, é possível utilizar dados referidos ao invés de valores aferidos.

SILVEIRA et al. (2005), em Pelotas (RS), mensuraram o peso e estatura de 140 adultos com 20 anos ou mais pertencentes a um estudo transversal de base populacional $(n=3934)$. O peso referido apresentou melhor validade $e$ concordância do que a estatura referida. O IMC calculado com base nos valores referidos foi subestimado por mulheres, independentemente de seu estado nutricional; entre os homens, este dado mostrou-se confiável. Entre as mulheres, idade e renda foram associadas positivamente com o IMC subestimado na análise multivariada. $\mathrm{O}$ uso do IMC referido para predizer $\mathrm{O}$ estado nutricional no adulto pode subestimar a prevalência da obesidade $e$ superestimar a de sobrepeso, devendo, portanto, ser utilizado com cautela. Para minimizar vieses e tornar os dados mais confiáveis, o estudo sugere o uso do IMC "corrigido", calculado pela equação de regressão linear ou o uso do IMC "semi-referido", calculado a partir do peso informado e estatura medida. 


\subsubsection{Validade e confiabilidade dos dados obtidos por telefone}

Nos países desenvolvidos, sistemas de monitoramento das condições de saúde vêm sendo utilizados com sucesso em populações servidas por serviços de telefonia com elevada cobertura residencial, permitindo uma amostra razoável a custo relativamente baixo e sem exigir grandes recursos humanos $\mathrm{e}$ materiais (CDC, 2002; PACCAUD et al., 2001).

Dentre as principais vantagens do monitoramento por telefone, destacam-se o seu baixo custo (cinco a seis vezes menor do que o custo de entrevistas domiciliares) e a possibilidade de sua implantação em localidades onde é improvável que existam os recursos humanos e materiais necessários para se conduzir inquéritos probabilísticos domiciliares (REMINGTON et al., 1988).

No entanto, a pesquisa telefônica apresenta certas limitações, como: a) exclusão de pessoas que não vivem em residências; b) exclusão de pessoas sem telefones residenciais; c) os dados coletados podem estar sujeitos aos vieses de memória, pois referem-se às informações fornecidas pelos entrevistados; d) exclusão de pessoas com menor status sócio-econômico ou de residências que tenham apenas telefones celulares (CDC, 2003).

Estudos de confiabilidade realizados em países desenvolvidos têm indicado alta concordância entre entrevistas telefônicas e entrevistas domiciliares e estudos de validade apontam que, na maior parte das vezes, estimativas provenientes de inquéritos telefônicos, quando ajustadas para eventual sub-representação de determinados estratos da população, não são significativamente diferentes das estimativas provenientes de inquéritos domiciliares tradicionais (REMINGTON et al., 1988). 
Alguns estudos examinaram a validade do peso e estatura informados a partir de entrevistas telefônicas determinaram sua acurácia em monitorar sobrepeso e obesidade na população (PACCAUD et al. 2001; FLOOD et al. 2000; BOWLIN et al. 1993; BOWLIN et al. 1996).

PACCAUD et al. (2001) realizaram um estudo comparando os resultados de duas pesquisas de saúde, uma por telefone $(n=820)$ e outra por exames físicos ( $n=1318$ ), na população suíça de 25 a 74 anos, no período de 19921993. O peso referido foi menor do que o diretamente aferido (em média $2,2 \mathrm{~kg}$ em homens e $3,5 \mathrm{~kg}$ em mulheres), enquanto a estatura informada foi maior que a medida $(1,2 \mathrm{~cm}$ em homens e $1,9 \mathrm{~cm}$ em mulheres). A magnitude das diferenças foi específica do grupo de idade e sexo, sendo maior em mulheres do que em homens e tendendo a aumentar com a idade. A comparação dos dois estudos levou a níveis substancialmente menores de IMC $\left(1-2 \mathrm{~kg} / \mathrm{m}^{2} \mathrm{em}\right.$ homens e $2-3 \mathrm{~kg} / \mathrm{m}^{2}$ em mulheres) e redução da prevalência da obesidade (IMC $>30 \mathrm{~kg} / \mathrm{m}^{2}$ ) mais do que a metade. Segundo os autores, a diferença relativa no IMC aumenta com a idade, não devido à tendência na diferença do peso (que geralmente diminui após a idade de 35 a 44 anos), mas na diferença da estatura (que aumenta com a idade), já que esta é elevada ao quadrado na fórmula do IMC, afetando profundamente seu valor final.

FLOOD et al. (2000) coletaram dados antropométricos via telefone de 227 adultos, residentes em Sidney, que haviam participado de uma pesquisa nacional de saúde em 1997. O IMC calculado com base nos valores aferidos classificou $62 \%$ dos homens e $47 \%$ das mulheres como tendo excesso de peso, comparado com os $39 \%$ e $32 \%$, respectivamente, provenientes dos valores referidos. Homens e mulheres com sobrepeso ou obesos tenderam a subestimar o peso numa extensão maior do que aqueles com peso adequado 
ou baixo peso. As mulheres que se pesavam pelo menos uma vez por mês (comparadas com as que o faziam poucas vezes ao ano) apresentavam menor diferença entre peso aferido e referido (pesagem freqüente: - $2 \mathrm{~kg}$; pesagem não freqüente: $-4,4 \mathrm{~kg}$ ). Os resultados deste estudo mostraram menor validade das informações para os valores mais altos de IMC, porém os valores médios e medianos de IMC são comparáveis àqueles obtidos pela pesagem direta.

Num estudo mais abrangente, BOWLIN et al. (1993) avaliaram a validade dos dados coletados por telefone sobre fatores de riscos para doenças cardiovasculares, em 282 homens e 344 mulheres com idades entre 20 e 69 anos. Utilizando-se o peso e estatura auto-referidos, foram identificados corretamente como obesos $77 \%$ dos homens e $72 \%$ das mulheres. A sensibilidade do diagnóstico da obesidade foi menor $(60 \%)$ em mulheres pertencentes à faixa etária de 20 a 29 anos e não variou entre as faixas etárias no caso dos homens. A especificidade do diagnóstico da obesidade foi elevada em todas as idades e em ambos os sexos. A prevalência de obesidade "referida" foi 10 pontos percentuais mais baixo do que real prevalência ( $34 \%$ vs $44 \%$ para homens e $26 \%$ vs $36 \%$ para mulheres), havendo aumento das discrepâncias com o aumento da idade. $O$ estudo encontrou, ainda, que $11 \%$ dos indivíduos informaram a estatura de maneira inacurada em pelo menos $5 \mathrm{~cm}$ e $52 \%$ informaram o peso com erro de pelo menos $2,20 \mathrm{~kg}$. Os autores afirmam que as entrevistas realizadas por telefone conferem erros maiores na informação do peso e estatura do que a entrevista face-a-face, e sugerem, portanto, que fatores de correção sejam usados para ajustar os erros na população estudada.

Alguns estudos também utilizaram entrevista telefônica para acompanhar participantes e ex-participantes de programas de perda de peso e concluíram que as discrepâncias entre $\circ$ peso atual e $\circ$ referido são freqüentemente 
substanciais e que a informação auto-referida sozinha não é adequada para avaliar a manutenção da perda de peso a longo prazo (TELL et al. 1987; DEL PRETE et al., 1992; JEFFERY, 1996; NAWAZ et al., 2001).

Nos Estados Unidos, DEL PRETE et al. (1992) estudaram a acurácia do peso e estatura informados por 82 adultos que tinham participado de um programa de perda de peso 1 a 2 anos antes. $O$ peso referido foi 2,3kg $(\mathrm{DP}=1,9 \mathrm{~kg})$ menor que o peso medido e a estatura $1,8 \mathrm{~cm}(\mathrm{DP}=2,7 \mathrm{~cm})$ maior que a aferida. As discrepâncias médias em referir o peso foram superiores àquelas encontradas na população geral. Os resultados indicam que os valores do peso e estatura auto-referidos por população com sobrepeso que já esteve envolvida em programas de perda de peso devem ser interpretados com cautela. Os autores sugerem que a pesagem antes da entrevista deve ser encorajada para aumentar a acurácia dos dados, uma vez que as pessoas que se pesam freqüentemente tendem a informar melhor.

Foram contatados por telefone 146 ex-participantes de um programa de perda de peso ( 4 a 5 anos antes) e obtidas as informações de peso e estatura atual dos mesmos. Após 3 dias da entrevista telefônica, uma carta era enviada ao ex-participante convidando-o a realizar a visita clínica de acompanhamento anual, onde o peso e a estatura eram aferidos. $O$ peso referido foi, em média, $2,7 \mathrm{~kg}$ menor que $o$ aferido. $O$ estudo concluiu que, a menos que a magnitude da discrepância seja ajustada, o uso do peso auto-referido não é adequado para avaliar a manutenção da perda de peso à longo prazo em ex-participantes de programas de perda de peso. Se o propósito fosse apenas comparar as mudanças relativas ao peso ocorridas ao longo do tratamento, o peso referido seria considerado válido, pois embora houvesse inacurácia na informação individual, quando se agrupam os dados os vieses parecem ter a mesma direção e magnitude daqueles observados em outras populações. No entanto, 
em termos de avaliação do tratamento, os vieses encontrados não podem ser considerados triviais (TELL et al., 1987).

No Japão, um estudo realizado com 95 mulheres obesas envolvidas atualmente em programas de perda de peso mostrou que as informações autoreferidas de peso e estatura obtidas por telefone eram inacuradas. Embora se esperasse informações mais acuradas de peso pelo fato dessas mulheres estarem envolvidas em programas de perda peso e, portanto, terem maior conhecimento do seu peso atual, houve diferenças significativas entre os valores medidos e referidos, sendo que as mulheres mais obesas tenderam a subestimar mais o peso $(-1,70 \mathrm{~kg})$ e superestimar mais a estatura $(+0,9 \mathrm{~cm})$ (NAWAZ et al., 2001).

No estudo de JEFFERY (1996), as informações de peso auto-referido de 4439 adultos foram obtidos por entrevista telefônica e questionário de autopreenchimento enviado pelo correio. A comparação do peso referido e aferido revelou uma subestimação sistemática de $1,09 \mathrm{~kg}$ ( $D P=2,31 \mathrm{~kg}$ ) no caso dos homens e 1,22 ( $D P=2,09 \mathrm{~kg})$ no caso das mulheres. $O$ erro em referir o peso, em ambos os sexos, foi significativamente relacionado com o peso e estatura atual e com participação em programas de perda de peso. Em homens somente, o erro esteve positivamente relacionado à idade, escolaridade $e$ histórico de tentativas de controle de peso. Globalmente, contudo, estas variáveis preditoras contaram com uma pequena fração da variância na subestimativa. Neste estudo, a informação auto-referida do peso foi extremamente acurada, no entanto, o autor chama atenção para o fato de que generalização dos resultados deve ser cuidadosa já que a população estudada era etnicamente homogênea e composta somente por pessoas empregadas. 
Alguns autores sugerem que sejam realizadas pesquisas periódicas no sentido de acompanhar as mudanças na acurácia dos dados ocorridas ao longo do tempo (FLOOD et al., 2000; GALUSKA et al., 1996).

Não foram encontrados na literatura nacional estudos sobre a validade da informação referida de peso e estatura por telefone. Tendo em vista que 0 conhecimento da natureza e da magnitude do erro associado com medidas auto-referidas é útil para planejar e interpretar dados de pesquisas que utilizam essa fonte de informação, o presente estudo teve como objetivo verificar a validade da informação referida de peso e estatura em população adulta com 40 anos e mais, residente no Município de São Paulo, por meio de entrevistas telefônicas.

Eventuais diferenças entre os valores referidos e os valores obtidos pela mensuração direta poderão estar associadas a fatores como idade, sexo, estratos de IMC e condição social. Nesse caso, será possível estabelecer fatores de ajuste que aplicados às informações referidas sobre peso e estatura permitirão melhorar a validade do método.

A Tabela 1 apresenta algumas informações sobre estudos internacionais e nacionais que utilizaram a informação auto-referida de peso e estatura. 
Tabela 1 - Características e conclusões de estudos nacionais e internacionais que utilizaram informações auto-referidas de peso e estatura.

\begin{tabular}{|c|c|c|c|c|c|}
\hline $\begin{array}{l}\text { Autores (ano e } \\
\text { local). } \\
\text { Métodos } \\
\text { empregados } \\
\text { para coleta } \\
\text { dos dados e } \\
\text { principais } \\
\text { análises } \\
\text { estatisticas } \\
\text { empregadas }\end{array}$ & $\begin{array}{c}\text { Tamanho da } \\
\text { amostra }\end{array}$ & $\begin{array}{c}\text { Tempo } \\
\text { decorrido } \\
\text { entre } \\
\text { aferição e } \\
\text { informa- } \\
\text { ção }\end{array}$ & $\begin{array}{l}\text { Faixa } \\
\text { etária } \\
\text { (anos) }\end{array}$ & $\begin{array}{c}\text { Diferença } \\
\text { média* } \\
\text { (DP) }\end{array}$ & Conclusőes \\
\hline $\begin{array}{l}\text { PIRIE et al., } \\
1981 \\
\text { (Minneapolis - } \\
\text { EUA) } \\
\text { Entrevista } \\
\text { domiciliar face- } \\
\text { a-face X exame } \\
\text { clínico } \\
\text { Regressão } \\
\text { linear (RL) } \\
\text { múltipla e } \\
\text { diferença média }\end{array}$ & $\begin{array}{l}1610 \text { homens } \\
1799 \text { mulheres }\end{array}$ & 1 mês & $20-59$ & $\begin{array}{c}\text { ठ: } 0,56 \mathrm{~cm} \\
-0,53 \mathrm{~kg} \\
(3,25 \mathrm{~kg}) \\
\\
\text { o: }-0,71 \mathrm{~cm} \\
-1,85 \mathrm{~kg} \\
(3,03 \mathrm{~kg})\end{array}$ & $\begin{array}{l}\text { Peso e estatura auto- } \\
\text { referidos não são } \\
\text { acurados. Autor sugere o } \\
\text { uso do peso referido como } \\
\text { um indicador de } \\
\text { obesidade em estudos de } \\
\text { comportamento alimentar } \\
\text { e pesquisas sobre saúde. }\end{array}$ \\
\hline $\begin{array}{l}\text { STUNKARD e } \\
\text { ALBAUM, } 1981 \\
\text { (EUA e } \\
\text { Dinamarca) } \\
\text { Questionário } \\
\text { auto- } \\
\text { preenchido X } \\
\text { pesagem direta } \\
\text { RL e Pearson }\end{array}$ & $\begin{array}{l}\text { EUA: } \\
105 \text { homens } \\
445 \text { mulheres } \\
\text { Dinamarca: } 594 \\
\text { homens e } 158 \\
\text { mulheres }\end{array}$ & Não citado & 29 a 55 & $\begin{array}{c}<40 \text { anos: } \\
-1,58 \mathrm{~kg} \\
\geq 40 \text { anos: } \\
-2,45 \mathrm{~kg}\end{array}$ & $\begin{array}{l}\text { EUA: peso auto-referido } \\
\text { foi acurado mesmo entre } \\
\text { pessoas obesas. } \\
\text { Dinamarca: peso auto- } \\
\text { referido foi menos } \\
\text { acurado, principalmente } \\
\text { em mulheres com mais de } \\
40 \text { anos. }\end{array}$ \\
\hline $\begin{array}{l}\text { PALTA et al., } \\
1982 \\
\text { (lowa -EUA) } \\
\text { Entrevista } \\
\text { domiciliar X } \\
\text { exame clinico } \\
\text { RL, ANOVA }\end{array}$ & $\begin{array}{l}851 \text { homens } \\
503 \text { mulheres }\end{array}$ & $\begin{array}{c}3 \\
\text { semanas }\end{array}$ & $30-69$ & $\begin{array}{l}\text { o: } 2,3 \mathrm{~cm} \\
(2,7 \mathrm{~cm}) \\
-1,5 \mathrm{~kg} \\
(3,2 \mathrm{~kg}) \\
\\
\text { o: } 0,9 \mathrm{~cm} \\
(2,4 \mathrm{~cm}) \\
-2,4 \mathrm{~kg} \\
(4,0 \mathrm{~kg})\end{array}$ & $\begin{array}{l}\text { Apesar dos erros } \\
\text { sistemáticos encontrados, } \\
\text { a influência dos vieses } \\
\text { pode ser pequena e sem } \\
\text { maiores conseqüências } \\
\text { em investigaçōes } \\
\text { epidemiológicas, sendo } \\
\text { pouco provável que os } \\
\text { erros na informação levem } \\
\text { à mudanças substanciais } \\
\text { nas conclusōes. }\end{array}$ \\
\hline
\end{tabular}




\begin{tabular}{|c|c|c|c|c|c|}
\hline $\begin{array}{l}\text { STEWART } \\
\text { AL,1982 (Ohio, } \\
\text { Washington, } \\
\text { Carolina do Sul } \\
\text { e } \\
\text { Massachusetts } \\
\text { - EUA) } \\
\text { Questionánio de } \\
\text { história médica } \\
\text { auto- } \\
\text { preenchido X } \\
\text { exame clínico } \\
\text { Pearson e RL }\end{array}$ & $\begin{array}{l}1552 \text { homens } \\
1821 \text { mulheres }\end{array}$ & $\begin{array}{l}1 \text { mês ou } \\
\text { menos }\end{array}$ & $14-61$ & $\begin{array}{c}6: 2,08 \mathrm{~cm} \\
-0,72 \mathrm{~kg} \\
(2,42 \mathrm{~kg}) \\
\text { : } 1,06 \mathrm{~cm} \\
-1,4 \mathrm{~kg} \\
(2,57 \mathrm{~kg})\end{array}$ & $\begin{array}{l}\text { Informações auto- } \\
\text { referidas de peso e } \\
\text { estatura são indicadores } \\
\text { muito acurados do peso e } \\
\text { estatura. A informação é } \\
\text { válida e confiável mesmo } \\
\text { nos obesos e naqueles } \\
\text { com menor escolaridade. }\end{array}$ \\
\hline $\begin{array}{l}\text { MILLAR WJ, } \\
1986 \\
\text { (Canadá) } \\
\text { Entrevista } \\
\text { telefônica X } \\
\text { entrevista } \\
\text { domiciliar } \\
\text { Diferença } \\
\text { média. } \\
\end{array}$ & 10649 adultos & Não citado & $20-69$ & $\begin{array}{c}\text { o: } 1,8 \mathrm{a} \\
3,2 \mathrm{~cm} \\
\text { (60 a } \\
69 \mathrm{anos}) \\
+3,8 \mathrm{~kg} \\
\\
\text { \%: } 0,8 \mathrm{a} \\
4,4 \mathrm{~cm} \\
-1,5 \mathrm{a}-1,8 \mathrm{~kg}\end{array}$ & $\begin{array}{l}\text { Prevalência de obesidade } \\
\text { obtida a partir de dados } \\
\text { referidos é subestimada. } \\
\text { Autor sugere que } \\
\text { pesquisadores } \\
\text { considerem métodos que } \\
\text { ajustem os vieses dos } \\
\text { dados provenientes de } \\
\text { informações auto- } \\
\text { referidas. }\end{array}$ \\
\hline $\begin{array}{l}\text { JALKANEN et } \\
\text { al., 1987 } \\
\text { (Karelia do } \\
\text { Norte e Kuopio } \\
\text {-Finlândia) } \\
\text { Questionário } \\
\text { auto- } \\
\text { preenchido por } \\
\text { correio X } \\
\text { exame clínico } \\
\text { Pearson e } \\
\text { RLM. }\end{array}$ & $\begin{array}{l}5790 \text { homens } \\
6090 \text { mulheres }\end{array}$ & 10 dias & $25-64$ & $\begin{array}{c}\text { o: }-0,4 \mathrm{~kg} \\
(3,0 \mathrm{~kg}) \\
\\
\text { o : }-0,6 \mathrm{~kg} \\
(2,0 \mathrm{~kg})\end{array}$ & $\begin{array}{l}\text { Informações auto- } \\
\text { referidas de peso podem } \\
\text { ser usadas em certas } \\
\text { condições, especialmente, } \\
\text { quando há ampla } \\
\text { população jovem. Em } \\
\text { geral, as mulheres } \\
\text { informaram peso mais } \\
\text { corretamente que os } \\
\text { homens. }\end{array}$ \\
\hline $\begin{array}{l}\text { STEWART et } \\
\text { al., 1987 } \\
\text { (Auckland - } \\
\text { Nova Zelândia) } \\
\text { Questionário } \\
\text { administrado X } \\
\text { pesagem direta } \\
\text { Pearson e } \\
\text { Sensibilidade. }\end{array}$ & 1598 adultos & 0 dias & $35-65$ & $\begin{array}{c}0: 2,14 \mathrm{~cm} ; \\
-1,4 \mathrm{~kg} ; \\
-0,9 \mathrm{~kg} / \mathrm{m}^{2} \\
\text { o: } 1,6 \mathrm{~cm} \\
-1,1 \mathrm{~kg} ; \\
-0,8 \mathrm{~kg} / \mathrm{m}^{2}\end{array}$ & $\begin{array}{l}\text { Apesar do alto grau de } \\
\text { acurácia do peso e } \\
\text { estatura auto-referidos, os } \\
\text { participantes } \\
\text { consistentemente } \\
\text { superestimaram sua } \\
\text { estatura e subestimaram o } \\
\text { peso, resultando numa } \\
\text { subestimação do IMC. }\end{array}$ \\
\hline
\end{tabular}




\begin{tabular}{|c|c|c|c|c|c|}
\hline $\begin{array}{l}\text { TELL et al., } \\
1987 \\
\text { (Minneapolis - } \\
\text { EUA) } \\
\text { Entrevista } \\
\text { telefônica X } \\
\text { exame clínico } \\
\text { Regressão } \\
\text { Linear }\end{array}$ & $\begin{array}{l}107 \text { homens } \\
39 \text { mulheres }\end{array}$ & $\begin{array}{c}2 \text { a } 64 \\
\text { dias }\end{array}$ & $28-63$ & $\begin{array}{l}\text { o: }-2,8 \mathrm{~kg} \\
(3,40 \mathrm{~kg}) \\
\\
\text { o: }-2,3 \mathrm{~kg} \\
(2,54 \mathrm{~kg})\end{array}$ & $\begin{array}{l}\text { A menos que a magnitude } \\
\text { da discrepância seja } \\
\text { ajustada, o uso do peso } \\
\text { auto-referido não é } \\
\text { adequado para avaliar a } \\
\text { manutenção da perda de } \\
\text { peso à longo prazo, em } \\
\text { pessoas envolvidas em } \\
\text { programa de perda de } \\
\text { peso. Autores sugerem } \\
\text { que pesquisadores } \\
\text { considerem fazer uma } \\
\text { validação em subamostra } \\
\text { da população a ser } \\
\text { estudada. }\end{array}$ \\
\hline $\begin{array}{l}\text { KUSKOWSKA- } \\
\text { WOLKK et al., } \\
1989 \\
\text { (Estocolmo - } \\
\text { Suécia) } \\
\text { Questionário } \\
\text { auto- } \\
\text { preenchido X } \\
\text { exame clínico } \\
\text { Linha de } \\
\text { regressão e de } \\
\text { identidade (não } \\
\text { menciona } \\
\text { coeficiente de } \\
\text { correlação de } \\
\text { concordância) }\end{array}$ & $\begin{array}{l}119 \text { homens } \\
182 \text { mulheres }\end{array}$ & 0 dias & $16-84$ & $\begin{array}{c}\delta: 1,0 \mathrm{~cm} ; \\
-0,5 \mathrm{~kg} ; \\
-0,40 \mathrm{~kg} / \mathrm{m}^{2} \\
\\
+: 1,9 \mathrm{~cm} ; \\
-0,6 \mathrm{~kg} ; \\
-0,70 \mathrm{~kg} / \mathrm{m}^{2}\end{array}$ & $\begin{array}{l}\text { O erro sistemático no } \\
\text { peso e estatura resultou } \\
\text { numa distribuiçăo } \\
\text { incorreta do IMC em } 30 \% \\
\text { dos individuos. Estes } \\
\text { vieses podem invalidar } \\
\text { dados e conclusōes de } \\
\text { pesquisas populacionais } \\
\text { se baseados em medidas } \\
\text { referidas. A subestimação } \\
\text { pode ter conseqüências } \\
\text { práticas em estudos } \\
\text { epidemiológicos, } \\
\text { especialmente no } \\
\text { planejamento de } \\
\text { programas preventivos e } \\
\text { educacionais em escala } \\
\text { nacional. }\end{array}$ \\
\hline $\begin{array}{l}\text { NIETO- } \\
\text { GARCIA et al., } \\
1990 \\
\text { (Baltimore- } \\
\text { EUA) } \\
\\
\text { Entrevista face- } \\
\text { a-face X exame } \\
\text { clínico } \\
\\
\text { Pearson, } \\
\text { Sensibilidade e } \\
\text { Especificidade. }\end{array}$ & $\begin{array}{l}3475 \text { homens } \\
3980 \text { mulheres }\end{array}$ & 0 dias & $20-79$ & $\begin{array}{l}\text { o: } 0,94 \mathrm{~cm} \\
-0,34 \mathrm{~kg} \\
\text { o: } 0,32 \mathrm{~cm} \\
-1,02 \mathrm{~kg}\end{array}$ & $\begin{array}{l}\text { Viés de classificação pode } \\
\text { ocorrer quando a } \\
\text { informação auto-referida é } \\
\text { usada para definir as } \\
\text { categorias do IMC. }\end{array}$ \\
\hline
\end{tabular}




\begin{tabular}{|c|c|c|c|c|c|}
\hline $\begin{array}{l}\text { ROWLAND } \\
\text { ML, 1990 } \\
\text { (EUA) } \\
\text { Entrevista } \\
\text { domiciliar } X \\
\text { exame clíico } \\
\text { Pearson } \\
\text { momento } \\
\text { produto. }\end{array}$ & 11284 adultos & $\begin{array}{c}2 \text { a } 6 \\
\text { semanas }\end{array}$ & $20-74$ & $\begin{array}{c}: 1,4 \mathrm{~cm} \\
(2,59 \mathrm{~cm}) \\
0,4 \mathrm{~kg} \\
(3,0 \mathrm{~kg}) \\
\\
\text { 일 } 0,6 \mathrm{~cm} \\
(2,81 \mathrm{~cm}) \\
-1,03 \mathrm{~kg} \\
(3,02 \mathrm{~kg})\end{array}$ & $\begin{array}{l}\text { Informação auto-referida } \\
\text { de peso e estatura não foi } \\
\text { acurada em determinados } \\
\text { grupos populacionais } \\
\text { (indivíduos mais velhos e } \\
\text { com maior peso). Erros } \\
\text { foram diretamente } \\
\text { relacionados com a } \\
\text { magnitude do sobrepeso, } \\
\text { e foram maiores entre as } \\
\text { mulheres do que entre os } \\
\text { homens. }\end{array}$ \\
\hline $\begin{array}{l}\text { FORTENBERRY } \\
\text { JD, 1992 } \\
\text { (Oklahoma - } \\
\text { EUA) } \\
\text { Entrevista face- } \\
\text { a-face X exame } \\
\text { clínico. } \\
\text { Diferença } \\
\text { média. }\end{array}$ & $\begin{array}{l}564 \text { homens } \\
161 \text { mulheres }\end{array}$ & 0 dias & $14-20$ & $\begin{array}{l}0: 0,6 \mathrm{~cm} \\
(3,5 \mathrm{~cm}) \\
-1,2 \mathrm{~kg} \\
(4,3 \mathrm{~kg}) \\
\\
\text { O: } 0,5 \mathrm{~cm} \\
(2,7 \mathrm{~cm}) \\
-1,5 \mathrm{~kg} \\
(3,8 \mathrm{~kg})\end{array}$ & $\begin{array}{l}\text { Autor sugere cautela ao } \\
\text { usar dados referidos de } \\
\text { adolescentes, embora a } \\
\text { magnitude da } \\
\text { subestimação tenha sido } \\
\text { pequena e sem maiores } \\
\text { consequêências com } \\
\text { relação às conclusões. }\end{array}$ \\
\hline $\begin{array}{l}\text { DEL PRETE et } \\
\text { al., 1992 } \\
\text { (Rhode Insland } \\
\text {-EUA) } \\
\text { Entrevista } \\
\text { telefônica X } \\
\text { pesagem direta } \\
\text { Diferença } \\
\text { média e } \\
\text { ANOVA. }\end{array}$ & $\begin{array}{l}13 \text { homens } \\
68 \text { mulheres }\end{array}$ & $\begin{array}{c}2 \text { a } 2,5 \\
\text { semanas }\end{array}$ & $\geq 18$ & $\begin{array}{c}0: 3,0 \\
(2,5 \mathrm{~cm}) \\
-2,1(1,5 \mathrm{~kg}) \\
\\
q: 1,3 \\
(2,6 \mathrm{~cm}) \\
-2,4(1,9 \mathrm{~kg})\end{array}$ & $\begin{array}{l}\text { Resultados em população } \\
\text { envolvida em programas } \\
\text { de perda de peso devem } \\
\text { ser interpretados com } \\
\text { cautela. Autores sugerem } \\
\text { que a pesagem antes da } \\
\text { entrevista deve ser } \\
\text { encorajada para aumentar } \\
\text { a acurácia dos dados, } \\
\text { uma vez que as pessoas } \\
\text { que se pesam } \\
\text { freqüentemente tendem a } \\
\text { informar melhor. }\end{array}$ \\
\hline $\begin{array}{l}\text { SMITH et al., } \\
1992 \\
\text { (Kentuchy - } \\
\text { EUA) } \\
\text { Entrevista } \\
\text { telefônica X } \\
\text { pesagem direta } \\
\text { Pearson e } \\
\text { RLM. }\end{array}$ & 101 mulheres & 0 dias & $\begin{array}{c}\text { Idade } \\
\text { média: } 23\end{array}$ & $\begin{array}{c}\text { Restrição } \\
\text { alimentar: } \\
-1,59 \mathrm{~kg} \\
(2,98 \mathrm{~kg}) \\
\text { Compulsão } \\
\text { alimentar: } \\
-2,03 \mathrm{~kg} \\
(3,38 \mathrm{~kg})\end{array}$ & $\begin{array}{l}\text { Mulheres que apresentam } \\
\text { desordens alimentares } \\
\text { (anorexia, bulimia e } \\
\text { tendência de restrição } \\
\text { alimentar) não foram nem } \\
\text { menos nem mais } \\
\text { acuradas do que mulheres } \\
\text { sem distúrbios } \\
\text { alimentares. A acurácia } \\
\text { dos dados não esteve } \\
\text { relacionada com a } \\
\text { presença de distúrbios } \\
\text { alimentares. }\end{array}$ \\
\hline
\end{tabular}




\begin{tabular}{|c|c|c|c|c|c|}
\hline $\begin{array}{l}\text { TIENBOON et } \\
\text { al., 1992 } \\
\text { (Victoria - } \\
\text { Austrália) } \\
\text { Questionário } \\
\text { auto- } \\
\text { preenchido X } \\
\text { pesagem direta } \\
\text { Pearson. }\end{array}$ & $\begin{array}{l}\text { Adolescentes: } \\
109 \text { homens } \\
95 \text { mulheres } \\
\text { Pais: } \\
135 \text { homens } \\
190 \text { mulheres }\end{array}$ & 0 dias & $\begin{array}{c}\text { adol.: } \\
\text { 14,9; } \\
\text { pais: } 44,8 \\
\text { mães: } \\
41,8\end{array}$ & 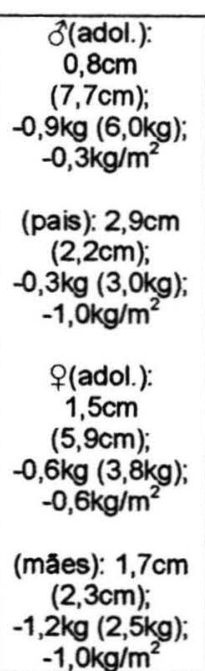 & $\begin{array}{l}\text { As informações de peso e } \\
\text { estatura fornecidas por } \\
\text { adolescentes são menos } \\
\text { confiáveis que a de seus } \\
\text { pais. Na média, contudo, a } \\
\text { extensão do erro não foi } \\
\text { maior do que a observada } \\
\text { em adulto sendo, portanto, } \\
\text { os valores referidos tão } \\
\text { válidos quanto em adultos. }\end{array}$ \\
\hline $\begin{array}{l}\text { ALVAREZ- } \\
\text { TORICES et } \\
\text { al., 1993 } \\
\text { (Leon-- } \\
\text { Espanha) } \\
\text { Entrevista face- } \\
\text { a-face X } \\
\text { pesagem direta } \\
\text { Pearson, } \\
\text { ANOVA, } \\
\text { Sensibilidade, } \\
\text { Especificidade, } \\
\text { VPN e VPP. }\end{array}$ & $\begin{array}{l}222 \text { homens e } \\
203 \text { mulheres }\end{array}$ & 0 dias & $\geq 18$ & $\begin{array}{l}0:-2,3 \mathrm{~cm} ; \\
0,2 \mathrm{~kg} \\
\text { o: }-2,2 \mathrm{~cm} ; \\
0,9 \mathrm{~kg}\end{array}$ & $\begin{array}{l}\text { Informação auto-referida } \\
\text { de peso e estatura deve } \\
\text { ser evitada em população } \\
\text { idosa, mas pode ser } \\
\text { usada em população com } \\
\text { alta proporção de jovens. }\end{array}$ \\
\hline $\begin{array}{l}\text { BOWLIN et al., } \\
1993 \\
\text { (Nova lorque - } \\
\text { EUA) } \\
\text { Entrevista } \\
\text { telefônica X } \\
\text { exame clínico } \\
\text { Pearson, } \\
\text { Sensibilidade, } \\
\text { Especificidade, } \\
\text { VPP e VPN. }\end{array}$ & $\begin{array}{l}282 \text { homens } \\
344 \text { mulheres }\end{array}$ & 1 mês & $20-69$ & $\begin{array}{r}\text { o: } 2,71 \mathrm{~cm} ; \\
-1,43 \mathrm{~kg} ; \\
-1,31 \mathrm{~kg} / \mathrm{m}^{2} \\
\\
\text { o:1,67cm; } \\
-2,87 \mathrm{~kg} ; \\
-1,65 \mathrm{~kg} / \mathrm{m}^{2}\end{array}$ & $\begin{array}{l}\text { Os autores sugerem que } \\
\text { fatores de correção sejam } \\
\text { usados para ajustar os } \\
\text { erros na populaçăo } \\
\text { estudada ou que medidas } \\
\text { diretas de peso e estatura } \\
\text { sejam tomadas. Sem isso, } \\
\text { a pesquisa telefônica deve } \\
\text { ser usada com cautela } \\
\text { para estimar a prevalência } \\
\text { ou identificar indivíduos } \\
\text { com fatores de risco para } \\
\text { doenças cardiovasculares, } \\
\text { pois a mesma leva a } \\
\text { maiores erros na } \\
\text { classificação do peso e } \\
\text { estatura do que a } \\
\text { entrevista face-a-face. }\end{array}$ \\
\hline
\end{tabular}




\begin{tabular}{|c|c|c|c|c|c|}
\hline $\begin{array}{l}\text { SCHMIDT et } \\
\text { al., 1993 } \\
\text { (Porto Alegre - } \\
\text { Brasil) } \\
\text { (Somente peso) } \\
\text { Entrevista } \\
\text { domiciliar } X \\
\text { pesagem direta } \\
\text { Pearson, } \\
\text { Sensibilidade, } \\
\text { Especificidade } \\
\text { e RLM. }\end{array}$ & $\begin{array}{l}254 \text { homens } \\
405 \text { mulheres }\end{array}$ & 0 dias & $15-64$ & $\begin{array}{l}\text { o: }+0,30 \mathrm{~kg} \\
\text { o: }-0,29 \mathrm{~kg}\end{array}$ & $\begin{array}{l}\text { Validade do peso é } \\
\text { aceitável para inquéritos } \\
\text { de prevalência realizados } \\
\text { em populaçöes urbanas } \\
\text { adultas. }\end{array}$ \\
\hline $\begin{array}{l}\text { ZHANG et al., } \\
1993 \text { (Carolina } \\
\text { do Norte -EUA) } \\
\text { Questionário } \\
\text { auto- } \\
\text { preenchido X } \\
\text { pesagem } \\
\text { direta. } \\
\text { Pearson. }\end{array}$ & 352 mulheres & $\begin{array}{l}\text { Algumas } \\
\text { semanas }\end{array}$ & 40 a 54 & $\begin{array}{c}0 \mathrm{~cm} \\
-1,37 \mathrm{~kg}\end{array}$ & $\begin{array}{l}\text { Entre mulheres brancas } \\
\text { peri-menopáusicas os } \\
\text { valores são acurados. }\end{array}$ \\
\hline $\begin{array}{l}\text { ROBERTS RJ, } \\
\text { 1995 } \\
\text { (País de Gales } \\
\text { - Reino Unido) } \\
\text { Questionário } \\
\text { auto- } \\
\text { preenchido X } \\
\text { exame clínico } \\
\text { (em } 10 \% \text { da } \\
\text { amostra) } \\
\text { Diferença } \\
\text { média. }\end{array}$ & $\begin{array}{l}806 \text { homens } \\
816 \text { mulheres }\end{array}$ & $\begin{array}{c}\begin{array}{c}3 \text { a } 8 \\
\text { meses }\end{array}\end{array}$ & $18-64$ & $\begin{array}{c}0: 1,44 \mathrm{~cm} \\
(2,28 \mathrm{~cm}) \\
-0,18 \mathrm{~kg} \\
(2,80 \mathrm{~kg}) \\
\\
9: 0,7 \mathrm{~cm} \\
(2,8 \mathrm{~cm}) \\
-1,1 \mathrm{~kg} \\
(2,59 \mathrm{~kg})\end{array}$ & $\begin{array}{l}\text { As informações auto- } \\
\text { referidas de peso e } \\
\text { estatura devem ser } \\
\text { usadas com cautela pois } \\
\text { têm importantes } \\
\text { implicaçōes em estudos } \\
\text { de prevalência de } \\
\text { sobrepeso, especialmente } \\
\text { em estudos longitudinais. } \\
\text { Autor sugere que mais } \\
\text { pesquisas sejam feitas no } \\
\text { sentido de encontrar } \\
\text { estabilidade nos vieses ao } \\
\text { longo do tempo. }\end{array}$ \\
\hline $\begin{array}{l}\text { TROY et al., } \\
\text { 1995 } \\
\text { (Massachusetts } \\
\text { - EUA) } \\
\text { Questionário } \\
\text { atual } \\
\text { (lembrança do } \\
\text { peso aos } 18 \\
\text { anos) X registro } \\
\text { médico (aos } 18 \\
\text { anos) } \\
\text { Spearman e } \\
\text { diferença } \\
\text { média. }\end{array}$ & 118 mulheres & 17 anos & $25-42$ & $\begin{array}{c}:+0,6 \mathrm{~cm} \\
-1,4 \mathrm{~kg} \\
-0,5 \mathrm{~kg} / \mathrm{m}^{2}\end{array}$ & $\begin{array}{l}\text { A validade do peso e } \\
\text { estatura recordados aos } \\
18 \text { anos de idade parece } \\
\text { ser alta entre as mulheres } \\
\text { desta coorte. }\end{array}$ \\
\hline
\end{tabular}




\begin{tabular}{|c|c|c|c|c|c|}
\hline $\begin{array}{l}\text { BOWLIN et al., } \\
1996 \\
\text { (Nova lorque - } \\
\text { EUA) } \\
\text { Entrevista } \\
\text { telefônica X } \\
\text { exame clínico } \\
\\
\text { Kappa, CCIC, } \\
\text { Pearson, } \\
\text { Sensibilidade, } \\
\text { Especificidade, } \\
\text { VPP e VPN. }\end{array}$ & 628 adultos & 1 mês & $20-69$ & $\begin{array}{c}1,95 \mathrm{~cm} ; \\
-1,56 \mathrm{~kg} ; \\
-1,21 \mathrm{~kg} / \mathrm{m}^{2}\end{array}$ & $\begin{array}{l}\text { Por tratar-se de um estudo } \\
\text { que visava monitorar os } \\
\text { fatores de risco para } \\
\text { doenças cardiovasculares, } \\
\text { houve subestimação da } \\
\text { obesidade, diabetes e } \\
\text { tabagismo em entrevista } \\
\text { telefônica, porém esta } \\
\text { subestimativa foi menos } \\
\text { severa do que para } \\
\text { hipertensão e } \\
\text { hipercolesterolemia. } \\
\text { Autores sugerem } \\
\text { avaliaçăo fisiológica ou o } \\
\text { uso de fatores de correção } \\
\text { para ajustar erros na } \\
\text { classificação dos } 2 \text { últimos } \\
\text { fatores de risco para DCV } \\
\text { quando se utiliza } \\
\text { entrevistas telefônicas. }\end{array}$ \\
\hline $\begin{array}{l}\text { JEFFERY RW, } \\
1996 \\
\text { (Minneapolis - } \\
\text { EUA) } \\
\text { (somente peso) } \\
\text { Entrevista } \\
\text { telefônica, } \\
\text { questionário } \\
\text { por correio X } \\
\text { pesagem direta } \\
\\
\text { Pearson, RLM } \\
\text { e diferença } \\
\text { média. }\end{array}$ & $\begin{array}{l}2046 \text { homens } \\
2393 \text { mulheres }\end{array}$ & 1 semana & $\begin{array}{c}\text { Idade } \\
\text { média: } 38\end{array}$ & $\begin{array}{c}\delta:-1,09 \mathrm{~kg} \\
(2,31 \mathrm{~kg}) \\
\\
\text { ᄋ: }-1,22 \mathrm{~kg} \\
(2,09 \mathrm{~kg})\end{array}$ & $\begin{array}{l}\text { Informação auto-referida } \\
\text { do peso é extremamente } \\
\text { acurada para vários } \\
\text { subgrupos populacionais. } \\
\text { Autor chama atenção para } \\
\text { o fato de que } \\
\text { generalização dos } \\
\text { resultados deve ser } \\
\text { cuidadosa já que a } \\
\text { população estudada era } \\
\text { etnicamente homogênea e } \\
\text { composta somente por } \\
\text { pessoas empregadas. }\end{array}$ \\
\hline $\begin{array}{l}\text { WEAVER et } \\
\text { al., } 1996 \\
\text { (Minnesota - } \\
\text { EUA) } \\
\text { Questionário } \\
\text { por correio + } \\
\text { instrução para } \\
\text { pesagem X } \\
\text { pesagem por } \\
\text { técnicos } \\
\text { Pearson, } \\
\text { Spearman, } \\
\text { gráficos de } \\
\text { Bland e Altman } \\
\text { e diferença } \\
\text { média. }\end{array}$ & 66 mulheres & $\begin{array}{l}\text { Entre } 11 \\
\text { meses }\end{array}$ & $40-81$ & $\begin{array}{c}0,045 \mathrm{~cm} \\
-0,70 \mathrm{~kg}\end{array}$ & $\begin{array}{l}\text { Informações auto- } \\
\text { referidas de peso, } \\
\text { estatura, cintura, quadril, } \\
\text { tórax e busto são } \\
\text { altamente acuradas até } \\
\text { mesmo quando usadas } \\
\text { para definir índices como } \\
\text { o IMC, sendo, portanto, } \\
\text { apropriadas para estudos } \\
\text { epidemiológicos. }\end{array}$ \\
\hline
\end{tabular}




\begin{tabular}{|c|c|c|c|c|c|}
\hline $\begin{array}{l}\text { BÖSTROM e } \\
\text { DIDERICHSEN, } \\
1997 \\
\text { (Estocolmo - } \\
\text { Suécia) } \\
\text { Questionário } \\
\text { por correio ou } \\
\text { telefone (quem } \\
\text { não retomou } \\
\text { carta) X prévio } \\
\text { exame físico } \\
\text { Sensibilidade e } \\
\text { diferença } \\
\text { média. }\end{array}$ & 3208 adultos & $\begin{array}{c}4 \text { a } 6 \\
\text { meses }\end{array}$ & $18-84$ & $\begin{array}{c}\text { o: } 0,6 \mathrm{~cm} ; \\
-0,74 \mathrm{~kg} ; \\
-0,4 \mathrm{~kg} / \mathrm{m}^{2} \\
\text { o: } 0,79 \mathrm{~cm} ; \\
-1,64 \mathrm{~kg} ; \\
-0,85 \mathrm{~kg} / \mathrm{m}^{2}\end{array}$ & $\begin{array}{l}\text { Estudo mostra que } \\
\text { diferenças } \\
\text { socioeconômicas podem } \\
\text { implicar em subestimaçäo } \\
\text { da estatura. A prevalência } \\
\text { da obesidade e sobrepeso } \\
\text { tende a ser superestimada } \\
\text { por homens com menor } \\
\text { nivel socioeconômico. A } \\
\text { prevalência de baixo peso } \\
\text { tende a ser subestimada } \\
\text { para homens, assim como } \\
\text { a obesidade para } \\
\text { mulheres. }\end{array}$ \\
\hline $\begin{array}{l}\text { BLACK et al., } \\
1998 \\
\text { (Utah -EUA) } \\
\text { (Apenas peso) } \\
\text { Questionário } \\
\text { (informando } \\
\text { possibilidade } \\
\text { de pesagem), } \\
\text { questionário } \\
\text { (sem } \\
\text { informação de } \\
\text { possivel } \\
\text { pesagem) X } \\
\text { pesagem } \\
\text { RLM }\end{array}$ & $\begin{array}{l}124 \text { homens } \\
99 \text { mulheres }\end{array}$ & 0 dias & $18-82$ & $\begin{array}{c}\text { Grupo } \\
\text { informado } \\
\text { de pesagem: } \\
-0,86 \mathrm{~kg} \\
(1,76 \mathrm{~kg}) \\
\text { Não } \\
\text { informado } \\
\text { de pesagem: } \\
-1,32 \mathrm{~kg} \\
(2,46 \mathrm{~kg})\end{array}$ & $\begin{array}{l}\text { O peso auto-referido foi } \\
\text { um substituto válido para } \\
\text { o peso aferido desde que } \\
\text { o individuo seja informado } \\
\text { da possibilidade de ser } \\
\text { pesado juntamente com a } \\
\text { entrevista, receba } \\
\text { instruçőes específicas e } \\
\text { responda à outras } \\
\text { informaçőes sobre o peso. }\end{array}$ \\
\hline $\begin{array}{l}\text { HILL e } \\
\text { ROBERTS, } \\
1998 \\
\text { (EUA) } \\
\text { Questionário } \\
\text { auto- } \\
\text { preenchido pelo } \\
\text { correio X } \\
\text { exame clínico } \\
\text { Valor aferido } \\
\text { plotado contra } \\
\text { diferença entre } \\
\text { valor aferido e } \\
\text { referido. }\end{array}$ & 2258 indivíduos & $\begin{array}{c}1 \text { a } 4 \\
\text { meses }\end{array}$ & $16-64$ & $\begin{array}{c}7,46 \mathrm{~cm} \\
0,85 \mathrm{~kg} ; \\
-1,29 \mathrm{~kg} / \mathrm{m}^{2}\end{array}$ & $\begin{array}{l}\text { Peso e estatura referidos } \\
\text { não são confiáveis e } \\
\text { devem ser usados com } \\
\text { cautela para monitorar a } \\
\text { saúde. }\end{array}$ \\
\hline
\end{tabular}




\begin{tabular}{|c|c|c|c|c|c|}
\hline $\begin{array}{l}\text { CHOR et al., } \\
1999 \\
\text { (Rio de Janeiro } \\
\text { - Brasil) } \\
\text { Questionário } \\
\text { auto- } \\
\text { preenchido X } \\
\text { pesagem direta } \\
\text { gráficos de } \\
\text { Bland e Altman, } \\
\text { CCIC }\end{array}$ & $\begin{array}{l}164 \text { homens } \\
158 \text { mulheres }\end{array}$ & 0 dias & $\begin{array}{c}\text { Média de } \\
\text { idade } 38,5\end{array}$ & 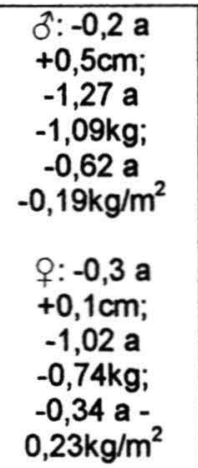 & $\begin{array}{l}\text { As informações auto- } \\
\text { referidas de peso e } \\
\text { estatura são válidas em } \\
\text { grupos populacionais com } \\
\text { alto nivel de escolaridade } \\
\text { e acesso à serviços de } \\
\text { saúde. }\end{array}$ \\
\hline $\begin{array}{l}\text { NAKAMURA et } \\
\text { al., 1999 } \\
\text { (Fukushima - } \\
\text { Japão) } \\
\text { Questionário } \\
\text { auto- } \\
\text { preenchido X } \\
\text { pesagem direta } \\
\text { gráficos de } \\
\text { Bland e Altman, } \\
\text { diferença média } \\
\text { e Pearson }\end{array}$ & 330 mulheres & 1 semana & $20-42$ & $\begin{array}{l}\text { O: }-0,1 \mathrm{~cm} \\
(0,7 \mathrm{~cm}) \\
-0,2 \mathrm{~kg} \\
(1,8 \mathrm{~kg}) \\
-0,1 \mathrm{~kg} / \mathrm{m}^{2}\end{array}$ & $\begin{array}{l}\text { Apesar de algumas } \\
\text { limitaçőes, as informaçōes } \\
\text { auto-referidas de peso e } \\
\text { estatura em mulheres } \\
\text { adultas japonesas são } \\
\text { precisas e acuradas, e } \\
\text { seu uso em pesquisas } \\
\text { epidemiológicas é } \\
\text { considerado aceitável. }\end{array}$ \\
\hline $\begin{array}{l}\text { STRAUSS RS, } \\
\text { 1999 } \\
\text { (EUA) } \\
\text { Entrevista face- } \\
\text { a-face X } \\
\text { pesagem } \\
\text { direta. } \\
\text { Pearson }\end{array}$ & $\begin{array}{l}1657 \\
\text { adolescentes }\end{array}$ & 0 dias & $12-16$ & $\begin{array}{c}6:-0,4 \mathrm{~cm} \\
(2,1 \mathrm{~cm}) \\
-0,1 \mathrm{~kg} \\
(6,1 \mathrm{~kg}) \\
\\
+:-0,5 \mathrm{~cm} \\
(2,1 \mathrm{~cm}) \\
-1,0 \mathrm{~kg} \\
(5,5 \mathrm{~kg})\end{array}$ & $\begin{array}{l}\text { O peso e estatura auto- } \\
\text { referidos foram } \\
\text { extremamente confiáveis } \\
\text { para predizer morbidades } \\
\text { relacionadas à obesidade. }\end{array}$ \\
\hline $\begin{array}{l}\text { BOLTON- } \\
\text { SMITH et al., } \\
2000 \\
\text { (Glasgow- } \\
\text { Escócia) } \\
\text { Questionário } \\
\text { auto- } \\
\text { preenchido por } \\
\text { correio X } \\
\text { exame clínico } \\
\text { Sensibilidade e } \\
\text { Especificidade, } \\
\text { RL e diferença } \\
\text { média. }\end{array}$ & $\begin{array}{l}865 \text { homens } \\
971 \text { mulheres }\end{array}$ & $\begin{array}{c}2 \\
\text { semanas }\end{array}$ & $25-64$ & $\begin{array}{c}\text { o: }-1,3 \mathrm{~cm} \\
(2,5 \mathrm{~cm}) ; \\
-0,63 \mathrm{~kg} \\
(3,45 \mathrm{~kg}) ; \\
+0,19 \mathrm{~kg} / \mathrm{m}^{2} \\
\\
+:-1,7 \mathrm{~cm} \\
(2,37 \mathrm{~cm}) ; \\
-0,95 \mathrm{~kg} \\
(2,64 \mathrm{~kg}) ; \\
+0,17 \mathrm{~kg} / \mathrm{m}^{2}\end{array}$ & $\begin{array}{l}\text { Esta população escocesa } \\
\text { foi a única a subestimar } \\
\text { peso e estatura, } \\
\text { resultando em IMC com } \\
\text { baixo erro. Informaçōes } \\
\text { auto-referidas de peso e } \\
\text { estatura são satisfatórias } \\
\text { para o monitoramento da } \\
\text { prevalência da obesidade } \\
\text { na população adulta. }\end{array}$ \\
\hline
\end{tabular}




\begin{tabular}{|c|c|c|c|c|c|}
\hline $\begin{array}{l}\text { FLOOD et al., } \\
2000 \\
\text { Western } \\
\text { Sidney - } \\
\text { Austrália) } \\
\text { Entrevista } \\
\text { telefônica X } \\
\text { pesagem } \\
\text { clínica } \\
\text { gráficos de } \\
\text { Bland e Altman } \\
\text { e diferença } \\
\text { média. }\end{array}$ & $\begin{array}{l}94 \text { homens } \\
133 \text { mulheres }\end{array}$ & $\begin{array}{l}2 \text { a } 4 \\
\text { meses }\end{array}$ & $16-85$ & $\begin{array}{c}:=2,0 \mathrm{~cm} ; \\
-1,4 \mathrm{~kg} \\
\text { o: } 0,8 \mathrm{~cm} ; \\
-3,0 \mathrm{~kg}\end{array}$ & $\begin{array}{l}\text { Autores sugerem cautela } \\
\text { ao usar dados auto- } \\
\text { referidos de peso e } \\
\text { estatura e sugerem que } \\
\text { sub-estudos periódicos de } \\
\text { validade sejam realizados } \\
\text { para indicar as mudanças } \\
\text { na acurácia ao longo do } \\
\text { tempo. }\end{array}$ \\
\hline $\begin{array}{l}\text { GUNNELL et } \\
\text { al., 2000 } \\
\text { (Inglaterra) } \\
\text { Questionário } \\
\text { por correio } \\
\text { (amostra) } X \\
\text { exame clínico } \\
\text { (sub-amostra) }\end{array}$ & $\begin{array}{l}3182 \text { adultos } \\
\text { sub-amostra: } \\
118 \text { homens } \\
139 \text { mulheres }\end{array}$ & 0 dias & $56-78$ & $\begin{array}{l}\delta: 2,1 \mathrm{~cm} ; \\
-1,9 \mathrm{~kg} ; \\
-1,3 \mathrm{~kg} / \mathrm{m}^{2} \\
\\
\text { o: } 1,7 \mathrm{~cm} ; \\
-1,2 \mathrm{~kg} ; \\
-1,2 \mathrm{~kg} / \mathrm{m}^{2}\end{array}$ & $\begin{array}{l}\text { Informaçōes auto- } \\
\text { referidas de peso e } \\
\text { estatura podem ser } \\
\text { usadas em estudos com } \\
\text { idosos, embora erros } \\
\text { sistemáticos possam } \\
\text { enviesar o efeito } \\
\text { estimado. }\end{array}$ \\
\hline $\begin{array}{l}\text { Pearson, Bland } \\
\text { e Altman. }\end{array}$ & & & & & \\
\hline $\begin{array}{l}\text { LARSON MR, } \\
2000 \text { (EUA) } \\
\text { Entrevista } \\
\text { telefônica X } \\
\text { exame clínico } \\
\text { RL }\end{array}$ & $\begin{array}{l}19 \text { homens } \\
37 \text { mulheres }\end{array}$ & 1 semana & 18 a 59 & $\begin{array}{l}25 \% \text { mais } \\
\text { pesados: } \\
-3,9 \mathrm{~kg} \\
25 \% \text { mais } \\
\text { magros: } \\
+0,6 \mathrm{~kg}\end{array}$ & $\begin{array}{l}\text { O erro em informar o peso } \\
\text { entre jovens e mulheres } \\
\text { não obesas pode ser } \\
\text { diretamente influenciado } \\
\text { pelo desejo de enquadrar- } \\
\text { se às normas sociais. }\end{array}$ \\
\hline $\begin{array}{l}\text { NIEDHAMMER } \\
\text { et al., 2000 } \\
\text { (França) } \\
\text { Questionário } \\
\text { auto- } \\
\text { preenchido por } \\
\text { correio X } \\
\text { exame clinico } \\
\text { Pearson, RLM, } \\
\text { Sensibilidade e } \\
\text { Especificidade } \\
\text { e Diferença } \\
\text { média. }\end{array}$ & $\begin{array}{l}5445 \text { homens } \\
1905 \text { mulheres }\end{array}$ & $\begin{array}{l}\text { Até } 6 \\
\text { meses }\end{array}$ & $\geq 40$ & $\begin{array}{r}\delta: 0,38 \mathrm{~cm} ; \\
-0,54 \mathrm{~kg} ; \\
-0,29 \mathrm{~kg} / \mathrm{m}^{2} \\
\text { o: } 0,4 \mathrm{~cm} \\
-0,85 \mathrm{~kg} ; \\
-0,44 \mathrm{~kg} / \mathrm{m}^{2}\end{array}$ & $\begin{array}{l}\text { Os erros de classificação } \\
\text { podem conduzir a vieses, } \\
\text { portanto, os resultados } \\
\text { sugerem que as } \\
\text { informaçōes auto-referidas } \\
\text { de peso e estatura devem } \\
\text { ser tratadas com cautela. }\end{array}$ \\
\hline
\end{tabular}




\begin{tabular}{|c|c|c|c|c|c|}
\hline $\begin{array}{l}\text { KUCZMARSKI } \\
\text { et al., 2001 } \\
\text { (EUA) } \\
\text { Entrevista } \\
\text { domiciliar face- } \\
\text { a-face X } \\
\text { pesagem } \\
\text { domiciliar ou } \\
\text { exame clinico. } \\
\text { Pearson, RLM, } \\
\text { Sensibilidade e } \\
\text { Especificidade, } \\
\text { teste T de } \\
\text { Student e } \\
\text { Diferença } \\
\text { média. }\end{array}$ & $\begin{array}{l}7772 \text { homens } \\
8801 \text { mulheres }\end{array}$ & $\begin{array}{c}\begin{array}{c}2 \text { a } 4 \\
\text { semanas }\end{array}\end{array}$ & $\geq 20$ & $\begin{array}{c}<60: \\
0,98 \mathrm{~cm} ; \\
0,35 \mathrm{~kg} ; \\
-0,18 \mathrm{~kg} / \mathrm{m}^{2} \\
\geq 60: \\
2,70 \mathrm{~cm} ; \\
0,51 \mathrm{~kg} ; \\
-0,64 \mathrm{~kg} / \mathrm{m}^{2} \\
0<60: \\
0,04 \mathrm{~cm} ; \\
-1,49 \mathrm{~kg} ; \\
-1,05 \mathrm{~kg} / \mathrm{m}^{2} \\
\geq 60: \\
2,53 \mathrm{~cm} ; \\
-0,56 \mathrm{~kg} ; \\
-0,58 \mathrm{~kg} / \mathrm{m}^{2}\end{array}$ & $\begin{array}{l}\text { Informaçōes auto- } \\
\text { referidas de peso e } \\
\text { estatura podem ser } \\
\text { usadas em relação a } \\
\text { adultos jovens, mas têm } \\
\text { limitações para pessoas } \\
\text { com mais de } 60 \text { anos. Se } \\
\text { possível pesquisador } \\
\text { deveria medir a estatura e } \\
\text { peso dos individuos mais } \\
\text { velhos. Pesquisadores } \\
\text { podem estimar a estatura } \\
\text { atual da estatura referida } \\
\text { para indivíduos mais } \\
\text { velhos usando as } \\
\text { equaçōes propostas. }\end{array}$ \\
\hline $\begin{array}{l}\text { NAWAZ et al., } \\
2001 \\
\text { (Connecticut - } \\
\text { EUA) } \\
\text { Entrevista } \\
\text { telefônica X } \\
\text { exame fisico } \\
\text { RL } \\
\end{array}$ & $\begin{array}{l}95 \text { mulheres } \\
\text { obesas }\end{array}$ & $\begin{array}{c}2 \\
\text { semanas }\end{array}$ & $30-65$ & $\begin{array}{c}: 0,88 \mathrm{~cm} \\
-1,70 \mathrm{~kg} ; \\
-1,14 \mathrm{~kg} / \mathrm{m}^{2}\end{array}$ & $\begin{array}{l}\text { Resultados sugerem que } \\
\text { as informaçōes auto- } \\
\text { referidas de peso e } \\
\text { estatura obtidos por } \\
\text { mulheres obesas } \\
\text { envolvidas em programas } \\
\text { de perda de peso são } \\
\text { inacuradas. }\end{array}$ \\
\hline $\begin{array}{l}\text { PACCAUD et } \\
\text { al., 2001 } \\
\text { (Canton of } \\
\text { Vaud -Suíça) } \\
\text { Entrevista } \\
\text { telefônica } X \\
\text { exame clínico } \\
\text { Diferença } \\
\text { média. }\end{array}$ & 2138 individuos & Não citado & $25-74$ & $\begin{array}{c}\text { o: } 1,2 \mathrm{~cm} ; \\
-2,2 \mathrm{~kg} ; \\
-1 \text { a } 2 \mathrm{~kg} / \mathrm{m}^{2} \\
\\
\text { o: } 1,9 \mathrm{~cm} ; \\
-3,5 \mathrm{~kg} ; \\
-2 \text { a } 3 \mathrm{~kg} / \mathrm{m}^{2}\end{array}$ & $\begin{array}{l}\text { Informaçōes auto- } \\
\text { referidas de peso e } \\
\text { estatura apresentam viés } \\
\text { sistemático, o qual } \\
\text { compromete a validade de } \\
\text { pesquisas telefônicas que } \\
\text { estimam a prevalência de } \\
\text { obesidade. }\end{array}$ \\
\hline $\begin{array}{l}\text { VILLANUEVA } \\
\text { EV, 2001 } \\
\text { (EUA) } \\
\text { Entrevista } \\
\text { domiciliar X } \\
\text { exame clínico } \\
\text { RL e diferença } \\
\text { média. }\end{array}$ & $\begin{array}{l}15994 \\
\text { individuos }\end{array}$ & Não citado & $\geq 17$ & $\begin{array}{c}\text { o: } 0,49 \mathrm{~kg} \\
1,0 \mathrm{~cm} \\
\\
\text { \%: }-1,63 \mathrm{~kg} \\
1,0 \mathrm{~cm}\end{array}$ & $\begin{array}{l}\text { As discrepâncias no peso } \\
\text { foram positivamente } \\
\text { associadas com idade e } \\
\text { negativamente associadas } \\
\text { com peso e IMC medidos. } \\
\text { Os preditores do grau de } \\
\text { discrepância no peso são } \\
\text { específicos de cada sexo } \\
\text { e requerem cuidado } \\
\text { quando examinados. }\end{array}$ \\
\hline
\end{tabular}




\begin{tabular}{|c|c|c|c|c|c|}
\hline $\begin{array}{l}\text { LAWLOR et } \\
\text { al., 2002 } \\
\text { (Inglaterra, } \\
\text { Escócia e País } \\
\text { de Gales) } \\
\text { Questionário } \\
\text { auto- } \\
\text { preenchido por } \\
\text { correio X } \\
\text { exame clinico } \\
\text { Pearson, } \\
\text { gráficos de } \\
\text { Bland e Altman, } \\
\text { Diferença } \\
\text { média. }\end{array}$ & 1310 mulheres & $\begin{array}{c}6 \\
\text { semanas }\end{array}$ & $60-79$ & o: $-0,97 \mathrm{~kg}$ & $\begin{array}{l}\text { Em estudos } \\
\text { epidemiológicos } \\
\text { prospectivos ou em } \\
\text { práticas clínicas, quando } \\
\text { for necessária maior } \\
\text { precisão nas medidas } \\
\text { individuais, a informação } \\
\text { de peso e estatura auto- } \\
\text { referidos não são } \\
\text { confiáveis. }\end{array}$ \\
\hline $\begin{array}{l}\text { SPENCER et } \\
\text { al., 2002 } \\
\text { (Oxford - } \\
\text { Inglaterra) } \\
\text { Questionário } \\
\text { auto- } \\
\text { preenchido X } \\
\text { exame clínico } \\
\text { Spearman. }\end{array}$ & $\begin{array}{l}1870 \text { homens } \\
2938 \text { mulheres }\end{array}$ & $\begin{array}{l}\text { Poucas } \\
\text { semanas }\end{array}$ & $35-76$ & $\begin{array}{l}0: 1,23 \mathrm{~cm} ; \\
-1,85 \mathrm{~kg} ; \\
-0,96 \mathrm{~kg} / \mathrm{m}^{2} \\
\\
\text { Q: } 0,60 \mathrm{~cm} ; \\
-1,40 \mathrm{~kg} ; \\
-0,72 \mathrm{~kg} / \mathrm{m}^{2}\end{array}$ & $\begin{array}{l}\text { O peso e estatura auto- } \\
\text { referidos são válidos para } \\
\text { identificar relaçőes em } \\
\text { estudos epidemiológicos. } \\
\text { Em análises onde os } \\
\text { fatores antropométricos } \\
\text { são as variáveis primárias } \\
\text { de interesse, pode-se usar } \\
\text { medidas aferidas em uma } \\
\text { amostra representativa da } \\
\text { população para melhorar } \\
\text { a acurácia das estimativas } \\
\text { de peso, estatura e IMC. }\end{array}$ \\
\hline $\begin{array}{l}\text { WANG ET AL., } \\
2002 \\
\text { (Queensland - } \\
\text { Austrália) } \\
\text { Entrevista face- } \\
\text { a-face X } \\
\text { pesagem } \\
\text { clínica. } \\
\text { Gráficos de } \\
\text { Bland e Altman } \\
\text { e diferença } \\
\text { média. }\end{array}$ & $\begin{array}{l}295 \text { homens } \\
277 \text { mulheres }\end{array}$ & $\begin{array}{l}\text { Poucas } \\
\text { semanas }\end{array}$ & $15-19$ & $\begin{array}{c}: 1,2 \mathrm{~cm} \\
(4,0 \mathrm{~cm}) ; \\
-2,0 \mathrm{~kg} \\
(6,1 \mathrm{~kg}) \\
\\
\text { : } 0,9 \mathrm{~cm} \\
(3,8 \mathrm{~cm}) ; \\
-2,1 \mathrm{~kg} \\
(4,0 \mathrm{~kg})\end{array}$ & $\begin{array}{l}\text { Informações auto- } \\
\text { referidas de peso e } \\
\text { estatura precisam ser } \\
\text { usadas com cautela, } \\
\text { principalmente por } \\
\text { adolescentes obesos e } \\
\text { com sobrepeso. }\end{array}$ \\
\hline $\begin{array}{l}\text { SANTILLAN e } \\
\text { CAMARGO JR, } \\
2003 \\
\text { (Monterrey- } \\
\text { México) } \\
\text { Entrevista face- } \\
\text { a-face X exame } \\
\text { clínico } \\
\text { RLM e } \\
\text { Logística e } \\
\text { Sensibilidade. }\end{array}$ & 961 adultos & 0 dias & $\begin{array}{l}\text { caso: } 42 \\
\text { controle: } \\
\quad 35\end{array}$ & $\begin{array}{c}\text { Caso: } \\
-0,91 \mathrm{~kg} / \mathrm{m}^{2} \\
\text { Controle: } \\
-0,61 \mathrm{~kg} / \mathrm{m}^{2}\end{array}$ & $\begin{array}{l}\text { Avaliou o efeito do erro de } \\
\text { classificação do IMC na } \\
\text { associaçăo entre } \\
\text { obesidade e asma. O uso } \\
\text { do IMC referido diminuiu } \\
\text { substancialmente a } \\
\text { associação entre } \\
\text { obesidade e asma quando } \\
\text { o diagnóstico da } \\
\text { obesidade foi feito a partir } \\
\text { de medidas referidas e } \\
\text { não aferidas. }\end{array}$ \\
\hline
\end{tabular}




\begin{tabular}{|c|c|c|c|c|c|}
\hline $\begin{array}{l}\text { OLIVEIRA et } \\
\text { al., } 2004 \\
\text { (Rio de Janeiro } \\
\text { - Brasil) } \\
\text { Entrevista face- } \\
\text { a-face X cartão } \\
\text { pré-natal. } \\
\text { Pearson, CCIC, } \\
\text { RL. }\end{array}$ & 150 gestantes & $\begin{array}{l}\text { Período } \\
\text { gestacio- } \\
\text { nal }\end{array}$ & Idade fértil & $\begin{array}{c}-1,23 \mathrm{~cm} \\
0,50 \mathrm{~kg}\end{array}$ & $\begin{array}{l}\text { As informações referidas } \\
\text { para peso pré-gestacional } \\
\text { aproximam-se dos valores } \\
\text { aferidos, o mesmo } \\
\text { ocorrendo em relação ao } \\
\text { peso final. Entretanto, } \\
\text { para a estatura, as } \\
\text { informações referidas } \\
\text { devem ser utilizadas com } \\
\text { cautela. }\end{array}$ \\
\hline $\begin{array}{l}\text { FONSECA et } \\
\text { al., 2004 (Rio } \\
\text { de Janeiro - } \\
\text { Brasil) } \\
\text { Questionário } \\
\text { auto- } \\
\text { preenchido X } \\
\text { pesagem direta } \\
\text { Teste T } \\
\text { pareado, } \\
\text { gráficos de } \\
\text { Bland e Altman, } \\
\text { CCIC, } \\
\text { Sensibilidade e } \\
\text { Especificidade. }\end{array}$ & 3713 adultos & 0 dias & 22 a 70 & $\begin{array}{c}\text { o: } 0,17 \mathrm{~cm} ; \\
-1,02 \mathrm{~kg} ; \\
-0,37 \mathrm{~kg} / \mathrm{m}^{2} \\
\text { o: } 1,05 \mathrm{~cm} ; \\
-1,14 \mathrm{~kg} ; \\
-0,77 \mathrm{~kg} / \mathrm{m}^{2}\end{array}$ & $\begin{array}{l}\text { As informações de peso e } \\
\text { estatura referidas } \\
\text { apresentam boa } \\
\text { concordância e validade. } \\
\text { Em populações similares } \\
\text { que disponham de } \\
\text { recursos escassos, é } \\
\text { possivel utilizar dados } \\
\text { informados ao invés de } \\
\text { aferidos. }\end{array}$ \\
\hline $\begin{array}{l}\text { ÁVILA-FUNES } \\
\text { et al., 2004 } \\
\text { (México) } \\
\text { Entrevista face- } \\
\text { a-face X } \\
\text { pesagem direta } \\
\text { Coeficiente de } \\
\text { correlação } \\
\text { Spearman, } \\
\text { teste de } \\
\text { Wilcoxon, RL, } \\
\text { limites de } \\
\text { concordância } \\
\text { de Bland } e \\
\text { Altman, CCIC. }\end{array}$ & $\begin{array}{l}836 \text { homens } \\
871 \text { mulheres }\end{array}$ & 0 dias & 24 a 75 & $\begin{array}{c}\delta:+1,20 \mathrm{~cm} ; \\
+0,40 \mathrm{~kg} ; \\
-0,30 \mathrm{~kg} / \mathrm{m}^{2} \\
\\
\text { o: }+2,20 \mathrm{~cm} ; \\
+0,70 \mathrm{~kg} ; \\
-0,50 \mathrm{~kg} / \mathrm{m}^{2}\end{array}$ & $\begin{array}{l}\text { O uso de medidas } \\
\text { referidas é válido na } \\
\text { população mexicana, } \\
\text { especialmente em } \\
\text { indivíduos com menos de } \\
75 \text { anos. }\end{array}$ \\
\hline
\end{tabular}




\begin{tabular}{|c|c|c|c|c|c|}
\hline $\begin{array}{l}\text { WADA et al., } \\
2005 \\
\text { (Japão) } \\
\text { Questionário } \\
\text { auto- } \\
\text { preenchido X } \\
\text { exame físico } \\
\text { anual } \\
\text { Diferença } \\
\text { média, } \\
\text { Pearson, } \\
\text { Limites de } \\
\text { concordância, } \\
\text { Sensibilidade, } \\
\text { Especificidade, } \\
\text { VPP, VPN, } \\
\text { Kappa. }\end{array}$ & $\begin{array}{l}4253 \text { homens } \\
1148 \text { mulheres }\end{array}$ & Até 1 ano & 35 a 64 & $\begin{array}{r}\text { o: } 0,078 \mathrm{~cm} ; \\
-0,034 \mathrm{~kg} ; \\
-0,035 \mathrm{~kg} / \mathrm{m}^{2} \\
\text { o: } 0,029 \mathrm{~cm} ; \\
0,024 \mathrm{~kg} ; \\
-0,002 \mathrm{~kg} / \mathrm{m}^{2}\end{array}$ & $\begin{array}{l}\text { Peso e estatura referidos } \\
\text { foram geralmente } \\
\text { confiáveis em população } \\
\text { japonesa empregada. O } \\
\text { IMC baseado nas medidas } \\
\text { referidas também foi útil } \\
\text { em estimar a prevalência } \\
\text { da obesidade e a } \\
\text { associação da obesidade } \\
\text { com várias doenças. }\end{array}$ \\
\hline $\begin{array}{l}\text { ELGAR et al., } \\
2005 \text { (País de } \\
\text { Gales - Reino } \\
\text { Unido) } \\
\text { Questionário } \\
\text { auto- } \\
\text { preenchido X } \\
\text { pesagem } \\
\text { Gráficos de } \\
\text { Bland e Altman, } \\
\text { RL, Modelos de } \\
\text { Regressão } \\
\text { Hierárquicos, } \\
\text { Pearson, } \\
\text { Sensibilidade e } \\
\text { Especificidade }\end{array}$ & $\begin{array}{l}190 \text { garotos e } \\
225 \text { garotas }\end{array}$ & 0 dias & $\begin{array}{l}\text { Idade } \\
\text { média: } \\
16,3\end{array}$ & $\begin{array}{r}0: 0,58 \mathrm{~cm} ; \\
-0,43 \mathrm{~kg} ; \\
-0,29 \mathrm{~kg} / \mathrm{m}^{2} \\
\text { \%: } 0,31 \mathrm{~cm} ; \\
-0,61 \mathrm{~kg} ; \\
-0,28 \mathrm{~kg} / \mathrm{m}^{2}\end{array}$ & $\begin{array}{l}\text { Os vieses provenientes de } \\
\text { medidas referidas têm } \\
\text { influências significativas } \\
\text { na acurácia em estimar } \\
\text { prevalência de obesidade } \\
\text { e sobrepeso. A checagem } \\
\text { destes vieses pode } \\
\text { melhorar a qualidade das } \\
\text { pesquisas sobre } \\
\text { problemas de peso em } \\
\text { adolescentes. }\end{array}$ \\
\hline $\begin{array}{l}\text { SILVEIRA et } \\
\text { al., 2005 } \\
\text { (Pelotas- Brasil) } \\
\text { Questionário } \\
\text { administrado X } \\
\text { entrevista } \\
\text { domiciliar } \\
\text { (subamostra) } \\
\text { Coeficiente de } \\
\text { Lin, gráficos de } \\
\text { Bland e Altman. }\end{array}$ & $\begin{array}{l}57 \text { homens e } \\
83 \text { mulheres }\end{array}$ & Até 7 dias & $\geq 20$ & $\begin{array}{c}0: 2,0 \mathrm{~cm} ; \\
1,93 \mathrm{~kg} ;{ }^{2} \\
0,17 \mathrm{~kg} / \mathrm{m}^{2} \\
\text { o: } 3,0 \mathrm{~cm} ; \\
0,4 \mathrm{~kg} ; \\
-1,0 \mathrm{~kg} / \mathrm{m}^{2}\end{array}$ & $\begin{array}{l}\text { Para avaliar o estado } \\
\text { nutricional de grupos } \\
\text { populacionais adultos, } \\
\text { deve-se utilizar com } \\
\text { cautela o IMC "referido", } \\
\text { devido ao erro na } \\
\text { classificação do IMC que } \\
\text { leva à subestimativa da } \\
\text { obesidade e } \\
\text { superestimativa do } \\
\text { sobrepeso. } \\
\text { O autor sugere o uso do } \\
\text { IMC "corrigido", calculado } \\
\text { pela equação de } \\
\text { regressãa linear ou o uso } \\
\text { do IMC "semi-referido" } \\
\text { calculado a partir do peso } \\
\text { informado e estatura } \\
\text { medida. }\end{array}$ \\
\hline
\end{tabular}




\begin{tabular}{|c|c|c|c|c|c|}
\hline $\begin{array}{l}\text { NG et al., } 2005 \\
\text { (Singapura) } \\
\text { Entrevista } \\
\text { domiciliar X } \\
\text { pesagem direta } \\
\text { Sensibilidade; } \\
\text { Especificidade; } \\
\text { Kappa Cohen. }\end{array}$ & $\begin{array}{l}525 \text { homens } \\
543 \text { mulheres }\end{array}$ & 0 dias & 18 a 74 & $\begin{array}{c}\delta:-0,19 \mathrm{~cm} ; \\
-0,34 \mathrm{~kg} ; \\
-0,04 \mathrm{~kg} / \mathrm{m}^{2} \\
\mathrm{O}: 0,74 \mathrm{~cm} ; \\
-0,42 \mathrm{~kg} ; \\
-0,35 \mathrm{~kg} / \mathrm{m}^{2}\end{array}$ & $\begin{array}{l}\text { O peso e estatura } \\
\text { referidos foram } \\
\text { indicadores acurados das } \\
\text { medidas atuais com } \\
\text { pequeno erro sistemático. } \\
\text { No entanto, estes valores } \\
\text { não foram indicadores } \\
\text { adequados para avaliar a } \\
\text { prevalência da obesidade } \\
\text { na população de } \\
\text { Singapura devido ao baixo } \\
\text { nível de conhecimento do } \\
\text { peso e estatura e a } \\
\text { subestimativa da real } \\
\text { prevalência de obesidade. }\end{array}$ \\
\hline $\begin{array}{l}\text { OSUNA- } \\
\text { RAMIREZ et } \\
\text { al., 2006 } \\
\text { (México) } \\
\text { Questionário } \\
\text { auto- } \\
\text { preenchido X } \\
\text { medida direta } \\
\text { Sensibilidade; } \\
\text { Especificidade; } \\
\text { AR Logística; } \\
\text { coeficiente de } \\
\text { Spearman, } \\
\text { ANOVA, } \\
\text { Kruska-Wallis. }\end{array}$ & $\begin{array}{l}349 \text { homens } \\
585 \text { mulheres }\end{array}$ & $\begin{array}{l}4 \text { a } 8 \\
\text { meses }\end{array}$ & 18 a 76 & $\begin{array}{c}\text { o:1,4cm; } \\
-1,68 \mathrm{~kg} ; \\
-1,04 \mathrm{~kg} / \mathrm{m}^{2} \\
\text { o: } 1,3 \mathrm{~cm} ; \\
-1,26 \mathrm{~kg} ; \\
-0,95 \mathrm{~kg} / \mathrm{m}^{2}\end{array}$ & $\begin{array}{l}\text { O peso e estatura auto- } \\
\text { referidos assim como a } \\
\text { percepção da imagem } \\
\text { corporal auto-referida são } \\
\text { medidas válidas que } \\
\text { podem ser utilizadas para } \\
\text { estimar o IMC da } \\
\text { população mexicana em } \\
\text { estudos epidemiológicos. }\end{array}$ \\
\hline
\end{tabular}

Nota:

*diferença calculada através do valor reportado menos o valor aferido. Números negativos indicam subestimação; positivos indicam superestimação. 


\section{OBJETIVOS}

\section{Geral}

1. Estudar a validade e confiabilidade do peso e estatura referidos em entrevistas telefônicas na população adulta da área metropolitana de São Paulo com 40 ou mais anos de idade.

\section{Específicos}

1. Investigar diferenças entre peso e estatura referidos e peso e estatura aferidos de acordo com sexo, idade, grupo étnico, nível de escolaridade e intervalos do índice de massa corporal aferido.

2. Determinar a validade e confiabilidade do IMC calculado a partir do peso e estatura referidos em diagnosticar obesidade e excesso de peso de acordo com sexo, idade, nível de escolaridade, grupo étnico e estado nutricional.

3. Desenvolver modelos de regressão que sirvam para predizer os verdadeiros valores do peso e da estatura a partir de valores referidos.

4. Estudar o desempenho dos modelos preditivos desenvolvidos em população diferente daquela que gerou os modelos. 


\section{MATERIAL E MÉTODOS}

O estudo de validade de pesos e estaturas auto-referidos foi feito no âmbito de um inquérito domiciliar probabilístico, sobre prevalência e distribuição de doença pulmonar obstrutiva crônica (DPOC) na população de indivíduos com 40 ou mais anos de idade residente na área metropolitana de São Paulo, em 2003. O referido inquérito fez parte do estudo multicêntrico PLATINO (Projeto Latino Americano para Investigação da Doença Obstrutiva Pulmonar) cujo objetivo era verificar a prevalência de DPOC em cinco áreas metropolitanas da América Latina (Cidade do México, Santiago, Montevidéu, Caracas e São Paulo). $O$ estudo de validade foi realizado com a inserção de uma entrevista telefônica entre o contato inicial e a tomada de medidas realizada pelo PLATINO, valendo-se do fato de que peso e estatura seriam aferidos pelo estudo multicêntrico e por tratar-se de uma amostra representativa da população com $\mathbf{4 0}$ ou mais anos de idade.

\subsection{Amostragem}

O estudo PLATINO envolveu uma amostra probabilística de 1000 indivíduos com 40 ou mais anos de idade residentes na área metropolitana de São Paulo. Os procedimentos de amostragem empregados pelo PLATINO estão descritos em MENEZES et al. (2004). O estudo de validade de pesos e estaturas auto-referidos foi realizado em 726 dos 1000 indivíduos estudados pelo PLATINO.

Não puderam ser estudados os indivíduos que não possuíam telefone ou cujos números informados estavam fora de serviço ou eram incorretos $(n=67)$. Uma vez que a auto-referência do peso e estatura foi obtida por meio de entrevista telefônica, também não foram incluídos no estudo de validade os indivíduos que desconheciam seu peso e/ou estatura $(n=40)$ ou que recusaramse a fornecer essas informações ( $n=26$ ), aqueles cujo contato não pôde ser 
estabelecido após quinze chamadas telefônicas $(n=22)$ e, ainda aqueles cujas fichas de controle não foram enviadas pelo PLATINO via fax $(n=93)$. Foram também excluídos indivíduos cuja tomada de peso e estatura tinha sido anterior a auto-referência das medidas ( $n=26$ ), devido à possibilidade das informações referidas sofrerem influência dos valores recém-aferidos. Assim, a amostra final constituiu-se do cruzamento das informaçōes antropométricas aferidas obtidas pelo PLATINO com as informações antropométricas referidas obtidas por telefone $(n=726)$.

\subsection{Coleta de dados}

A coleta de dados relativa ao estudo de validade envolveu três etapas: $1^{\mathrm{a}}$ etapa - visita domiciliar para identificação da amostra; $2^{a}$ etapa - entrevista telefônica para obtenção da auto-referência do peso e estatura e $3^{a}$ etapa visita domiciliar para tomada de peso e estatura e obtenção das demais informações utilizadas pelo estudo PLATINO.

Na primeira visita domiciliar, eram preenchidas fichas de controle onde constavam a identificação do domicílio, endereço, telefone, dia da primeira visita domiciliar, nome, idade e disponibilidades de dia e horário das pessoas elegíveis, ainda nesta primeira visita, uma carta oficial explicando os objetivos do estudo era deixada com o morador.

O contato telefônico era realizado com base nos números (residencial, comercial, celular ou comunitário) registrados nas fichas de controle do PLATINO, em até 7 dias decorridos da primeira visita. Após a obtenção da aquiescência dos indivíduos em participar da entrevista telefônica, perguntavase se os mesmos tinham conhecimento do seu peso e estatura atuais e, em seguida, registravam-se estes dados. Os indivíduos incluídos no estudo de 
validade foram contatados em dia e horário sugeridos pelo respondente do domicílio por ocasião do primeiro contato e, em caso de insucesso, em horários e dias variados, incluindo fins de semana e períodos noturnos. Os valores antropométricos referidos eram obtidos, preferencialmente, do próprio indivíduo estudado. Havendo dificuldade em se entrevistar um ou mais indivíduos do domicílio, solicitava-se que os dados fossem anotados pelo respondente e deixados próximo ao telefone para serem fornecidos num próximo contato. Os participantes não eram informados, quer na primeira visita, quer durante os contatos telefônicos, que seriam pesados e medidos no momento da entrevista domiciliar.

A segunda visita domiciliar acontecia, normalmente, sete a catorze dias após a data do primeiro contato. Nesta segunda visita, os indivíduos respondiam o questionário do estudo PLATINO (dados sócio-demográficos e fatores de risco para DPOC) e eram submetidos aos exames espirométrico e antropométrico. As medidas antropométricas foram realizadas por entrevistadores previamente treinados do PLATINO e coletadas em duplicata de cada indivíduo, tendo sido utilizado seu valor médio. Os indivíduos foram examinados usando roupas leves e descalços. A aferição do peso foi feita por meio de balanças eletrônicas $\operatorname{Tanita}^{\circledR}$ com precisão de $200 \mathrm{~g}$ e a estatura foi aferida por meio de estadiômetro portátil $\mathrm{Seca}^{\circledR}$ com precisão de $0,1 \mathrm{~cm}$, estando os indivíduos com a cabeça posicionada no plano de Frankfurt. Os valores de peso e estatura auto-referidos foram obtidos entre 13 de janeiro e 31 de maio de 2003 por meio de entrevista telefônica realizada pela autora deste estudo e por uma auxiliar de pesquisa treinada pela autora.

\subsection{Variáveis de estudo}

As variáveis analisadas neste estudo são: peso e estatura referidos; peso e estatura aferidos; IMC (razão do peso, em quilo, pelo quadrado da 
estatura, em metro) calculado com base nos dados de peso e estatura referidos e aferidos; sexo; idade (calculada a partir da informação da data de nascimento menos a data de entrevista e estratificada em 3 categorias: 40-49, 50-59, 60 e mais anos); grupo étnico (informado pelo entrevistado a partir de classificação do IBGE: branca, negra, parda, amarela e indigena); e escolaridade (considerada segundo categorias constituídas conforme o número de anos de estudo completos: $0,1-4,5-8,9-11$ e 12 ou mais anos).

\subsection{Análise dos dados}

Antes da digitação, procedeu-se à revisão de todas as fichas de controle e à crítica dos dados. Aqueles valores que chamavam a atenção por serem muito altos ou muito baixos eram conferidos.

Inicialmente, foi feita uma análise das diferenças entre medidas referidas e aferidas comparando-se médias e desvios padrão de peso, estatura e IMC, empregando-se teste $t$ pareado para identificação de diferenças estatisticamente significativas.

Em seguida, procedeu-se à análise da magnitude e direção das diferenças (erros) entre valores aferidos e referidos. A distribuição das diferenças entre valores aferidos e referidos foi apresentada graficamente em intervalos de $1 \mathrm{~kg}$ para peso e $1 \mathrm{~cm}$ para estatura, no sentido de auxiliar a visualização da distribuição dos erros. Foram realizados testes para verificar se as diferenças entre peso, estatura e IMC aferidos e referidos variaram de acordo com faixa etária, escolaridade, grupo étnico e quartis de peso e estatura e IMC aferido (ANOVA).

Para a identificação de erros e padrões sistemáticos de diferenciação entre valores referidos e aferidos utilizou-se a metodologia proposta por BLAND 
e ALTMAN (1986) que consiste em apresentar graficamente as diferenças dos valores referidos e aferidos em relação à média dos mesmos, os limites de concordância e seus respectivos intervalos de confiança. Este método permite identificar a existência de erro sistemático pela eventual concentração dos pontos acima ou abaixo da linha horizontal que passa pelo valor zero do eixo $\mathrm{Y}$. Os limites de concordância são estimados pela diferença média $\pm 1,96$ desvios padrão das diferenças, assumindo que as diferenças estão normalmente distribuídas. O erro padrão do limite de concordância é aproximado por $\left(3 s^{2} / n\right)^{1 / 2}$, onde $n$ representa o tamanho da amostra e $s$ o desvio padrão das diferenças. $O$ intervalo de confiança para estes limites é calculado pelo limite de concordância $\pm \mathrm{t}$ (erro padrão do limite) onde $\mathrm{o}$ valor $\mathrm{t}$ é proveniente da distribuição do t Student com $n-1$ graus de liberdade.

Em seguida, para verificar o impacto dos erros de medidas auto-referidas na aferição da magnitude da obesidade e do excesso de peso na população, comparam-se as prevalências de $I M C \geq 30 \mathrm{~kg} / \mathrm{m}^{2}$ e $I M C \geq 25 \mathrm{~kg} / \mathrm{m}^{2}$ obtidas a partir de valores aferidos e referidos, empregando-se o teste de McNemar.

A validade dos valores referidos foi analisada por meio do cálculo da sensibilidade e especificidade da classificação do estado nutricional baseada nos valores referidos de peso e estatura. Sensibilidade, neste caso, é a probabilidade de uma pessoa que é verdadeiramente obesa com base nos valores aferidos ser classificada como obesa com base nos valores referidos. Por sua vez, especificidade é a probabilidade de uma pessoa que não é verdadeiramente obesa com base nos valores aferidos ser classificada como não obesa com base nos valores referidos. A sensibilidade e a especificidade da classificação do IMC a partir de medidas referidas foram calculadas segundo sexo, idade, escolaridade e intervalos do IMC aferido. 
Foram também calculados os valores preditivos positivos e negativos e a eficiência do diagnóstico de excesso de peso e de obesidade baseado nos valores referidos de peso e estatura. $O$ valor preditivo positivo é a proporção de verdadeiros positivos entre todos os indivíduos com teste positivo, isto é, expressa a probabilidade de um indivíduo ser de fato obeso quando é diagnosticado como obeso. $O$ valor preditivo negativo é a proporção de verdadeiros negativos entre todos os indivíduos com teste negativo, ou seja, expressa a probabilidade de um indivíduo com teste negativo para obesidade, de fato, não ser obeso. Por sua vez, a eficiência do teste representa a proporção de testes corretos dentro de todos os testes realizados.

Para avaliar a confiabilidade dos valores referidos de peso e estatura foram utilizados três coeficientes distintos: coeficiente de correlação de Pearson (r); o coeficiente de correlação intraclasse (CCIC) e o coeficiente de correlação de concordância (CCC) proposto por LIN (1989). A combinação da abordagem gráfica (BLAND e ALTMAN, 1986), coeficiente de correlação intraclasse, coeficiente de Pearson e coeficiente de correlação de concordância serão complementares e poderão permitir uma eventual identificação de padrões de concordância heterogêneos.

Embora o coeficiente de correlação de Pearson seja uma das medidas de concordância mais freqüentemente usadas para variáveis contínuas, é também uma das menos indicadas (BARTKO e CARPENTER, 1976). O coeficiente de correlação de Pearson é um índice de associação linear, mas não é necessariamente um bom medidor de concordância entre duas séries de leituras (BLAND e ALTMAN, 1986), pois falha em detectar qualquer desvio da linha de $45^{\circ}$ (LIN, 1989), não identifica erros sistemáticos (ENGSTROM 1988) e sofre grande influência dos valores extremos ("outliers"). O coeficiente de correlação de Pearson entre valores aferidos e referidos de peso e estatura foi 
calculado para efeito de comparação dos dados deste estudo com os demais estudos que se utilizam deste coeficiente.

O CCIC é apropriado para variáveis contínuas, estima a proporção da variabilidade total observada atribuível à variabilidade entre os indivíduos e é usado para a obtenção de uma medida sumária de concordância entre duas fontes de informação obtidas de um mesmo indivíduo. Considerando-se a existência de dois grupos de fatores que causam variação, o coeficiente de correlação intraclasse é utilizado como uma medida que quantifica a importância relativa de um dos fatores que causam variação nos valores observados (Fisher 1925 citado por BERGAMASCHI, 1999). Para análise intraclasse, existem duas principais fontes de variação: variação inter-indivíduos (no caso deste estudo, variação entre os pares de medidas antropométricas aferida e referida - de indivíduos distintos) e variação intra-indivíduos (variação devido a cada medida - aferida ou referida - dentro de cada par para um único indivíduo). Se a variabilidade inter-indivíduos for pequena então a variância total será em grande parte devida à variação intra-indivíduos. Neste caso o CCIC será pequeno, próximo a zero, indicando baixa confiabilidade dos dados. Quando a variabilidade intra-indivíduos for pequena, então a variabilidade total será em grande parte explicada pela variabilidade inter-indivíduos. Neste caso o CCIC estará próximo de +1 e pode-se dizer que existe alta confiabilidade dos dados e, como conseqüência, as observações estarão fortemente correlacionadas dentro das classes (dentro de cada par). Assim, a semelhança de valores aferidos e referidos (dentro de um par) indica dados confiáveis, pois a variabilidade total será em maior parte atribuída à variabilidade interindivíduos e não à variabilidade nas medidas de cada indivíduo (intraindivíduos). 
O coeficiente de correlação de concordância proposto por LIN (1989) é um índice que contempla medidas de acurácia e precisão, e avalia a concordância entre duas medidas (obtidas a partir da mesma amostra) pela mensuração da variação da linha de igualdade $\left(45^{\circ}\right)$ da origem (linha de concordância). Quando o valor do coeficiente de correlação de concordância é igual a um, significa que a reta de regressão está exatamente sobre a reta de concordância perfeita.

Posteriormente, foram feitas análises de regressão linear para gerar equações que servissem para predizer o verdadeiro peso e estatura a partir dos valores referidos. As variáveis desfecho foram o peso e estatura aferidos e as variáveis explanatórias foram peso e estatura referidos, sexo, idade, escolaridade e grupo étnico. Foram feitas, ainda, análises de resíduos para verificar as suposições dos modelos, análises de multicolinearidade entre variáveis independentes e testes com a inclusão de termos de interação. $\mathrm{Na}$ análise de resíduos, foram utilizadas técnicas gráficas para detectar observações aberrantes e/ou influentes (observações que podem influenciar nas estimativas dos parâmetros dos modelos) e a suposição de homocedasticidade (variância constante dos erros). A suposição de distribuição normal das variáveis incluídas no modelo foi verificada por meio de histogramas e gráficos normais de probabilidade. As observações consideradas discrepantes ( 3 desvios padrão acima ou abaixo da média) foram excluídas com o objetivo de obter um melhor ajuste das estimativas. As variáveis explanatórias cujos coeficientes de regressão (B) não apresentaram significância estatística $(p>0,05)$ após 0 ajuste por outras características foram retiradas dos modelos. 
Para verificar a utilidade das equações preditoras dos valores verdadeiros de peso e estatura, as referidas equações foram aplicadas em outra população para a qual se dispunha de informações sobre valores de peso e estatura referidos e aferidos. A população em questão corresponde a 3713 funcionários de uma universidade pública no Rio de Janeiro que vem sendo acompanhada pelo Estudo Pró-Saúde (FONSECA et al., 2004). Inicialmente, foram contrastados a média e o desvio padrão das medidas de interesse (peso, estatura e IMC) provenientes de valores aferidos, referidos e ajustados conforme as equações preditoras desenvolvidas para correção dos erros de informação, empregando-se o teste t pareado. Em seguida, comparou-se a distribuição do estado nutricional obtida a partir dos valores antropométricos aferidos, referidos e ajustados, empregando-se o teste de McNemar. A utilidade das equações preditoras foi analisada por meio do cálculo da sensibilidade e especificidade da classificação do estado nutricional baseada nos valores corrigidos de peso e estatura. Foram também calculados a eficiência do teste e os valores preditivos positivos e negativos do diagnóstico de obesidade e excesso de peso. Foram também calculados os coeficientes de correlação de concordância (CCC) entre peso, estatura e IMC obtidos a partir de valores referidos, aferidos e ajustados pelas equações preditoras.

Finalmente, como última etapa deste estudo, por meio de análise de regressão linear, foram geradas equações preditoras dos verdadeiros valores de peso e estatura a partir dos valores referidos, utilizando-se apenas metade da amostra proveniente do estudo PLATINO. Posteriormente, as referidas equações foram aplicadas na metade restante da amostra, com o objetivo de indicar a utilidade das mesmas em população semelhante. Os procedimentos utilizados neste caso foram semelhantes àqueles já adotados na elaboração das equações preditoras do peso e estatura a partir de medidas antropométricas referidas. 
A digitação dos valores aferidos e referidos foi realizada no programa dBase e utilizou-se o programa SPSS, versão 11.0 e Stata na análise dos dados. 


\section{RESULTADOS}

A Tabela 2 descreve a distribuição de variáveis sócio-demográficas da população adulta com 40 ou mais anos de idade residente na área metropolitana de São Paulo. A idade média foi de 54,6 anos ( $D P=10,4)$ para homens e 53,2 anos ( $D P=11,4)$ para mulheres.

Tabela 2 - Distribuição da população adulta com 40 ou mais anos de idade da área metropolitana de São Paulo (2003), segundo variáveis sócio-demográficas, por sexo.

\begin{tabular}{|c|c|c|c|c|c|c|}
\hline \multirow{2}{*}{$\begin{array}{l}\text { Variáveis sócio- } \\
\text { demográficas }\end{array}$} & \multicolumn{2}{|c|}{ Homem $(\mathrm{N}=321)$} & \multicolumn{2}{|c|}{ Mulher $(\mathrm{N}=405)$} & \multicolumn{2}{|c|}{ Total $(\mathrm{N}=726)$} \\
\hline & $\mathbf{N}$ & $\%$ & $\mathbf{N}$ & $\%$ & $\mathbf{N}$ & $\%$ \\
\hline \multicolumn{7}{|l|}{ Idade (anos) } \\
\hline $40-49$ & 125 & 38,9 & 154 & 38,0 & 279 & 38,4 \\
\hline $50-59$ & 116 & 36,1 & 134 & 33,1 & 250 & 34,4 \\
\hline $60-69$ & 51 & 15,9 & 68 & 16,8 & 119 & 16,4 \\
\hline $70-79$ & 20 & 6,2 & 33 & 8,1 & 53 & 7,3 \\
\hline $80-89$ & 9 & 2,8 & 13 & 3,2 & 22 & 3,0 \\
\hline $90-94$ & - & - & 3 & 0,7 & 3 & 0,4 \\
\hline \multicolumn{7}{|l|}{ Etnicidade } \\
\hline Branca & 191 & 59,5 & 235 & 58,0 & 426 & 58,7 \\
\hline Preta & 31 & 9,7 & 42 & 10,4 & 73 & 10,1 \\
\hline Amarela & 5 & 1,6 & 13 & 3,2 & 18 & 2,5 \\
\hline Parda & 87 & 27,0 & 103 & 25,4 & 190 & 26,2 \\
\hline Indigena & 7 & 2,2 & 12 & 3,0 & 19 & 2,6 \\
\hline \multicolumn{7}{|c|}{$\begin{array}{l}\text { Escolaridade (anos } \\
\text { de estudo) }\end{array}$} \\
\hline 0 & 32 & 10,0 & 42 & 10,4 & 74 & 10,2 \\
\hline 1 a 4 & 125 & 38,9 & 175 & 43,2 & 300 & 41,3 \\
\hline 5 a 8 & 80 & 24,9 & 92 & 22,7 & 172 & 23,7 \\
\hline 9 a 11 & 38 & 11,8 & 48 & 11,9 & 86 & 11,8 \\
\hline $12 \mathrm{e}$ mais & 46 & 14,3 & 46 & 11,4 & 92 & 12,7 \\
\hline Sem informação & - & - & 2 & 0,5 & 2 & 0,3 \\
\hline
\end{tabular}

A Tabela 3 apresenta as médias de peso, estatura e IMC obtidas a partir de valores antropométricos aferidos e referidos. Em média, o peso referido foi cerca de $500 \mathrm{~g}$ superior ao peso aferido em homens e cerca de $500 \mathrm{~g}$ inferior em 
mulheres. A diferença média entre peso aferido e referido foi estatisticamente significativa para mulheres (teste t pareado) e ficou próxima da significância estatística para homens $(p=0,069)$.

A estatura referida tendeu a ser superior à estatura aferida em cerca de $2 \mathrm{~cm}$ e $4 \mathrm{~cm}$, em homens e mulheres, respectivamente. O IMC calculado a partir dos valores referidos tendeu a ser menor do que 0 calculado a partir dos valores reais: cerca de $0,4 \mathrm{~kg} / \mathrm{m}^{2}$ menor entre os homens e cerca de $1,5 \mathrm{~kg} / \mathrm{m}^{2}$ menor entre as mulheres. Houve diferenças estatisticamente significativas entre a estatura aferida e referida e entre o IMC calculado a partir dos valores aferidos e referidos, em ambos os sexos (teste t pareado).

Tabela 3 - Média (desvio-padrão) e média das diferenças de peso, estatura e índice de massa corporal (IMC) segundo medidas aferidas e referidas, por sexo. População adulta com $\mathbf{4 0}$ ou mais anos de idade da área metropolitana de São Paulo, 2003.

\begin{tabular}{l|c|c|c|c}
\hline Sexo/ Medida & $\begin{array}{c}\text { Medidas } \\
\text { aferidas }\end{array}$ & $\begin{array}{c}\text { Medidas } \\
\text { referidas }\end{array}$ & $\begin{array}{c}\text { Médias das } \\
\text { diferenças }\end{array}$ & Valor $\mathbf{p}$ \\
\hline Masculino $(\mathrm{N}=321)$ & $73,98(15,86)$ & $74,53(14,69)$ & $-0,55$ & 0,069 \\
Peso $(\mathrm{kg})$ & $1,67(0,08)$ & $1,69(0,09)$ & $-0,02$ & $<0,001$ \\
Estatura $(\mathrm{m})$ & $26,31(4,78)$ & $25,91(4,25)$ & 0,40 & 0,003 \\
IMC $\left(\mathrm{kg} / \mathrm{m}^{2}\right)$ & & & 0,48 & 0,036 \\
Feminino $(\mathrm{N}=405)$ & $1,55(0,06)$ & $1,59(0,08)$ & $-0,04$ & $<0,001$ \\
Peso $(\mathrm{kg})$ & $28,17(6,25)$ & $26,68(6,04)$ & 1,49 & $<0,001$ \\
Estatura $(\mathrm{m})$ & & & \\
\hline IMC $\left(\mathrm{kg} / \mathrm{m}^{2}\right)$ & &
\end{tabular}


Em face de se identificar um padrão diferenciado segundo sexo, para diferenças entre medidas referidas e aferidas, todas as análises deste estudo foram feitas separadamente para homens e mulheres.

\subsection{Análise das diferenças entre peso referido e aferido}

A Tabela 4 descreve o comportamento das diferenças entre peso referido e aferido, segundo variáveis sócio-demográficas, quartis de peso e estatura aferidos e categorias de IMC aferido. A idade e escolaridade parecem ter influenciado as diferenças entre o peso referido e aferido apenas no sexo feminino, onde se nota que a tendência em subestimar o peso real diminui com a idade e, de modo menos intenso aumenta com a escolaridade. $O$ grupo étnico não aparentou influenciar o erro das medidas referidas.

$O$ peso aferido e o IMC calculado a partir dos valores aferidos parecem ter influenciado as diferenças entre o peso referido e aferido, apresentando padrão semelhante em ambos os sexos. Nota-se que a tendência em subestimar 0 peso real aumenta com o peso e $\circ$ IMC aferidos, sendo a magnitude de erro sensivelmente maior entre aqueles cujo IMC é igual ou superior a $30 \mathrm{~kg} / \mathrm{m}^{2}$. Aqueles indivíduos situados nos primeiros quartis de peso e cujo IMC era menor do que $25 \mathrm{~kg} / \mathrm{m}^{2}$ tenderam a informar um peso maior que 0 real. 
Tabela 4 - Médias das diferenças entre peso referido e aferido, segundo faixa etária, escolaridade, grupo étnico, quartis de peso e estatura aferidos e categorias de índice de massa corporal (IMC) aferido, por sexo. População adulta com 40 ou mais anos de idade da área metropolitana de São Paulo, 2003.

\begin{tabular}{|c|c|c|c|c|c|c|}
\hline \multirow{3}{*}{$\begin{array}{l}\text { Variáveis sócio- } \\
\text { demograficas e } \\
\text { antropométricas }\end{array}$} & \multicolumn{3}{|c|}{ HOMENS } & \multicolumn{3}{|c|}{ MULHERES } \\
\hline & \multirow[b]{2}{*}{$\mathrm{N}$} & \multicolumn{2}{|c|}{$\begin{array}{c}\text { Peso referido - peso } \\
\text { aferido }(\mathrm{kg})\end{array}$} & \multirow[b]{2}{*}{$\mathbf{N}$} & \multicolumn{2}{|c|}{$\begin{array}{c}\text { Peso referido - peso aferido } \\
(\mathrm{kg})\end{array}$} \\
\hline & & Média (EP*) & $\mathrm{p}$ & & Média (EP) & $p$ \\
\hline $\begin{array}{l}\text { Faixa etária (anos) } \\
40-49 \\
50-59 \\
60-69 \\
70-99\end{array}$ & $\begin{array}{l}125 \\
116 \\
51 \\
29\end{array}$ & $\begin{array}{c}0,35(0,44) \\
-0,05(0,46) \\
1,16(0,85) \\
2,66(1,24)\end{array}$ & 0,077 & $\begin{array}{c}154 \\
134 \\
68 \\
49\end{array}$ & $\begin{array}{l}-1,01^{\S}(0,32) \\
-0,68^{\dagger}(0,46) \\
-0,36(0,39) \\
1,57^{+\S}(0,74)\end{array}$ & 0,006 \\
\hline $\begin{array}{l}\text { Escolaridade (anos de } \\
\text { estudo) } \\
0 \text { a } 4 \\
5 \text { a } 8 \\
9 \text { a } 11 \\
12 \text { e mais }\end{array}$ & $\begin{array}{c}157 \\
80 \\
38 \\
46\end{array}$ & $\begin{array}{c}1,07(0,45) \\
0,07(0,16) \\
-0,07(0,95) \\
0,08(0,84)\end{array}$ & 0,395 & $\begin{array}{c}217 \\
92 \\
48 \\
46\end{array}$ & $\begin{array}{c}0,13^{\ddagger}(0,30) \\
-0,53^{\dagger}(0,41) \\
-2,68(0,99) \\
-0,72^{+\ddagger}(0,38)\end{array}$ & 0,002 \\
\hline $\begin{array}{l}\text { Etnicidade } \\
\text { Branca } \\
\text { Não branca }\end{array}$ & $\begin{array}{l}191 \\
130\end{array}$ & $\begin{array}{l}0,41(0,35) \\
0,74(0,53)\end{array}$ & 0,596 & $\begin{array}{l}235 \\
170\end{array}$ & $\begin{array}{l}-0,80(0,30) \\
-0,04(0,34)\end{array}$ & 0,099 \\
\hline $\begin{array}{l}\text { Quartis de peso aferido** } \\
1^{\circ} \text { quartil } \\
2^{\circ} \text { quartil } \\
3^{\circ} \text { quartil } \\
4^{\circ} \text { quartil }\end{array}$ & $\begin{array}{l}80 \\
80 \\
81 \\
80\end{array}$ & $\begin{array}{c}3,21^{\ddagger 8}(0,72) \\
1,14^{*}(0,41) \\
-0,11^{+8}(0,43) \\
-2,17^{\dagger \neq *}(0,61)\end{array}$ & $<0,001$ & $\begin{array}{l}101 \\
101 \\
102 \\
101\end{array}$ & $\begin{array}{c}0,46^{\ddagger}(0,39) \\
0,55^{8}(0,32) \\
-0,48^{5}(0,31) \\
-2,45^{5 \neq 8}(0,66)\end{array}$ & $<0,001$ \\
\hline $\begin{array}{l}\text { Quartis de estatura } \\
\text { aferida } \\
1^{\circ} \text { quartil } \\
2^{\circ} \text { quartil } \\
3^{\circ} \text { quartil } \\
4^{\circ} \text { quartil }\end{array}$ & $\begin{array}{l}75 \\
76 \\
85 \\
85\end{array}$ & $\begin{array}{c}1,36(0,67) \\
0,79(0,47) \\
0,54(0,62) \\
-0,39(0,59)\end{array}$ & 0,211 & $\begin{array}{c}90 \\
96 \\
117 \\
102\end{array}$ & $\begin{array}{c}0,44^{\dagger}(0,43) \\
-0,03(0,48) \\
-1,56^{\dagger}(0,52) \\
-0,53(0,30)\end{array}$ & 0,010 \\
\hline $\begin{array}{l}\text { IMC aferido }\left(\mathrm{kg} / \mathrm{m}^{2}\right) \\
\text { IMC } \leq 24,9 \\
\text { IMC } 25 \text { a } 29,9 \\
\text { IMC } \geq 30\end{array}$ & $\begin{array}{c}133 \\
129 \\
59 \\
\end{array}$ & $\begin{array}{l}2,35^{\text {t8 }}(0,47) \\
-0,07^{8+}(0,36) \\
-2,19^{\text {t+ }}(0,78) \\
\end{array}$ & $<0,001$ & $\begin{array}{l}137 \\
139 \\
129 \\
\end{array}$ & $\begin{array}{c}0,29^{\ddagger}(0,3) \\
-0,04^{5}(0,29) \\
-1,77^{ \pm 5}(0,54) \\
\end{array}$ & $<0,001$ \\
\hline TOTAL & 321 & $0,54(0,30)$ & & 405 & $-0,48(0,23)$ & \\
\hline
\end{tabular}

Nota:"EP = erro padrão; ** $\leq 62,69 ; 62,7$ a 71,$79 ; 71,8$ a 82,64 e $\geq 82,65 \mathrm{~kg}$ para homens e $\leqq 56,74 ; 56,75$ a 65,$0 ; 65,1$ a 75,94 e $\geq 75,95 \mathrm{~kg}$ para mulheres; ${ }^{* \star \star} \leq 1,61 ; 1,62$ a 1,$66 ; 1,67$ a 1,71 e $\geq 1,72 \mathrm{~m}$ para homens $\mathrm{e}$ $\leq 1,49 ; 1,50$ a 1,$53 ; 1,54$ a 1,58 e $\geq 1,59 \mathrm{~m}$ para mulheres; Diferença estatisticamente significativa pelo Teste de Bonferroni: ${ }^{t} p<0,05 ;{ }^{\S} p<0,01 e^{\ddagger 3 \psi} p<0,001$. 
A Figura 1 apresenta a distribuição das diferenças entre peso referido e aferido, em homens e mulheres. A distribuição dos erros foi deslocada discretamente para a direita no caso dos homens (Assimetria: 0,980) e para a esquerda no caso das mulheres (Assimetria: -2,007). Diferenças de até $2 \mathrm{~kg}$ (para mais ou para menos) em relação ao peso aferido foram observadas em $52,3 \%$ dos homens e $71,8 \%$ das mulheres, evidenciando que, em média, as mulheres informaram melhor o peso do que os homens, isto é, houve maior freqüência de erros de maior magnitude no caso dos homens.

Figura 1 - Diferenças entre peso referido e aferido por sexo. População adulta com 40 ou mais anos de idade da área metropolitana de São Paulo, 2003.
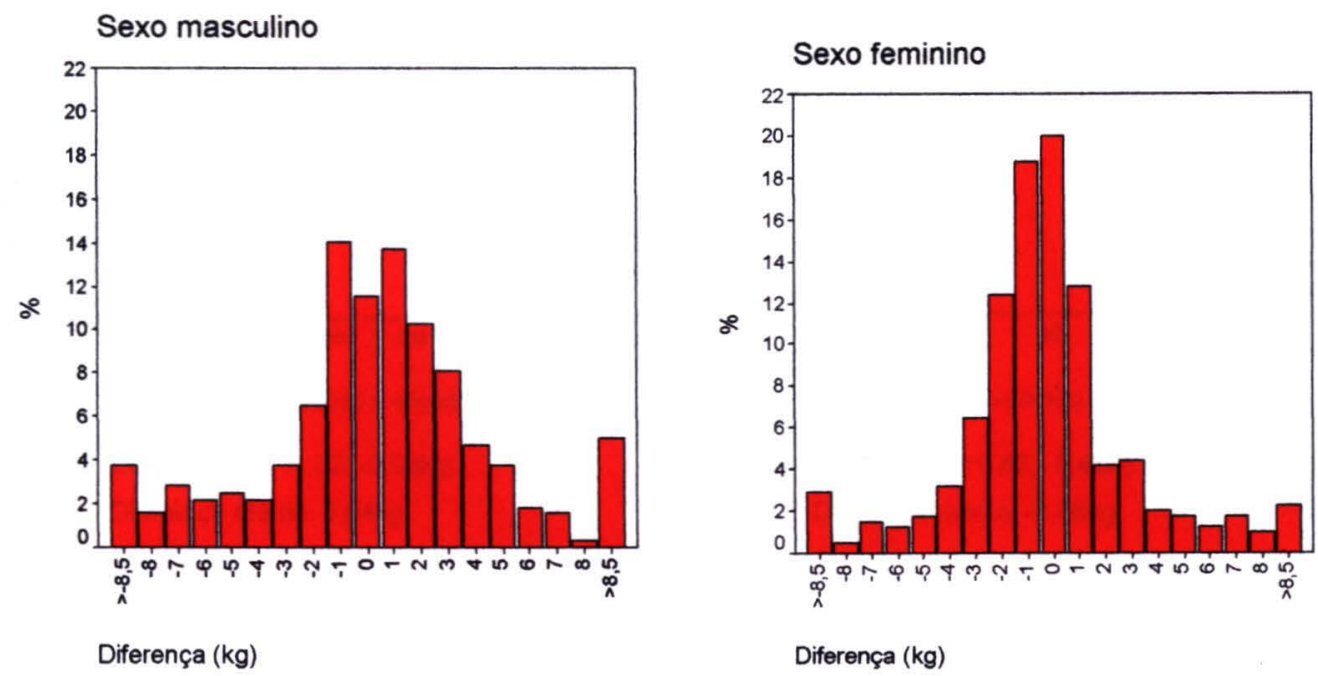

A Figura 2 apresenta a distribuição das diferenças entre valores referidos e aferidos de peso em relação à média desses valores, assim como os respectivos limites de concordância de $95 \%$. Confirmam-se, inicialmente, as tendências de superestimação do peso entre os homens (maior concentração de pontos acima da linha horizontal central) e de subestimação (maior concentração de pontos abaixo da linha horizontal central) entre as mulheres. No caso dos homens, a superestimação do peso ocorre, sobretudo, até $80 \mathrm{~kg}$, 
enquanto a subestimação do peso entre as mulheres parece ocorrer independentemente do peso.

Figura 2 - Diferenças entre peso aferido e referido segundo o valor médio desses pesos e limites de concordância de 95\% (LC). População adulta masculina e feminina com 40 ou mais anos de idade da área metropolitana de São Paulo, 2003.
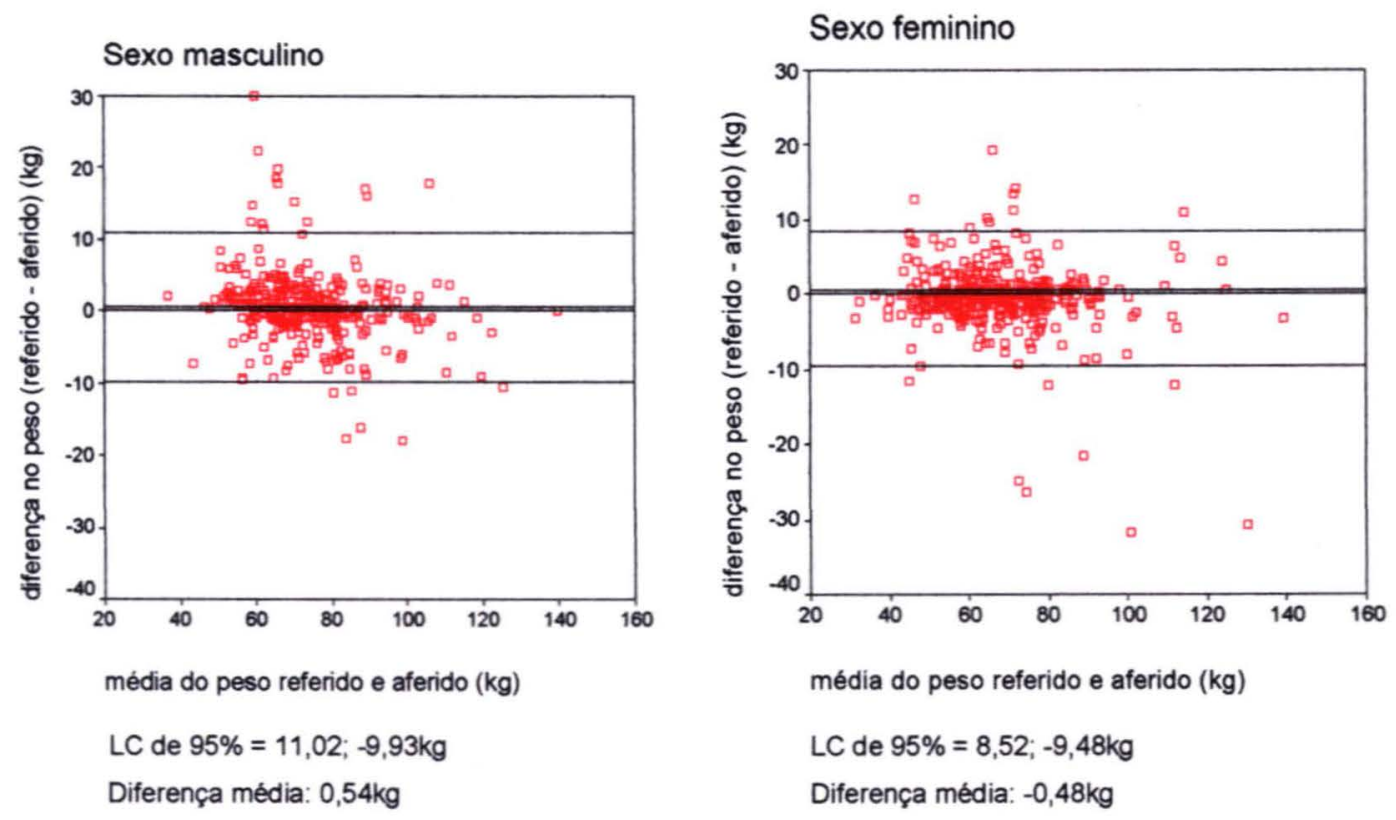

\subsection{Análise das diferenças entre estatura referida e aferida}

A Tabela 5 descreve a variação na diferença entre estatura referida $\mathrm{e}$ aferida, por sexo, segundo faixa etária, escolaridade, grupo étnico, quartis de peso e estatura aferidos e categorias de IMC aferido. Nota-se que, de modo geral, a estatura referida é superestimada em ambos os sexos, ainda que seja maior a superestimativa no sexo feminino. Em ambos os sexos, apenas idade $e$ estatura aferida parecem influenciar as diferenças entre estatura referida e aferida, onde se nota que a tendência em superestimar a estatura real aumenta com a idade e diminui com o aumento da estatura. 
Tabela 5 - Médias das diferenças entre estatura referida e aferida, por sexo, segundo faixa etária, escolaridade, grupo étnico, quartis de peso e estatura aferidos e categorias de índice de massa corporal (IMC) aferido. População adulta com 40 ou mais anos de idade da área metropolitana de São Paulo, 2003.

\begin{tabular}{|c|c|c|c|c|c|c|}
\hline \multirow{3}{*}{$\begin{array}{l}\text { Variáveis sócio- } \\
\text { demográficas e } \\
\text { antropométricas }\end{array}$} & \multicolumn{3}{|c|}{ HOMENS } & \multicolumn{3}{|c|}{ MULHERES } \\
\hline & \multirow[b]{2}{*}{$\mathrm{N}$} & \multicolumn{2}{|c|}{$\begin{array}{c}\text { Estatura referida - } \\
\text { estatura aferida }(\mathrm{cm})\end{array}$} & \multirow[b]{2}{*}{$\mathrm{N}$} & \multicolumn{2}{|c|}{$\begin{array}{c}\text { Estatura referida - estatura } \\
\text { aferida }(\mathrm{cm})\end{array}$} \\
\hline & & Média (EP*) & $p$ & & Média (EP) & $p$ \\
\hline $\begin{array}{l}\text { Faixa etária (anos) } \\
40-49 \\
50-59 \\
60-69 \\
70-99\end{array}$ & $\begin{array}{r}125 \\
116 \\
51 \\
29\end{array}$ & $\begin{array}{c}1,42^{\dagger}(0,47) \\
1,29^{8}(0,51) \\
3,30(0,76) \\
4,82^{+8}(1,06)\end{array}$ & 0,003 & $\begin{array}{c}154 \\
134 \\
68 \\
49\end{array}$ & $\begin{array}{l}2,86^{\dagger *}(0,37) \\
3,30^{*}(0,47) \\
5,22^{\dagger}(0,70) \\
7,55^{ \pm *}(1,04)\end{array}$ & $<0,001$ \\
\hline $\begin{array}{l}\text { Escolaridade (anos de } \\
\text { estudo) } \\
0 \text { a } 4 \\
5 \text { a } 8 \\
9 \text { a } 11 \\
12 \text { e mais }\end{array}$ & $\begin{array}{c}157 \\
80 \\
38 \\
46\end{array}$ & $\begin{array}{l}2,37(0,46) \\
1,85(0,77) \\
2,14(0,47) \\
0,75(0,48)\end{array}$ & 0,373 & $\begin{array}{c}217 \\
92 \\
48 \\
46\end{array}$ & $\begin{array}{l}4,60(0,42) \\
3,61(0,61) \\
3,30(0,63) \\
2,41(0,36)\end{array}$ & 0,065 \\
\hline Etnicidade & & & 0,878 & & & 0,405 \\
\hline $\begin{array}{l}\text { Branca } \\
\text { Não branca }\end{array}$ & $\begin{array}{l}191 \\
130\end{array}$ & $\begin{array}{l}2,02(0,37) \\
1,92(0,52)\end{array}$ & & $\begin{array}{l}235 \\
170\end{array}$ & $\begin{array}{l}4,17(0,36) \\
3,70(0,45)\end{array}$ & \\
\hline Quartis de peso aferido & & & 0,348 & & & 0,158 \\
\hline $\begin{array}{l}1^{\circ} \text { quartil } \\
2^{\circ} \text { quartil } \\
3^{\circ} \text { quartil } \\
4^{\circ} \text { quartil }\end{array}$ & $\begin{array}{l}80 \\
80 \\
81 \\
80\end{array}$ & $\begin{array}{l}2,06(0,86) \\
1,42(0,50) \\
1,58(0,50) \\
2,86(0,51)\end{array}$ & & $\begin{array}{l}101 \\
101 \\
102 \\
101\end{array}$ & $\begin{array}{l}5,08(0,67) \\
3,55(0,52) \\
3,71(0,57) \\
3,54(0,45)\end{array}$ & \\
\hline $\begin{array}{l}\text { Quartis de estatura } \\
\text { aferida } \\
1^{\circ} \text { quartil } \\
2^{\circ} \text { quartil } \\
3^{\circ} \text { quartil } \\
4^{\circ} \text { quartil }\end{array}$ & $\begin{array}{l}75 \\
76 \\
85 \\
85\end{array}$ & $\begin{array}{l}3,09(0,87) \\
2,67(0,56) \\
1,17(0,45) \\
1,20(0,53)\end{array}$ & 0,050 & $\begin{array}{c}90 \\
96 \\
117 \\
102\end{array}$ & $\begin{array}{l}5,14^{\dagger}(0,84) \\
4,63(0,54) \\
3,71(0,42) \\
2,62^{\dagger}(0,42)\end{array}$ & 0,011 \\
\hline $\begin{array}{l}\text { IMC aferido }\left(\mathrm{kg} / \mathrm{m}^{2}\right) \\
\text { IMC } \leq 24,9 \\
\text { IMC } 25 \text { a } 29,9 \\
\text { IMC } \geq 30\end{array}$ & $\begin{array}{l}133 \\
129 \\
59 \\
\end{array}$ & $\begin{array}{l}1,25(0,56) \\
2,22(0,39) \\
3,10(0,68)\end{array}$ & 0,080 & $\begin{array}{l}137 \\
139 \\
129 \\
\end{array}$ & $\begin{array}{l}3,99(0,52) \\
3,88(0,50) \\
4,03(0,43)\end{array}$ & 0,976 \\
\hline TOTAL & 321 & $1,98(0,31)$ & & 405 & $3,97(0,28)$ & \\
\hline
\end{tabular}

Nota: ${ }^{*} E P=$ erro padrão; ** $\leq 62,69 ; 62,7$ a 71,$79 ; 71,8$ a 82,64 e $\geqq 82,65 \mathrm{~kg}$ para homens e $\leqq 56,74 ; 56,75$ a 65,$0 ; 65,1$ a 75,94 e $\geq 75,95 \mathrm{~kg}$ para mulheres; ${ }^{* *} \leq 1,61 ; 1,62$ a 1,$66 ; 1,67$ a 1,71 e $\geq 1,72 \mathrm{~m}$ para homens e $\leq 1,49 ; 1,50$ a 1,$53 ; 1,54$ a 1,58 e $\geq 1,59 \mathrm{~m}$ para mulheres; Diferença estatisticamente significativa pelo Teste de Bonferroni: ${ }^{\dagger \&} p<0,05 ;{ }^{5} p<0,01$ e ${ }^{\ddagger k} p<0,001$. 
A Figura 3 apresenta a distribuição das diferenças entre estatura referida e aferida. A distribuição dos erros foi deslocada para a esquerda no caso dos homens (Assimetria: -0,981) e para a direita nos caso das mulheres (Assimetria: 0,054 ). A estatura foi superestimada em algum grau (maior que $1,5 \mathrm{~cm}$ ) por $53,9 \%$ dos homens e $66,9 \%$ das mulheres. Referiram a estatura dentro de uma diferença de $3 \mathrm{~cm}$ da estatura real (para mais ou para menos) $49 \%$ dos homens e $45 \%$ das mulheres.

Figura 3 - Diferenças entre estatura referida e aferida por sexo. População adulta com 40 ou mais anos de idade da área metropolitana de São Paulo, 2003.
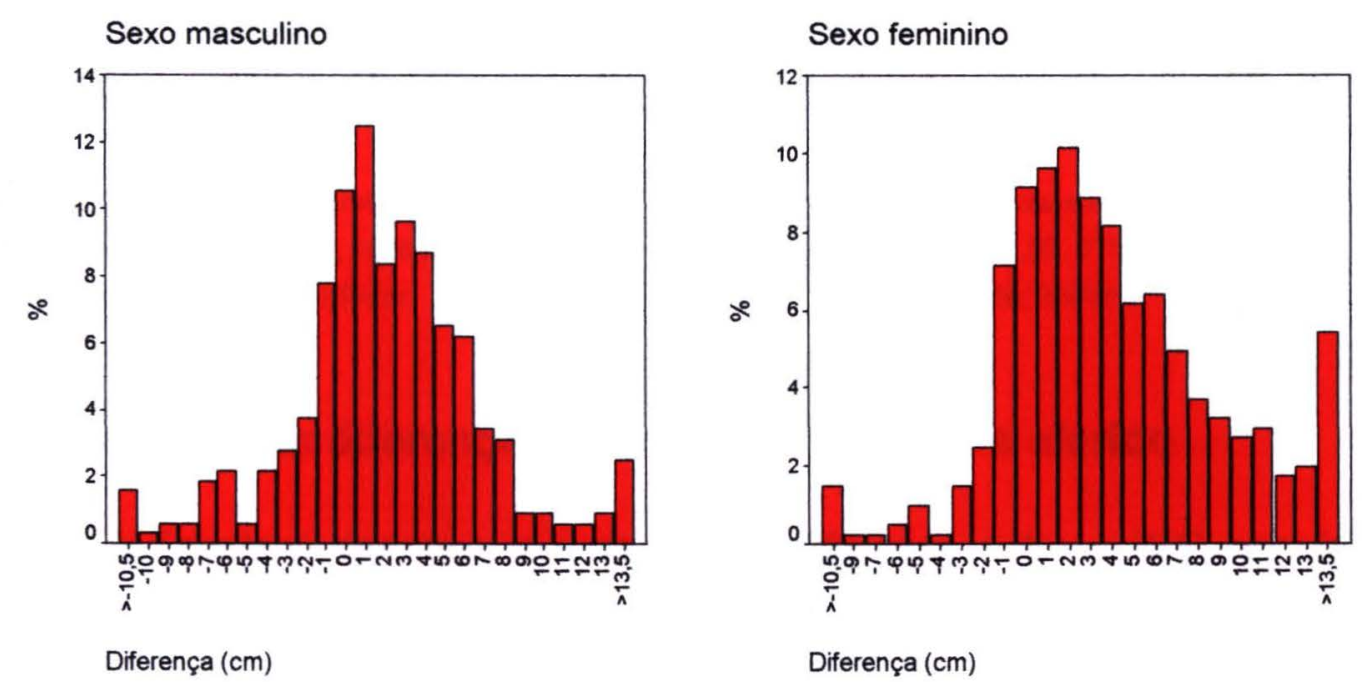

A Figura 4 apresenta a distribuição das diferenças entre valores referidos e aferidos de estatura em relação à média desses valores, bem como os respectivos intervalos de confiança de $95 \%$ (limites de concordância). Confirmase a tendência de superestimação da estatura, em ambos os sexos, ainda que mais intensa entre as mulheres. A tendência de superestimação da estatura não parece ser influenciada pela média entre as estaturas aferidas e referidas. 
Figura 4 - Diferenças entre estatura aferida e a estatura referida segundo o valor médio dessas estaturas e limites de concordância de $95 \%$ (LC). População adulta masculina e feminina com 40 ou mais anos de idade da área metropolitana de São Paulo, 2003.
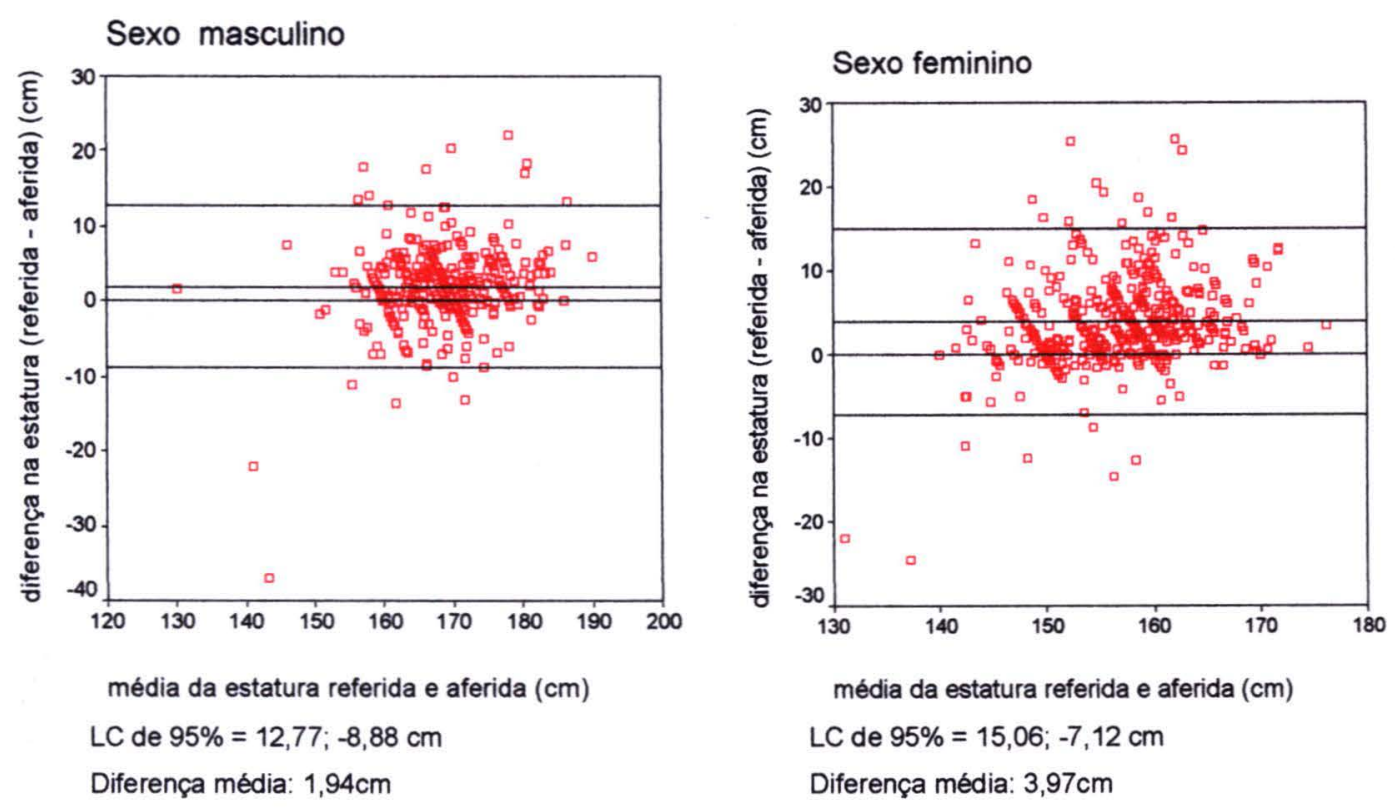

\subsection{Análise das diferenças entre o IMC referido e aferido}

A Tabela 6 descreve a variação na diferença entre o IMC calculado a partir de valores referidos e aferidos, por sexo, segundo faixa etária, escolaridade, grupo étnico, quartis de peso e estatura aferidos e categorias de IMC aferido. As diferenças entre O IMC calculado com base nos valores referidos e aferidos parecem ter sido influenciadas apenas pelo peso e IMC aferidos. Em ambos os sexos, nota-se tendência de subestimação do IMC calculado com base nos valores referidos, porém a extensão dessa subestimação tendeu a ser maior entre as mulheres e, nos dois sexos, foi maior em indivíduos com IMC igual ou superior a $25 \mathrm{~kg} / \mathrm{m}^{2}$. 
Tabela 6 - Médias das diferenças entre o índice de massa corporal (IMC) calculado com base nos valores referidos e aferidos, por sexo, segundo faixa etária, escolaridade, grupo étnico, quartis de peso e estatura aferidos e categorias de IMC aferido. População adulta com $\mathbf{4 0}$ ou mais anos de idade da área metropolitana de São Paulo, 2003.

\begin{tabular}{|c|c|c|c|c|c|c|}
\hline \multirow{3}{*}{$\begin{array}{l}\text { Variáveis sócio- } \\
\text { demográficas e } \\
\text { antropométricas }\end{array}$} & \multicolumn{3}{|c|}{ HOMENS } & \multicolumn{3}{|c|}{ MULHERES } \\
\hline & \multirow[b]{2}{*}{$\mathrm{N}$} & \multicolumn{2}{|c|}{ IMC referido - IMC aferido } & \multirow[b]{2}{*}{$\mathrm{N}$} & \multicolumn{2}{|c|}{ IMC referido - IMC aferido } \\
\hline & & Média (EP*) & $p$ & & Média (EP) & $p$ \\
\hline $\begin{array}{l}\text { Faixa etária (anos) } \\
40-49 \\
50-59 \\
60-69 \\
70-99\end{array}$ & $\begin{array}{l}125 \\
116 \\
51 \\
29\end{array}$ & $\begin{array}{l}-0,33(0,19) \\
-0,40(0,23) \\
-0,51(0,33) \\
-0,38(0,45)\end{array}$ & 0,975 & $\begin{array}{c}154 \\
134 \\
68 \\
49\end{array}$ & $\begin{array}{l}-1,34(0,19) \\
-1,40(0,25) \\
-1,86(0,26) \\
-1,63(0,54)\end{array}$ & 0,580 \\
\hline $\begin{array}{l}\text { Escolaridade (anos de } \\
\text { estudo) } \\
0 \text { a } 4 \\
5 \text { a } 8 \\
9 \text { a } 11 \\
12 \text { e mais }\end{array}$ & $\begin{array}{l}157 \\
80 \\
38 \\
46\end{array}$ & $\begin{array}{l}-0,32(0,19) \\
-0,52(0,28) \\
-0,67(0,39) \\
-0,17(0,26)\end{array}$ & 0,727 & $\begin{array}{l}217 \\
92 \\
48 \\
46\end{array}$ & $\begin{array}{l}-1,43(0,20) \\
-1,36(0,27) \\
-2,20(0,45) \\
-1,07(0,20)\end{array}$ & 0,201 \\
\hline $\begin{array}{l}\text { Etnicidade } \\
\text { Branca } \\
\text { Não branca }\end{array}$ & $\begin{array}{l}191 \\
130\end{array}$ & $\begin{array}{l}-0,45(0,16) \\
-0,30(0,21)\end{array}$ & 0,586 & $\begin{array}{l}235 \\
170\end{array}$ & $\begin{array}{l}-1,71(0,18) \\
-1,17(0,21)\end{array}$ & 0,053 \\
\hline $\begin{array}{l}\text { Quartis de peso } \\
\text { aferido } \\
1^{\circ} \text { quartil } \\
2^{\circ} \text { quartil } \\
3^{\circ} \text { quartil } \\
4^{\circ} \text { quartil }\end{array}$ & $\begin{array}{l}80 \\
80 \\
81 \\
80\end{array}$ & $\begin{array}{c}0,73^{\S \pm}(0,32) \\
-0,03^{*}(0,20) \\
-0,52^{\$ \&}(0,19) \\
-1,74^{\ddagger * 8}(0,24)\end{array}$ & $<0,001$ & $\begin{array}{l}101 \\
101 \\
102 \\
101\end{array}$ & $\begin{array}{c}-1,13^{\S}(0,28) \\
-0,86^{\ddagger}(0,22) \\
-1,48(0,22) \\
-2,45^{\S \ddagger}(0,33)\end{array}$ & $<0,001$ \\
\hline $\begin{array}{l}\text { Quartis de estatura } \\
\text { aferida } \\
1^{\circ} \text { quartil } \\
2^{\circ} \text { quartil } \\
3^{\circ} \text { quartil } \\
4^{\circ} \text { quartil }\end{array}$ & $\begin{array}{l}75 \\
76 \\
85 \\
85\end{array}$ & $\begin{array}{l}-0,35(0,35) \\
-0,50(0,20) \\
-0,18(0,25) \\
-0,53(0,23)\end{array}$ & 0,764 & $\begin{array}{c}90 \\
96 \\
117 \\
102\end{array}$ & $\begin{array}{l}-1,48(0,37) \\
-1,48(0,27) \\
-1,92(0,26) \\
-0,99(0,17)\end{array}$ & 0,103 \\
\hline $\begin{array}{l}\text { IMC aferido }\left(\mathrm{kg} / \mathrm{m}^{2}\right) \\
\text { IMC } \leq 24,9 \\
\text { IMC } 25 \text { a } 29,9 \\
\text { IMC } \geq 30\end{array}$ & $\begin{array}{c}133 \\
129 \\
59 \\
\end{array}$ & $\begin{array}{l}0,59^{\ddagger *}(0,21) \\
-0,72^{\ddagger \S}(0,15) \\
-1,89^{\S *}(0,31)\end{array}$ & $<0,001$ & $\begin{array}{l}137 \\
139 \\
129 \\
\end{array}$ & $\begin{array}{l}-0,89^{\ddagger}(0,21) \\
-1,25^{\S}(0,19) \\
-2,36^{\S \ddagger}(0,28) \\
\end{array}$ & $<0,001$ \\
\hline TOTAL & 321 & $-0,39(0,13)$ & & 405 & $-1,48(0,14)$ & \\
\hline
\end{tabular}

Nota: ${ }^{*} E P=$ erro padrão; ${ }^{* *} \leq 62,69 ; 62,7$ a 71,$79 ; 71,8$ a 82,64 e $\geqq 82,65 \mathrm{~kg}$ para homens e $\leqq 56,74 ; 56,75$ a 65,$0 ; 65,1$ a 75,94 e $\geq 75,95 \mathrm{~kg}$ para mulheres; ${ }^{* * *} \leq 1,61 ; 1,62$ a 1,$66 ; 1,67$ a 1,71 e $\geq 1,72 \mathrm{~m}$ para homens e $\leq 1,49 ; 1,50$ a 1,$53 ; 1,54$ a 1,58 e $\geq 1,59 \mathrm{~m}$ para mulheres; Diferença estatisticamente significativa pelo Teste de Bonferroni: ${ }^{8 \&} p<0,01 ;{ }^{* *} p<0,001$. 
A Figura 5 apresenta a distribuição das diferenças entre o IMC calculado a partir dos valores referidos e aferidos. A distribuição dos erros foi deslocada para a direita em ambos os sexos (Assimetria: 1,003 e 0,179, entre homens e mulheres, respectivamente). O IMC com base nos valores referidos foi subestimado em algum grau (maior que $0,5 \mathrm{~kg} / \mathrm{m}^{2}$ ) por $47,7 \%$ dos homens e $67,9 \%$ das mulheres, evidenciando que, em média, o peso e a estatura referidos pelos homens apresentaram erros que levaram a uma menor subestimação do IMC, quando comparados às informações obtidas pelas mulheres. Diferenças de até $1 \mathrm{~kg} / \mathrm{m}^{2}$ (para mais ou para menos) em relação ao IMC aferido foram observadas em $60,5 \%$ dos homens e $55 \%$ das mulheres.

Figura 5 - Diferenças entre o índice de massa corporal (IMC) calculado a partir dos valores referidos e aferidos por sexo. População adulta com 40 ou mais anos de idade da área metropolitana de São Paulo, 2003.
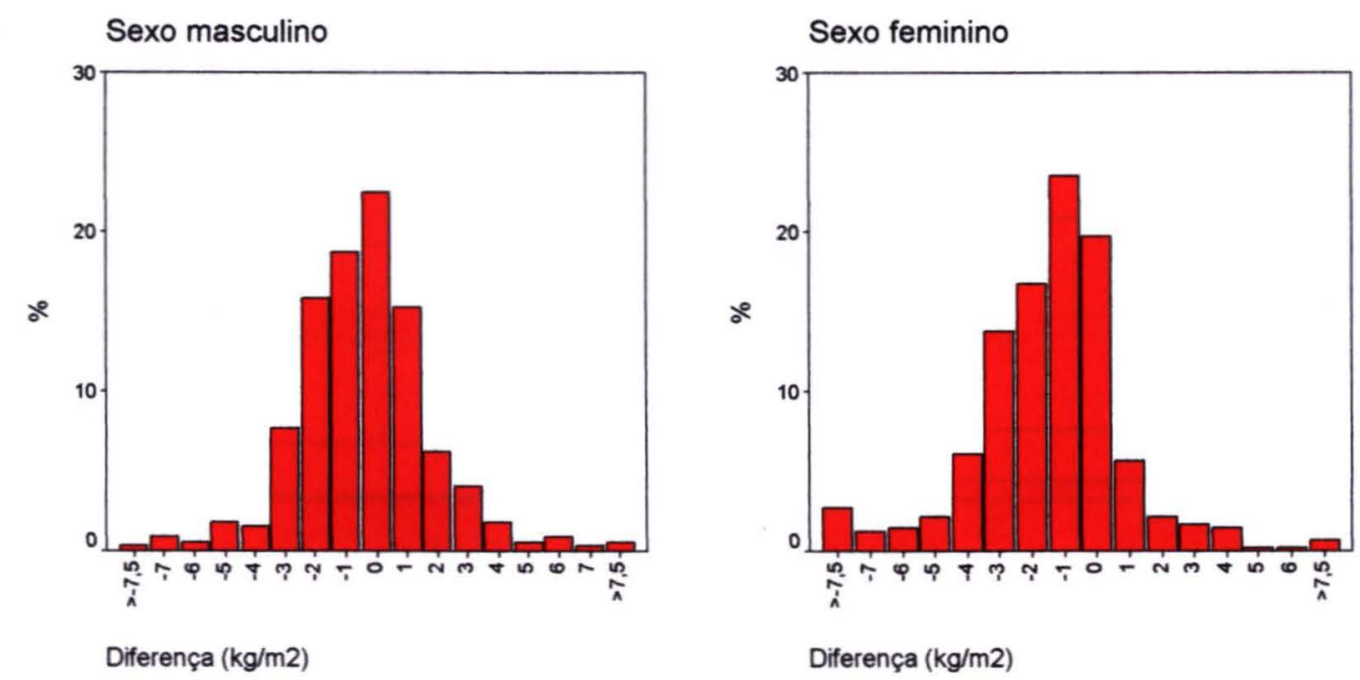
A Figura 6 apresenta as diferenças entre 0 IMC aferido e referido segundo o valor médio entre esses valores. Nota-se uma tendência de subestimação do IMC (maior concentração de pontos abaixo da linha horizontal central) em ambos os sexos, no entanto, esta tendência é mais clara entre as mulheres. No caso dos homens, até $25 \mathrm{~kg} / \mathrm{m}^{2}$ não há tendência clara de variação da diferença com a média dos valores. Acima deste valor, nota-se tendência crescente de subestimação do IMC referido. No caso das mulheres, nota-se padrão semelhante de subestimação de IMC, independentemente da média entre valores referidos e aferidos, ou seja, mesmo mulheres com valores relativamente baixos de IMC tenderam a subestimá-lo, tendência que cresce à medida que o IMC aumenta.

Figura 6 - Diferenças entre o índice de massa corporal (IMC) aferido e referido segundo o valor médio desses IMCs e limites de concordância de $95 \%$ (LC). População adulta masculina e feminina com 40 ou mais anos de idade da área metropolitana de São Paulo, 2003.
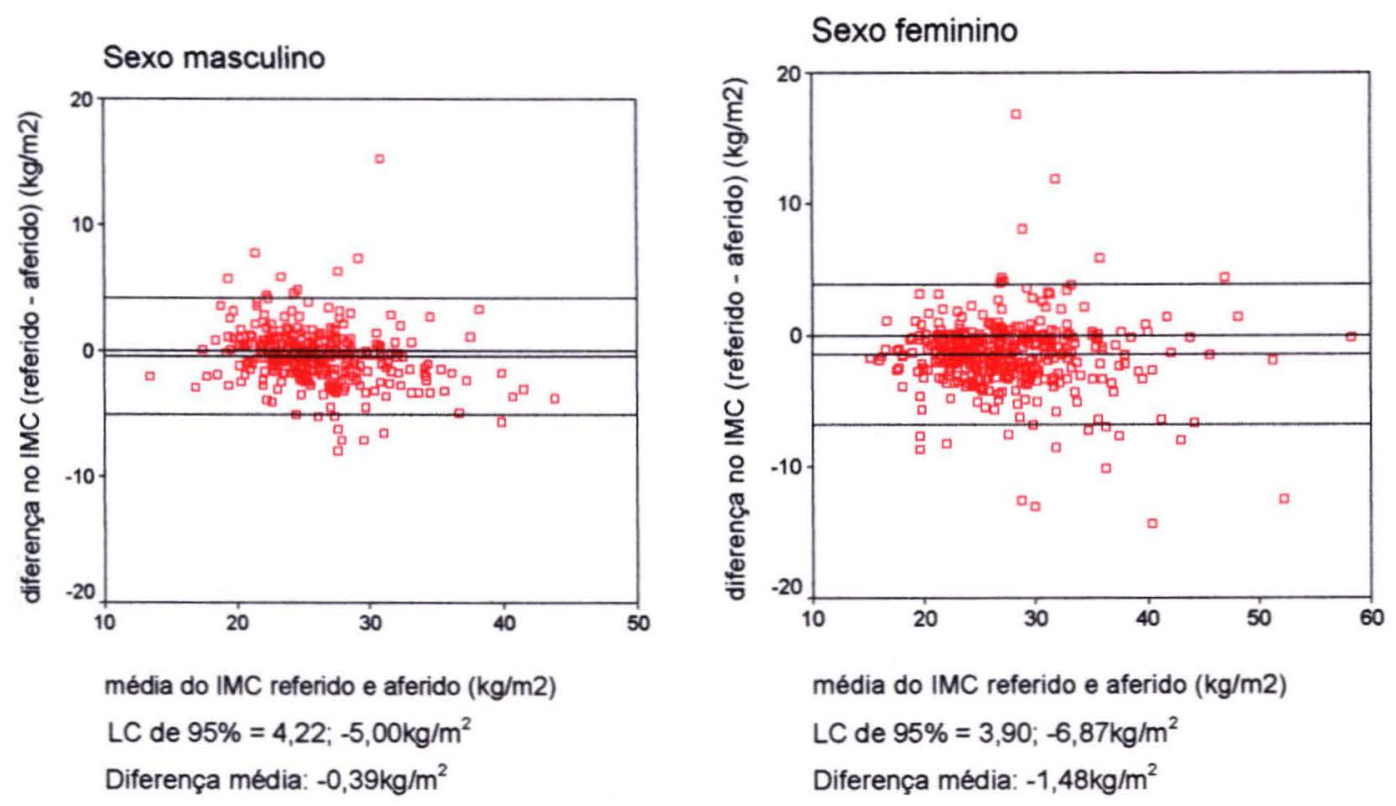
4.4. Estudo do impacto dos erros de medidas auto-referidas na aferição da magnitude da obesidade e do excesso de peso

A Tabela 7 apresenta a distribuição de homens e mulheres segundo o estado nutricional calculado com base no peso e estatura aferidos e referidos. Em ambos os sexos, as prevalências tanto de obesidade quanto de excesso de peso com base nas medidas referidas foram inferiores à que seria obtida com as medidas aferidas. No caso dos homens, a prevalência de obesidade baseada nas medidas referidas equivale a $86,4 \%$ das medidas aferidas e, no caso das mulheres, a $79,9 \%$. A distribuição do estado nutricional a partir dos valores aferidos foi estatisticamente diferente da calculada a partir de valores referidos (Teste de McNemar - $p<0,001$ ), tanto em homens quanto em mulheres.

Tabela 7 - Distribuição da população adulta com 40 ou mais anos de idade da área metropolitana de São Paulo (2003) segundo estado nutricional baseado no peso e estatura aferidos e referidos, por sexo.

\begin{tabular}{|c|c|c|c|c|c|}
\hline \multirow{2}{*}{$\begin{array}{c}\text { Sexo/ Estado } \\
\text { nutricional } \\
\text { Masculino }\end{array}$} & \multicolumn{2}{|c|}{ Medidas aferidas } & \multicolumn{3}{|c|}{ Medidas referidas } \\
\hline & $\mathrm{N}$ & $\%$ & $\mathrm{~N}$ & $\%$ & \\
\hline IMC $\leq 18,49$ & 9 & 2,8 & 6 & 1,9 & \\
\hline IMC 18,5 a 24,9 & 124 & 38,6 & 146 & 45,5 & \\
\hline IMC 25 a 29,9 & 129 & 40,2 & 118 & 36,8 & \\
\hline IMC 30 a 34,9 & 43 & 13,4 & 40 & 12,5 & \\
\hline IMC 35 a 39,9 & 11 & 18,4 & 9 & $2,8\}$ & 15,9 \\
\hline$I M C \geq 40$ & 5 & $1,6 \mathrm{~J}$ & 2 & 0,6 & \\
\hline Total & 321 & 100 & 321 & 100 & \\
\hline Feminino & $\mathrm{N}$ & $\%$ & $\mathrm{~N}$ & $\%$ & \\
\hline IMC $\leq 18,49$ & 8 & 2,0 & 20 & 4,9 & \\
\hline IMC 18,5 a 24,9 & 128 & 31,6 & 162 & 40,0 & \\
\hline IMC 25 a 29,9 & 140 & 34,6 & 120 & 29,6 & \\
\hline IMC 30 a 34,9 & 81 & 20,0 & 67 & 16,5 & \\
\hline IMC 35 a 39,9 & 30 & $7,4\} 31,8$ & 24 & $5,9\}$ & 25,4 \\
\hline $\mid M C \geq 40$ & 18 & $4,4 \mathrm{~J}$ & 12 & $3,0 \mathrm{~J}$ & \\
\hline Total & 405 & 100 & 405 & 100 & \\
\hline
\end{tabular}


A Tabela 8 mostra a sensibilidade e a especificidade do diagnóstico de obesidade baseado em peso e estatura referidos, por sexo, segundo faixa etária e escolaridade, considerando-se o diagnóstico baseado nos valores aferidos como padrão-ouro. A sensibilidade do diagnóstico de obesidade a partir de medidas referidas foi de $71,3 \%$ entre mulheres e de $78 \%$ entre homens. Valores de sensibilidade superiores a $70 \%$ foram encontrados em todos os subgrupos estudados, com exceção dos homens com 5 a 8 anos de estudo, das mulheres com mais de 70 anos ou com 9 e 11 anos de estudos.

A especificidade do diagnóstico da obesidade a partir de medidas referidas foi de $98,1 \%$ entre homens e de $96 \%$ entre mulheres. Valores de especificidade superiores a $90 \%$ foram encontrados em todos os subgrupos estudados, com exceção das mulheres mais velhas $(88,9 \%)$. No caso das mulheres, observa-se aumento da especificidade com 0 aumento da escolaridade. Já no caso dos homens, nota-se aumento da especificidade com aumento da idade. 
Tabela 8 - Sensibilidade (\%) e Especificidade (\%) do diagnóstico de obesidade (IMC $\geq 30 \mathrm{~kg} / \mathrm{m}^{2}$ ) com base em medidas referidas, por sexo, segundo faixa etária e escolaridade. População adulta com $\mathbf{4 0}$ ou mais anos de idade da área metropolitana de São Paulo, 2003.

\begin{tabular}{|c|c|c|c|c|c|c|}
\hline \multirow{2}{*}{$\begin{array}{l}\text { Variáveis sócio- } \\
\text { demográficas }\end{array}$} & \multicolumn{3}{|c|}{ Homens } & \multicolumn{3}{|c|}{ Mulheres } \\
\hline & $\mathbf{N}$ & $\begin{array}{c}\text { Sensibili- } \\
\text { dade }\end{array}$ & $\begin{array}{l}\text { Especifi- } \\
\text { idade }\end{array}$ & $\mathbf{N}$ & $\begin{array}{c}\text { Sensibili- } \\
\text { dade }\end{array}$ & $\begin{array}{c}\text { Especifi- } \\
\text { cidade }\end{array}$ \\
\hline $\begin{array}{l}\text { Faixa etária } \\
\text { (anos) } \\
40 \text { a } 49 \\
50 \text { a } 59 \\
60 \text { a } 69 \\
70 \text { a } 99\end{array}$ & $\begin{array}{c}125 \\
116 \\
51 \\
29\end{array}$ & $\begin{array}{c}76,0 \\
75,0 \\
81,8 \\
100,0\end{array}$ & $\begin{array}{c}96,0 \\
99,0 \\
100,0 \\
100,0\end{array}$ & $\begin{array}{c}154 \\
134 \\
68 \\
49\end{array}$ & $\begin{array}{l}72,9 \\
74,4 \\
72,0 \\
53,8\end{array}$ & $\begin{array}{l}98,1 \\
95,6 \\
97,7 \\
88,9\end{array}$ \\
\hline $\begin{array}{l}\text { Escolaridade } \\
\text { (anos de estudo) }\end{array}$ & & & & & & \\
\hline $\begin{array}{l}0 \text { a } 4 \\
5 \text { a } 8 \\
9 \text { a } 11 \\
12 \text { e mais }\end{array}$ & $\begin{array}{c}157 \\
80 \\
38 \\
46\end{array}$ & $\begin{array}{l}82,8 \\
62,5 \\
87,5 \\
83,3\end{array}$ & $\begin{array}{c}99,2 \\
96,9 \\
93,3 \\
100,0\end{array}$ & $\begin{array}{l}217 \\
92 \\
48 \\
46\end{array}$ & $\begin{array}{l}70,1 \\
75,9 \\
61,5 \\
77,8\end{array}$ & $\begin{array}{c}93,6 \\
96,8 \\
100,0 \\
100,0\end{array}$ \\
\hline Total & 321 & 78,0 & 98,1 & 405 & 71,3 & 96,0 \\
\hline
\end{tabular}

A Tabela 9 focaliza a sensibilidade e a especificidade do diagnóstico do excesso de peso baseado no peso e estatura referidos segundo faixa etária e escolaridade, por sexo, considerando-se os valores aferidos como padrão-ouro. De maneira semelhante ao encontrado no diagnóstico de obesidade, os valores de sensibilidade do diagnóstico do excesso de peso foram superiores a $70 \% \mathrm{em}$ todos os subgrupos, com exceção das mulheres mais velhas e com maior escolaridade. A especificidade do diagnóstico do excesso de peso aumentou com o aumento da escolaridade, no caso das mulheres, semelhante ao encontrado no diagnóstico da obesidade. 
Tabela 9 - Sensibilidade (\%) e Especificidade (\%) do diagnóstico de excesso de peso (IMC $\geq 25 \mathrm{~kg} / \mathrm{m}^{2}$ ) com base em medidas referidas, por sexo, segundo faixa etária e escolaridade. População adulta com $\mathbf{4 0}$ ou mais anos de idade da área metropolitana de São Paulo, 2003.

\begin{tabular}{l|c|c|c|c|c|c}
\hline $\begin{array}{l}\text { Variáveis } \\
\text { sócio- } \\
\text { demográficas }\end{array}$ & $\mathbf{N}$ & $\begin{array}{c}\text { Sensibili- } \\
\text { dade }\end{array}$ & $\begin{array}{c}\text { Especifi- } \\
\text { cidade }\end{array}$ & $\mathbf{N}$ & $\begin{array}{c}\text { Sulheres } \\
\text { Sensibili- } \\
\text { dade }\end{array}$ & $\begin{array}{c}\text { Especifi- } \\
\text { cidade }\end{array}$ \\
\hline $\begin{array}{l}\text { Faixa etária } \\
\text { (anos) }\end{array}$ & & & & & \\
40 a 49 & 125 & 84,9 & 86,5 & 154 & 79,4 & 96,5 \\
50 a 59 & 116 & 82,4 & 88,1 & 134 & 83,3 & 95,5 \\
60 a 69 & 51 & 72,4 & 95,5 & 68 & 88,5 & 100,0 \\
70 a 99 & 29 & 83,3 & 88,2 & 49 & 65,5 & 90,0 \\
& & & & & & \\
Escolaridade & & & & & & \\
(anos de estudo) & 157 & 82,2 & 86,6 & 217 & 84,2 & 92,3 \\
0 a 4 & 80 & 85,0 & 95,0 & 92 & 85,7 & 97,2 \\
5 a 8 & 38 & 81,5 & 81,8 & 48 & 66,7 & 100,0 \\
9 a 11 & 46 & 77,4 & 86,7 & 46 & 68,0 & 100,0 \\
12 e mais & $\mathbf{3 2 1}$ & $\mathbf{8 1 , 9}$ & $\mathbf{8 8 , 7}$ & $\mathbf{4 0 5}$ & $\mathbf{8 1 , 0}$ & $\mathbf{9 5 , 6}$ \\
\hline Total &
\end{tabular}

A Tabela 10 mostra os valores preditivos positivos e negativos, bem como a eficiência do teste em identificar a obesidade e o excesso de peso com base em medidas referidas. No caso dos homens, houve queda do valor preditivo negativo (VPN) do diagnóstico do excesso de peso, quando comparado ao VPN do diagnóstico de obesidade, passando de $95 \%$ para $77,6 \%$. A eficiência do teste em diagnosticar a obesidade $(94,4 \%)$ foi maior que a eficiência em diagnosticar o excesso de peso $(84,7 \%)$. No caso das mulheres, o valor preditivo positivo (VPP) do diagnóstico do excesso de peso foi 8 pontos percentuais maior que o VPP do diagnóstico de obesidade, porém 0 valor preditivo negativo (VPN) do diagnóstico do excesso de peso diminuiu 16,3 pontos percentuais quando comparado aos valores do VPN do diagnóstico da obesidade. 
Tabela 10 - Valor Preditivo Positivo (\%), Valor Preditivo Negativo (\%) e Eficiência do teste (\%) do diagnóstico de obesidade $\left(I M C \geq 30 \mathrm{~kg} / \mathrm{m}^{2}\right)$ e de excesso de peso (IMC $\geq 25 \mathrm{~kg} / \mathrm{m}^{2}$ ) com base em medidas referidas, por sexo. População adulta com 40 ou mais anos de idade da área metropolitana de São Paulo, 2003.

\begin{tabular}{|l|c|c|c|c|c|c|}
\hline \multirow{2}{*}{ Sexo } & \multicolumn{3}{|c|}{ Obesidade } & \multicolumn{3}{c|}{ Excesso de peso } \\
\cline { 2 - 7 } & VPP & VPN & $\begin{array}{c}\text { Eficiência } \\
\text { do teste }\end{array}$ & VPP & VPN & $\begin{array}{c}\text { Eficiência } \\
\text { do teste }\end{array}$ \\
\hline Homens & 90,2 & 95,2 & 94,4 & 91,1 & 77,6 & 84,7 \\
Mulheres & 89,3 & 87,7 & 88,1 & 97,3 & 71,4 & 85,9 \\
\hline
\end{tabular}

\subsection{Confiabilidade das medidas auto-referidas}

\subsubsection{Coeficiente de Correlação de Pearson}

Os coeficientes de correlação de Pearson entre peso aferido e referido foram elevados tanto entre as mulheres $(0,96)$ quanto entre os homens $(0,94)$, não se observando diferenças substanciais conforme a faixa etária, grupo étnico e escolaridade dos indivíduos.

Com relação às estaturas aferidas e referidas, o coeficiente de correlação de Pearson foi maior entre os homens $(0,78)$ do que entre as mulheres $(0,70)$ e tendeu a elevar-se com o aumento da escolaridade, sobretudo entre as mulheres.

O coeficiente de correlação de Pearson entre o IMC calculado com base nos valores de peso e estatura aferidos e referidos foi ligeiramente superior entre as mulheres $(0,90)$ em relação aos homens $(0,87)$ e tendeu a elevar-se com o aumento da escolaridade, sobretudo no sexo feminino. 
Tabela 11 - Coeficiente de correlação de Pearson* entre medidas referidas e aferidas, por sexo, segundo variáveis sócio-demográficas. População adulta com 40 ou mais anos de idade da área metropolitana de São Paulo, 2003.

\begin{tabular}{|c|c|c|c|c|c|c|}
\hline \multirow{2}{*}{$\begin{array}{l}\text { Variáveis } \\
\text { sócio- } \\
\text { demográficas }\end{array}$} & \multicolumn{3}{|c|}{ Homens } & \multicolumn{3}{|c|}{ Mulheres } \\
\hline & Peso (kg) & $\begin{array}{c}\text { Estatura } \\
\text { (cm) }\end{array}$ & $\begin{array}{c}\text { IMC } \\
\left(\mathbf{k g} / \mathbf{m}^{2}\right)\end{array}$ & Peso (kg) & $\begin{array}{l}\text { Estatura } \\
\text { (cm) }\end{array}$ & $\begin{array}{c}\mathrm{IMC} \\
\left(\mathrm{kg} / \mathrm{m}^{2}\right)\end{array}$ \\
\hline $\begin{array}{l}\text { Faixa etária } \\
\text { (anos) } \\
40 \text { a } 49 \\
50 \text { a } 59 \\
60 \text { a } 69 \\
70 \text { a } 99\end{array}$ & $\begin{array}{l}0,959 \\
0,940 \\
0,908 \\
0,898\end{array}$ & $\begin{array}{l}0,809 \\
0,743 \\
0,756 \\
0,826\end{array}$ & $\begin{array}{l}0,911 \\
0,838 \\
0,829 \\
0,870\end{array}$ & $\begin{array}{l}0,959 \\
0,950 \\
0,983 \\
0,933\end{array}$ & $\begin{array}{l}0,786 \\
0,684 \\
0,701 \\
0,673\end{array}$ & $\begin{array}{l}0,904 \\
0,900 \\
0,952 \\
0,816\end{array}$ \\
\hline $\begin{array}{l}\text { Grupo étnico } \\
\text { Brancos } \\
\text { Não brancos }\end{array}$ & $\begin{array}{l}0,953 \\
0,919\end{array}$ & $\begin{array}{l}0,807 \\
0,726\end{array}$ & $\begin{array}{l}0,868 \\
0,869\end{array}$ & $\begin{array}{l}0,963 \\
0,947\end{array}$ & $\begin{array}{l}0,685 \\
0,717\end{array}$ & $\begin{array}{l}0,912 \\
0,888\end{array}$ \\
\hline $\begin{array}{l}\text { Escolaridade } \\
\text { (anos de } \\
\text { estudo) } \\
0 \\
1 \text { a } 4 \\
5 \text { a } 8 \\
9 \text { a } 11 \\
12 \text { e mais }\end{array}$ & $\begin{array}{l}0,869 \\
0,941 \\
0,964 \\
0,958 \\
0,896\end{array}$ & $\begin{array}{l}0,752 \\
0,755 \\
0,738 \\
0,906 \\
0,851\end{array}$ & $\begin{array}{l}0,763 \\
0,895 \\
0,851 \\
0,894 \\
0,871\end{array}$ & $\begin{array}{l}0,967 \\
0,958 \\
0,963 \\
0,955 \\
0,979\end{array}$ & $\begin{array}{l}0,641 \\
0,656 \\
0,699 \\
0,778 \\
0,926\end{array}$ & $\begin{array}{l}0,828 \\
0,913 \\
0,884 \\
0,932 \\
0,967\end{array}$ \\
\hline TOTAL & 0,942 & 0,777 & 0,871 & 0,957 & 0,699 & 0,901 \\
\hline
\end{tabular}

\subsubsection{Coeficiente de Correlação Intraclasse (CCIC)}

A Tabela 12 apresenta o coeficiente de correlação intraclasse entre medidas aferidas e referidas, segundo variáveis sócio-demográficas, por sexo. No caso dos homens, os valores tenderam a diminuir com a idade e o menor valor de $\mathrm{CCIC}$ foi encontrado entre aqueles com menor escolaridade. As mulheres apresentaram valores superiores aos dos homens, sendo o menor valor de $\mathrm{CCIC}$ encontrado entre as mulheres mais velhas.

Com relação à estatura referida e aferida, observaram-se valores de CCIC bem inferiores aos observados para peso $(0,68$ para homens e 0,61 para 
mulheres). Os coeficientes tenderam a elevar-se com a escolaridade, sobretudo entre as mulheres, sendo os menores valores encontrados entre aqueles com menor escolaridade (0,53 para mulheres e 0,59 para homens).

Os valores do CCIC em relação ao IMC calculado com base no peso e estatura referido e aferido foram superiores a 0,744 , exceto no caso dos homens com menor escolaridade e mulheres mais velhas. No caso do sexo feminino, os coeficientes tenderam a elevar-se com a escolaridade.

Tabela 12 - Coeficiente de correlação intraclasse (CCIC) entre medidas referidas e aferidas, segundo variáveis sócio-demográficas, por sexo. População adulta com $\mathbf{4 0}$ ou mais anos de idade da área metropolitana de São Paulo, 2003.

\begin{tabular}{|c|c|c|c|c|c|c|}
\hline \multirow{2}{*}{$\begin{array}{l}\text { Variáveis } \\
\text { sócio- } \\
\text { demográficas }\end{array}$} & \multicolumn{3}{|c|}{ Homens } & \multicolumn{3}{|c|}{ Mulheres } \\
\hline & Peso (kg) & $\begin{array}{c}\text { Estatura } \\
\text { (cm) }\end{array}$ & IMC $\left(\mathrm{kg} / \mathrm{m}^{2}\right)$ & Peso (kg) & $\begin{array}{c}\text { Estatura } \\
(\mathrm{cm})\end{array}$ & IMC $\left(\mathrm{kg} / \mathrm{m}^{2}\right)$ \\
\hline $\begin{array}{l}\text { Faixa etária } \\
\text { (anos) } \\
40 \text { a } 49 \\
50 \text { a } 59 \\
60 \text { a } 69 \\
70 \text { a } 99\end{array}$ & $\begin{array}{l}0,919 \\
0,891 \\
0,840 \\
0,825\end{array}$ & $\begin{array}{l}0,711 \\
0,653 \\
0,668 \\
0,736\end{array}$ & $\begin{array}{l}0,827 \\
0,753 \\
0,745 \\
0,785\end{array}$ & $\begin{array}{l}0,923 \\
0,902 \\
0,967 \\
0,880\end{array}$ & $\begin{array}{l}0,694 \\
0,598 \\
0,623 \\
0,566\end{array}$ & $\begin{array}{l}0,837 \\
0,827 \\
0,912 \\
0,726\end{array}$ \\
\hline $\begin{array}{l}\text { Grupo étnico } \\
\text { Brancos } \\
\text { Não brancos }\end{array}$ & $\begin{array}{l}0,910 \\
0,856\end{array}$ & $\begin{array}{l}0,717 \\
0,629\end{array}$ & $\begin{array}{l}0,786 \\
0,781\end{array}$ & $\begin{array}{l}0,927 \\
0,904\end{array}$ & $\begin{array}{l}0,613 \\
0,625\end{array}$ & $\begin{array}{l}0,846 \\
0,816\end{array}$ \\
\hline $\begin{array}{l}\text { Escolaridade } \\
\text { (anos de } \\
\text { estudo) }\end{array}$ & & & & & & \\
\hline $\begin{array}{l}0 \\
1 \text { a } 4 \\
5 \text { a } 8 \\
9 \text { a } 11 \\
12 \text { e mais }\end{array}$ & $\begin{array}{l}0,767 \\
0,893 \\
0,930 \\
0,914 \\
0,819\end{array}$ & $\begin{array}{l}0,591 \\
0,659 \\
0,648 \\
0,841 \\
0,763\end{array}$ & $\begin{array}{l}0,646 \\
0,823 \\
0,764 \\
0,808 \\
0,789\end{array}$ & $\begin{array}{l}0,937 \\
0,923 \\
0,931 \\
0,882 \\
0,958\end{array}$ & $\begin{array}{l}0,532 \\
0,590 \\
0,611 \\
0,697 \\
0,996\end{array}$ & $\begin{array}{l}0,744 \\
0,851 \\
0,812 \\
0,834 \\
0,935\end{array}$ \\
\hline TOTAL & 0,891 & 0,686 & 0,787 & 0,919 & 0,613 & 0,834 \\
\hline
\end{tabular}




\subsubsection{Coeficiente de Correlação de Concordância (CCC)}

A Tabela 13 apresenta o coeficiente de correlação de concordância entre medidas aferidas e referidas, segundo variáveis sócio-demográficas, por sexo. Valores elevados de CCC (acima de 0,838) entre o peso referido e aferido foram observados em ambos os sexos, exceto para homens com escolaridade entre 5 a 8 anos de estudo. As mulheres apresentaram valores mais elevados que os homens $(>0,924)$.

Com relação à estatura referida e aferida, os valores de CCC foram inferiores aos observados para peso (variando de 0,438 para 0,862 ). Os coeficientes tenderam a elevar-se com a escolaridade e diminuir com a idade, sobretudo entre as mulheres.

Valores de CCC em relação ao IMC calculado com base no peso e estatura referido e aferido apresentaram valores superiores a 0,822 , exceto entre as mulheres mais velhas. No caso dos homens os valores apresentaram pequena variação em todos os subgrupos $(0,822$ a 0,893$)$, já no caso das mulheres os valores apresentaram uma variação maior (de 0,784 a 0,945). 
Tabela 13 - Coeficiente de correlação de concordância (CCC) entre medidas referidas e aferidas, segundo variáveis sócio-demográficas, por sexo. População adulta com $\mathbf{4 0}$ ou mais anos de idade da área metropolitana de São Paulo, 2003.

\begin{tabular}{|c|c|c|c|c|c|c|}
\hline \multirow{2}{*}{$\begin{array}{l}\text { Variáveis } \\
\text { sócio- } \\
\text { demográficas }\end{array}$} & \multicolumn{3}{|c|}{ Homens } & \multicolumn{3}{|c|}{ Mulheres } \\
\hline & Peso (kg) & $\begin{array}{c}\text { Estatura } \\
\text { (cm) }\end{array}$ & $\begin{array}{c}\text { IMC } \\
\left(\mathrm{kg} / \mathrm{m}^{2}\right)\end{array}$ & Peso (kg) & $\begin{array}{c}\text { Estatura } \\
\text { (cm) }\end{array}$ & $\begin{array}{c}\text { IMC } \\
\left(\mathrm{kg} / \mathrm{m}^{2}\right)\end{array}$ \\
\hline $\begin{array}{l}\text { Faixa etária } \\
\text { (anos) } \\
40 \text { a } 49 \\
50 \text { a } 59 \\
60 \text { a } 69 \\
70 \text { a } 99\end{array}$ & $\begin{array}{l}0,956 \\
0,939 \\
0,875 \\
0,878\end{array}$ & $\begin{array}{l}0,789 \\
0,725 \\
0,685 \\
0,727\end{array}$ & $\begin{array}{l}0,893 \\
0,833 \\
0,822 \\
0,860\end{array}$ & $\begin{array}{l}0,956 \\
0,945 \\
0,983 \\
0,927\end{array}$ & $\begin{array}{l}0,718 \\
0,595 \\
0,552 \\
0,438\end{array}$ & $\begin{array}{l}0,876 \\
0,874 \\
0,918 \\
0,784\end{array}$ \\
\hline $\begin{array}{l}\text { Grupo étnico } \\
\text { Brancos } \\
\text { Năo brancos }\end{array}$ & $\begin{array}{l}0,950 \\
0,914\end{array}$ & $\begin{array}{l}0,782 \\
0,685\end{array}$ & $\begin{array}{l}0,860 \\
0,857\end{array}$ & $\begin{array}{l}0,960 \\
0,947\end{array}$ & $\begin{array}{l}0,576 \\
0,621\end{array}$ & $\begin{array}{l}0,878 \\
0,869\end{array}$ \\
\hline $\begin{array}{l}\text { Escolaridade } \\
\text { (anos de } \\
\text { estudo) } \\
0 \\
1 \text { a } 4 \\
5 \text { a } 8 \\
9 \text { a } 11 \\
12 \text { e mais }\end{array}$ & $\begin{array}{l}0,838 \\
0,939 \\
0,776 \\
0,953 \\
0,890\end{array}$ & $\begin{array}{l}0,545 \\
0,721 \\
0,717 \\
0,862 \\
0,842\end{array}$ & $\begin{array}{l}0,885 \\
0,891 \\
0,841 \\
0,873 \\
0,865\end{array}$ & $\begin{array}{l}0,967 \\
0,958 \\
0,962 \\
0,924 \\
0,976\end{array}$ & $\begin{array}{l}0,468 \\
0,535 \\
0,609 \\
0,690 \\
0,859\end{array}$ & $\begin{array}{l}0,934 \\
0,890 \\
0,858 \\
0,857 \\
0,945\end{array}$ \\
\hline TOTAL & 0,939 & 0,749 & 0,862 & 0,965 & 0,597 & 0,875 \\
\hline
\end{tabular}

As Figuras 7, 8 e 9 mostram os gráficos de concordância de LIN e coeficientes de correlação de concordância (CCC) entre peso, estatura e IMC referidos e aferidos, por sexo. A linha tracejada corresponde à concordância perfeita; a linha cheia representa a reta ajustada por regressão linear simples.

Observa-se alta concordância entre o peso referido e aferido (CCC próximo de 0,95 ). Em ambos os sexos, houve uma clara tendência para a síndrome do "flat slope", ou seja, superestimação do peso real entre aqueles com menor peso e subestimação entre aqueles com maior peso (Figura 7). 
Figura 7 - Gráficos de concordância e coeficientes de correlação de concordância entre peso referido e aferido, por sexo. População adulta com 40 ou mais anos de idade da área metropolitana de São Paulo, 2003.

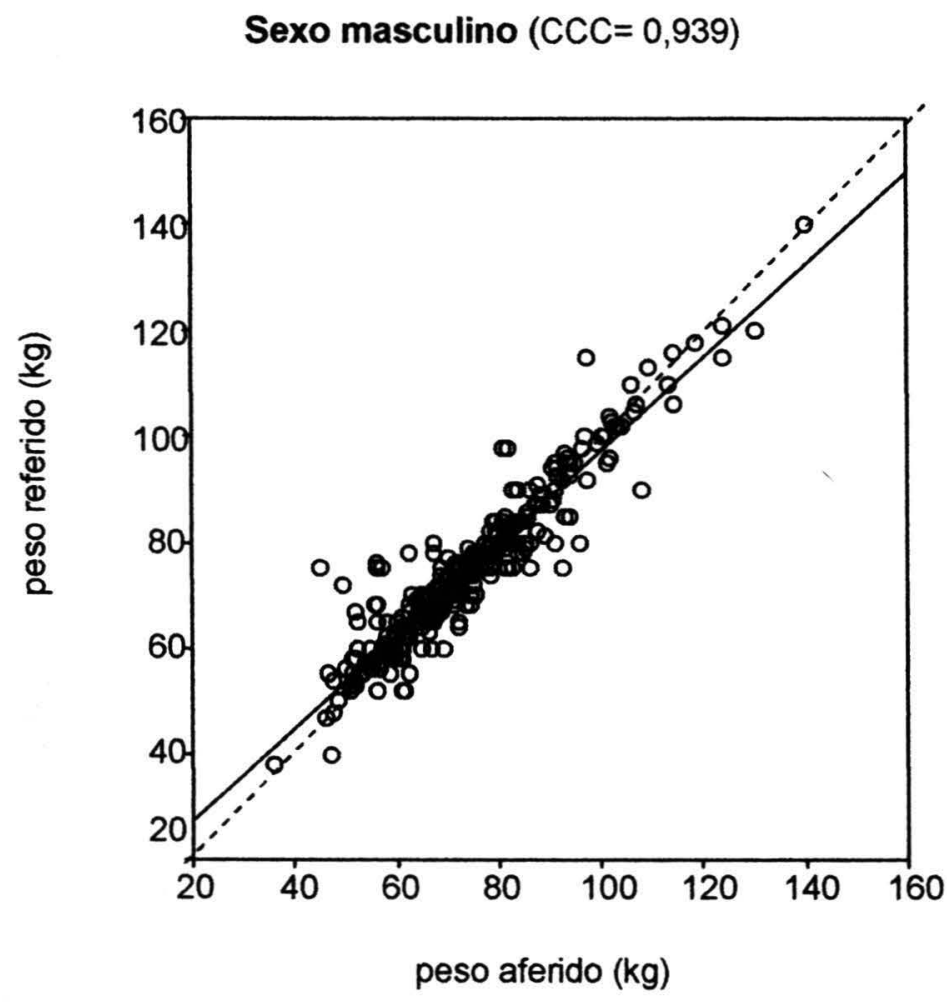


Sexo feminino $(C C C=0,955)$

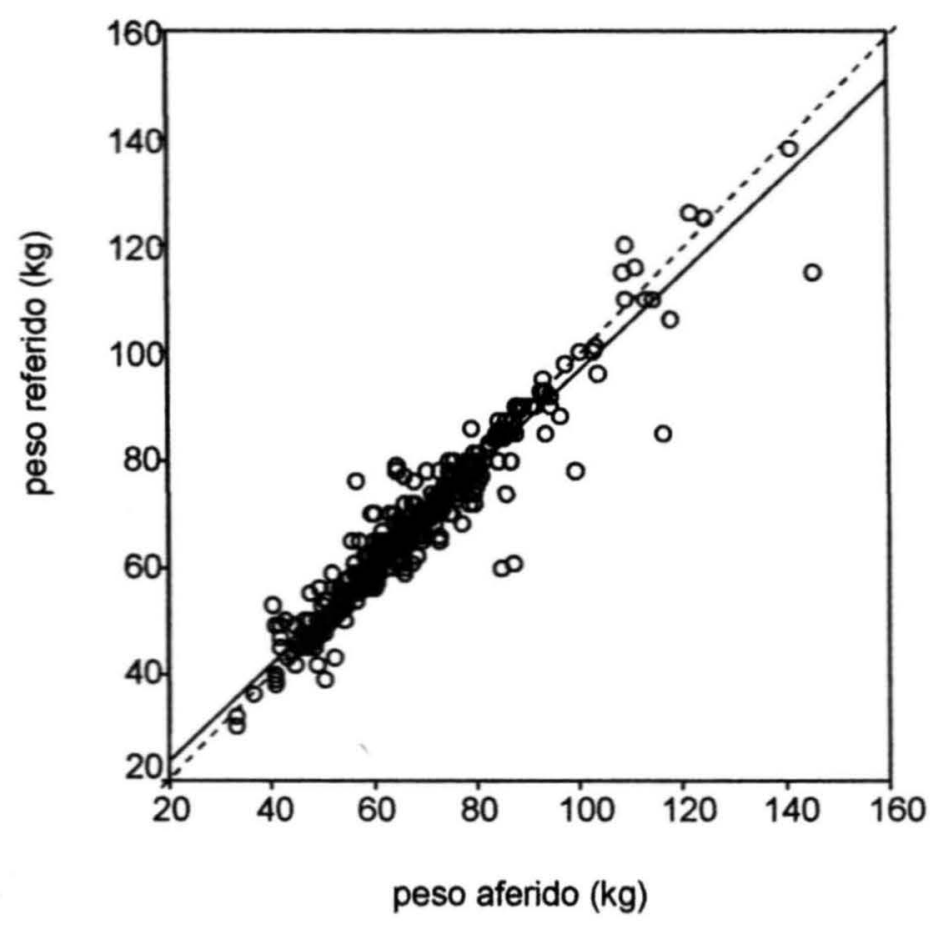

Observam-se valores de concordância apenas razoáveis entre as medidas de estatura referidas e aferidas (CCC de 0,75 para homens e 0,60 para mulheres). Entre os homens, houve uma tendência sistemática para a síndrome do "flat slope", ou seja, superestimação da estatura real entre os mais baixos e subestimação entre os mais altos. Entre as mulheres, nota-se claramente que a estatura referida foi superestimada, sobretudo entre as mais baixas (Figura 8 ). 
Figura 8 - Gráficos de concordância e coeficientes de correlação de concordância entre estatura referida e aferida, por sexo. População adulta com 40 ou mais anos de idade da área metropolitana de São Paulo, 2003.

Sexo masculino $(C C C=0,749)$

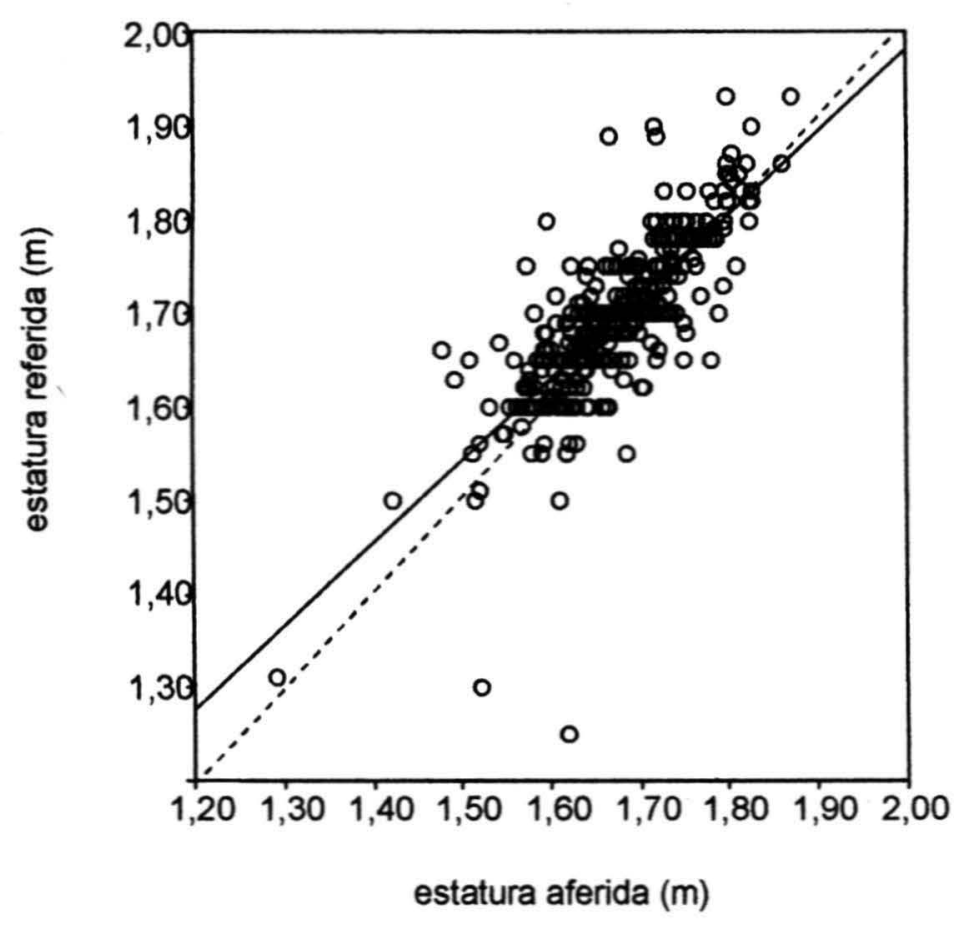


Sexo feminino $(C C C=0,597)$

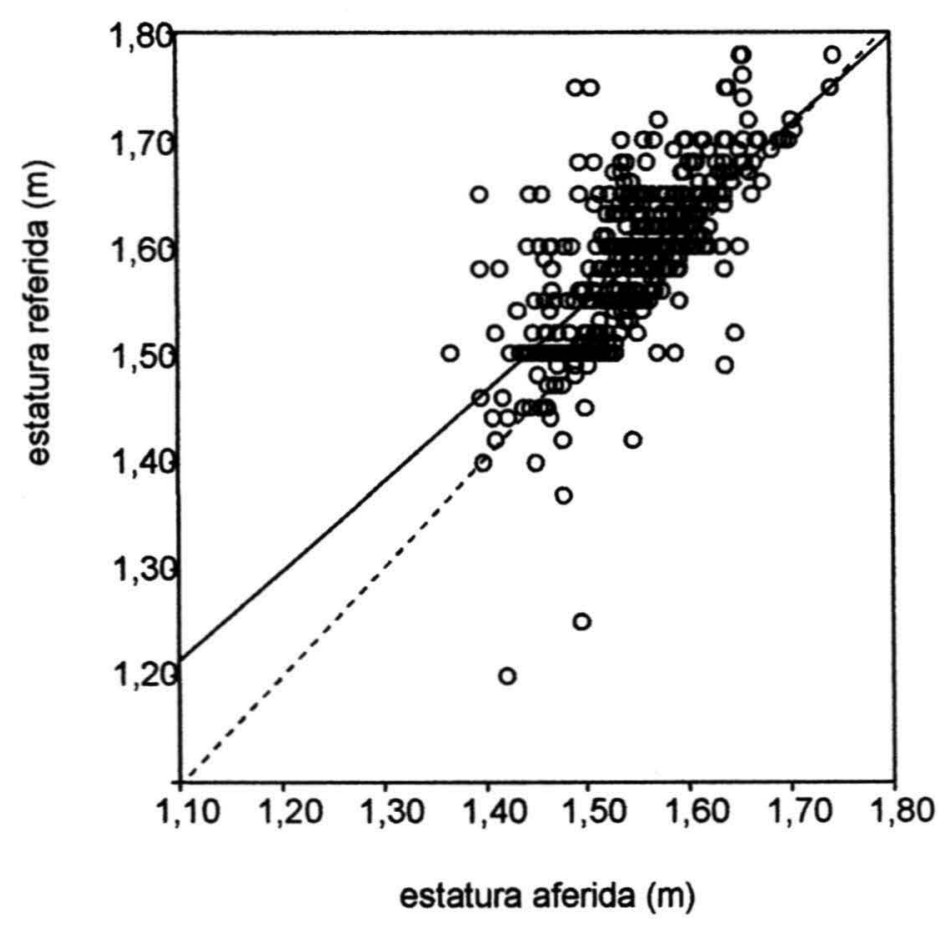

Observam-se valores intermediários de concordância entre 0 IMC calculado com base nos valores referidos e aferidos (CCC de 0,86 para homens e 0,87 para mulheres). Entre os homens, houve uma tendência clara para a síndrome do "flat slope", isto é, superestimação do IMC real entre aqueles com IMC mais baixo e subestimação entre aqueles com IMC mais alto. Entre as mulheres com IMC aferido superior a $25 \mathrm{~kg} / \mathrm{m}^{2}$ nota-se clara subestimação do IMC, no entanto, entre aquelas com IMC aferido inferior a $25 \mathrm{~kg} / \mathrm{m}^{2}$ a subestimação do IMC referido foi mais discreta (Figura 9). 
Figura 9 - Gráficos de concordância e coeficientes de correlação de concordância entre índice de massa corporal (IMC) referido e aferido, por sexo. População adulta com $\mathbf{4 0}$ ou mais anos de idade da área metropolitana de São Paulo, 2003.

Sexo masculino $(C C C=0,862)$

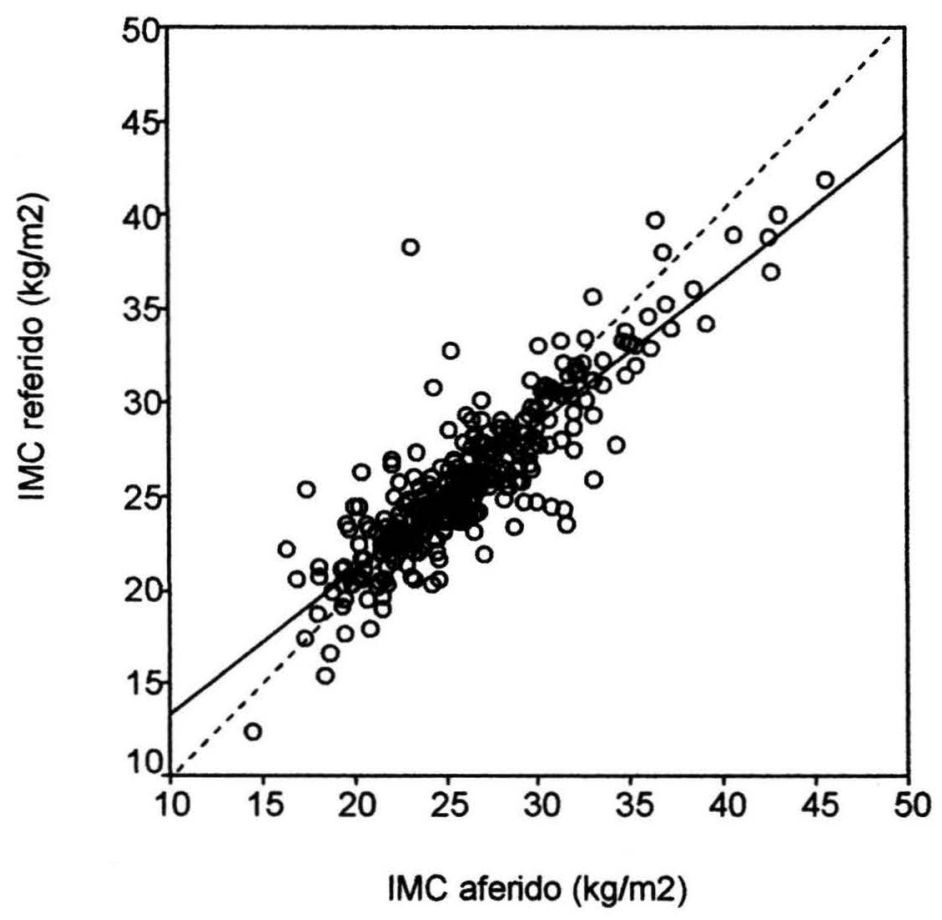


Sexo feminino $(\mathrm{CCC}=0,875)$

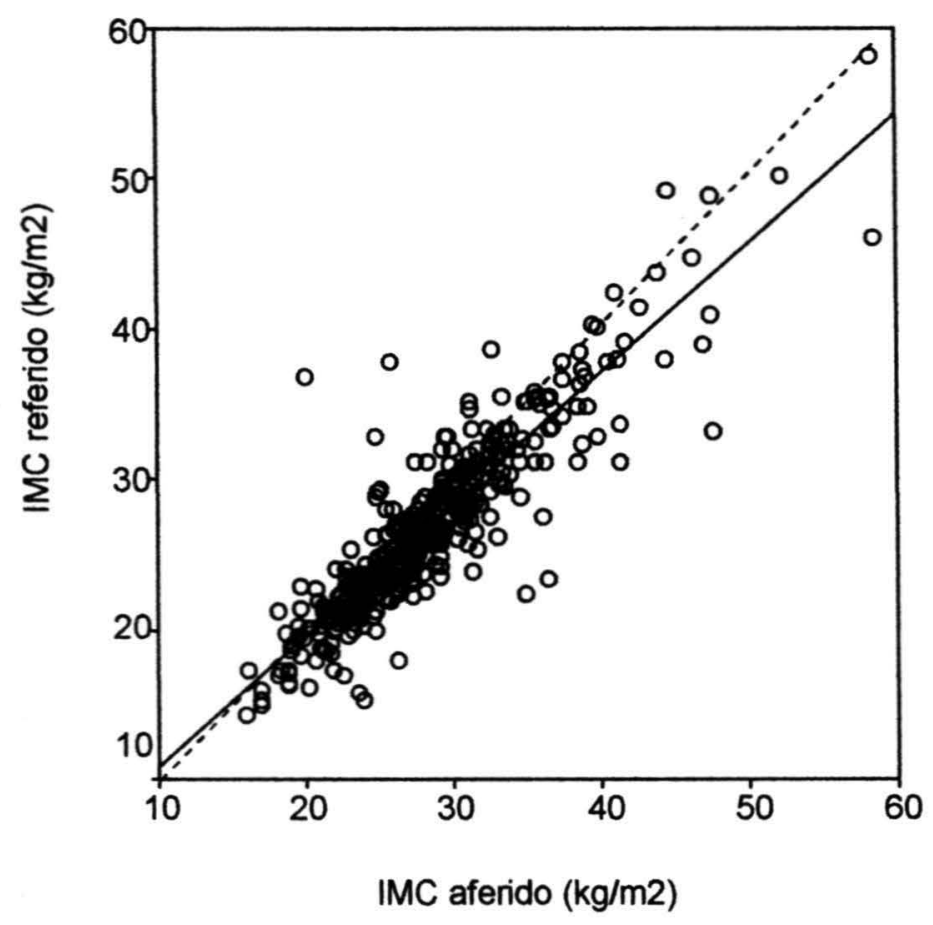

A Tabela 14 mostra uma comparação entre os três coeficientes empregados neste estudo para avaliar o desempenho das medidas referidas de peso e estatura. Exceto no caso do peso, onde os coeficientes de correlação de Pearson e o CCC foram semelhantes, os três coeficientes apresentaram valores distintos, para homens e mulheres. O CCIC apresentou os menores valores para peso, estatura e IMC quando comparados ao coeficiente de correlação de Pearson e ao coeficiente de correlação de concordância. 
Tabela 14 - Coeficientes de Pearson, correlação intraclasse e correlação de concordância entre medidas referidas e aferidas, por sexo. População adulta com 40 ou mais anos de idade da área metropolitana de São Paulo, 2003.

\begin{tabular}{l|c|c|c}
\hline Coeficientes & Peso & Estatura & IMC \\
\hline $\begin{array}{l}\text { Pearson } \\
\text { Homem }\end{array}$ & & & \\
Mulher & 0,942 & 0,777 & 0,871 \\
\hline Total & 0,957 & 0,699 & 0,901 \\
\hline CCIC & 0,952 & 0,825 & 0,889 \\
Homem & & & \\
Mulher & 0,891 & 0,686 & 0,787 \\
\hline Total & 0,919 & 0,613 & 0,834 \\
\hline & 0,910 & 0,739 & 0,815 \\
CCC & & & \\
Homem & 0,939 & 0,749 & 0,862 \\
Mulher & 0,955 & 0,597 & 0,875 \\
\hline Total & 0,951 & $\mathbf{0 , 7 8 4}$ & $\mathbf{0 , 8 7 3}$ \\
\hline
\end{tabular}

\subsection{Modelos para correção de medidas referidas - I}

Os modelos de regressão podem ser feitos de duas formas. A primeira considerando como variáveis dependentes as medidas aferidas e a segunda considerando como variáveis dependentes as medidas referidas. $\mathrm{Na}$ análise onde a variável dependente é a medida referida e a independente é a medida aferida, a idéia é que o valor informado possa ser decomposto por uma parte real e um erro de medida, isto é:

Valor referido $($ observado $)=$ valor aferido $($ real $)+$ erro

Estes modelos são chamados de calibração. O termo "calibrar" vem de estudos experimentais cujo objetivo era calibrar instrumentos de medida indireta, conhecendo-se as medidas reais. 
Embora ambas estejam corretas, os objetivos das duas análises são diferentes. Cabe ao pesquisador escolher qual a mais adequada tendo em vista os objetivos do trabalho. Neste trabalho, serão apresentadas apenas as equações para estimação dos valores aferidos a partir dos valores referidos.

Assim, nesta seção, foram desenvolvidos modelos que corrigissem as medidas de peso e estatura referidos pelos indivíduos de modo a aproximá-las das medidas reais (medidas aferidas). As variáveis dependentes desse modelo foram os valores aferidos e as variáveis explicativas (independentes) foram os valores referidos e outras variáveis que exerceram influências sobre as diferenças existentes entre valores referidos e aferidos.

Selecionaram-se as variáveis que apresentaram significância estatística na análise bivariada. São elas: peso referido $(\mathrm{em} \mathrm{kg}$ ), estatura referida (em metros), sexo, idade (em anos), escolaridade (em anos) e grupo étnico (brancos e não-brancos). Em seguida, estas variáveis foram incluídas e testadas no modelo de correção das medidas referidas em ordem decrescente de significância estatística na análise bivariada. A opção "enter" foi utilizada para permitir que as variáveis independentes entrassem no modelo em ordem de sua capacidade explanatória. Vale observar que nos modelos de correção, os valores de IMC não foram incluídos como variáveis independentes devido ao problema de multicolinearidade entre as variáveis independentes.

Para cada variável (peso e estatura) foram construídos três modelos: um modelo para o total da amostra e dois modelos específicos segundo sexo. A Tabela 15 mostra os resultados de modelos de regressão para correção do peso referido. 
Tabela 15 - Resultados de modelos de regressão para correção do peso referido. População adulta com 40 ou mais anos de idade da área metropolitana de São Paulo, 2003.

\begin{tabular}{l|c|c|c|c}
\hline SEXO/ TERMOS & $\begin{array}{c}\text { Coeficiente } \\
\text { de } \\
\text { regressão }\end{array}$ & EP & $\mathbf{p}$ & $\mathbf{R}^{2}$ \\
\hline AMBOS OS SEXOS & 3,520 & 1,289 & 0,006 & 0,917 \\
\hline Constante & 0,998 & 0,012 & $<0,001$ & \\
\hline Peso referido (kg) & 0,844 & 0,353 & 0,017 & \\
\hline Sexo & $-0,070$ & 0,016 & $<0,001$ & \\
Idade (anos) & $-3,339$ & 1,412 & 0,019 & 0,908 \\
\hline MASCULINO & 1,031 & 0,019 & $<0,001$ & \\
\hline Constante & 0,112 & 0,052 & 0,033 & \\
\hline Peso referido (kg) & & 1,360 & $<0,001$ & 0,931 \\
\hline Escolaridade (anos) & 0,277 & 0,013 & $<0,001$ & \\
\hline FEMININO & 0,982 & 0,017 & $<0,001$ & \\
\hline Constante & $-0,067$ & 0,017 & \\
\hline Peso referido (kg) & Idade (anos) &
\end{tabular}

Nota:

$E P=$ erro padrão; $p$-valor $=$ nivel descritivo referente à hipótese de beta $=0 ; R^{2}=$ coeficiente de determinação.

Equação geral para correção do peso referido (ambos os sexos):

Peso aferido $=3,52+0,998$ (peso referido, em $\mathrm{kg}$ ) $+0,844$ (sexo) - 0,07 (idade, em anos)

Onde: masculino $=0 ;$ feminino $=1$. 
Equação para correção do peso referido, sexo masculino:

Peso aferido $=-3,34+1,031$ (peso referido, em $\mathrm{kg}$ ) $+0,112$ (escolaridade, em anos)

Equação para correção do peso referido, sexo feminino:

Peso aferido $=5,28+0,982$ (peso referido, em $\mathrm{kg}$ ) $-0,067$ (idade, em anos)

Os três modelos apresentaram um bom ajuste com valores de $R^{2}$ superiores a 0,90 . Termos de interação entre sexo e idade não foram significantes e, nesta medida, não estão presentes nos modelos.

Da mesma forma como foi feito para o peso, foram utilizadas equações de regressão linear para identificar características preditoras da estatura aferida. As variáveis que apresentaram significância estatística na análise bivariada foram: estatura referida (em metros), sexo, peso referido (em $\mathrm{kg}$ ), escolaridade (em anos) e idade (em anos). Os valores de IMC não foram incluídos como variáveis independentes devido ao problema de multicolinearidade entre as variáveis independentes. A Tabela 16 mostra os resultados de modelos de regressão para correção da estatura referida, considerando a estatura aferida como variável dependente. 
Tabela 16 - Resultados de modelos de regressão para correção da estatura referida. População adulta com $\mathbf{4 0}$ ou mais anos de idade da área metropolitana de São Paulo, 2003.

\begin{tabular}{|c|c|c|c|c|}
\hline SEXO/ TERMOS & $\begin{array}{l}\text { Coeficiente de } \\
\text { regressão }\end{array}$ & EP & $\mathbf{p}$ & $\mathbf{R}^{2}$ \\
\hline \multicolumn{5}{|l|}{ AMBOS OS SEXOS } \\
\hline Constante & 0,587 & 0,036 & $<0,001$ & 0,798 \\
\hline Estatura referida $(\mathrm{m})$ & 0,672 & 0,021 & $<0,001$ & \\
\hline Sexo & $-0,005$ & 0,004 & $<0,001$ & \\
\hline Escolaridade (anos) & 0,0017 & 0,000 & $<0,001$ & \\
\hline Idade (anos) & $-0,0011$ & 0,000 & $<0,001$ & \\
\hline \multicolumn{5}{|l|}{ MASCULINO } \\
\hline Constante & 0,481 & 0,054 & $<0,001$ & 0,700 \\
\hline Estatura referida $(\mathrm{m})$ & 0,728 & 0,031 & $<0,001$ & \\
\hline Escolaridade (anos) & 0,0018 & 0,000 & $<0,001$ & \\
\hline Idade (anos) & $-0,0009$ & 0,000 & $<0,001$ & \\
\hline \multicolumn{5}{|l|}{ FEMININO } \\
\hline Constante & 0,587 & 0,047 & $<0,001$ & 0,593 \\
\hline Estatura referida (m) & 0,643 & 0,029 & $<0,001$ & \\
\hline Escolaridade (anos) & 0,0012 & 0,000 & 0,011 & \\
\hline Idade (anos) & $-0,0012$ & 0,000 & $<0,001$ & \\
\hline
\end{tabular}

Nota:

$\mathrm{EP}=$ erro padrão; $\mathrm{p}$-valor $=$ nível descritivo referente à hipótese de beta $=0 ; \mathrm{R}^{2}=$ coeficiente de determinação.

\section{Equação geral para correção da estatura referida, ambos os sexos:}

Estatura aferida $=0,587+0,672$ (estatura referida, em metros) - 0,0054 (sexo) $+0,0017$ (escolaridade, em anos) $-0,0011$ (idade, em anos)

Onde: masculino $=0 ;$ feminino $=1$. 
Equação para correção da estatura referida, sexo masculino:

Estatura aferida $=0,481+0,728$ (estatura referida, em metros) $-0,00097$ (idade, em anos) $+0,00184$ (escolaridade, em anos)

Equação para correção da estatura referida, sexo feminino:

Estatura aferida $=0,587+0,643$ (estatura referida, em metros) - 0,0012 (idade, em anos) $+0,0012$ (escolaridade, em anos)

Neste caso, a qualidade de ajuste avaliada pelo $R^{2}$ não foi tão boa quanto nos modelos para o peso. Nos modelos estatura por sexo, as variáveis estatisticamente significativas foram estatura referida, idade e escolaridade.

\subsection{Aplicação dos modelos de correção para peso e estatura referidos em população distinta daquela que deu origem aos modelos (População do Estudo Pró-Saúde)}

No sentido de verificar a utilidade dos modelos desenvolvidos, as equações para correção de peso e estatura referidos foram aplicadas na população de funcionários da Universidade Estadual do Rio de Janeiro estudada pelo Estudo Pró-Saúde. Com o propósito de aproximar a referida população daquela estudada na área metropolitana de São Paulo, foram considerados apenas os funcionários com 40 ou mais anos de idade, os quais corresponderam a 1808 indivíduos. 
A Tabela 17 apresenta as médias de peso, estatura e IMC calculadas a partir de medidas referidas e aferidas da população do Estudo Pró-Saúde. Em média, o peso referido foi inferior ao peso aferido em cerca de $1 \mathrm{~kg}$, tanto em homens quanto em mulheres, havendo diferenças estatisticamente significativas entre as medidas aferidas e referidas, em ambos os sexos. Em média, a estatura referida tendeu a ser $1,0 \mathrm{~cm}$ superior à estatura aferida, em ambos os sexos. $O \mathrm{IMC}$ calculado a partir dos valores referidos foi menor que 0 calculado a partir dos valores aferidos, em média, cerca de $0,41 \mathrm{~kg} / \mathrm{m}^{2}$ entre os homens e $0,91 \mathrm{~kg} / \mathrm{m}^{2}$ entre as mulheres, sendo essas diferenças estatisticamente significativas.

O peso e estatura médios aferidos da população do Estudo Pró-Saúde foram superiores aos da população da Grande São Paulo. Ao contrário do encontrado na população da Grande São Paulo, a população masculina do Estudo Pró-Saúde informou peso inferior ao peso real. De maneira semelhante ao encontrado na população da Grande São Paulo, a estatura informada pela população do Estudo Pró-Saúde foi superior à aferida, em ambos os sexos.

O IMC médio aferido da população do Estudo Pró-Saúde foi superior ao da população da Grande São Paulo, no caso do sexo masculino e inferior, no caso das mulheres. Da mesma forma que o observado na população da Grande São Paulo, o IMC referido foi inferior ao aferido, em ambos os sexos. 
Tabela 17 - Média (desvio-padrão) e média das diferenças de peso, estatura e índice de massa corporal (IMC) segundo medidas aferidas e referidas, por sexo. Adultos com 40 ou mais anos de idade do Estudo Pró-Saúde, 2003.

\begin{tabular}{|c|c|c|c|c|}
\hline Sexo/ Medidas & $\begin{array}{l}\text { Medidas } \\
\text { aferidas }\end{array}$ & $\begin{array}{l}\text { Medidas } \\
\text { referidas }\end{array}$ & $\begin{array}{l}\text { Médias das } \\
\text { diferenças }\end{array}$ & Valor $p$ \\
\hline \multicolumn{5}{|c|}{ Homens $(\mathrm{N}=775)$} \\
\hline Peso (kg) & $78,07(13,91)$ & $77,00(13,72)$ & 1,07 & $<0,001$ \\
\hline Estatura (m) & $1,71(0,06)$ & $1,72(0,07)$ & $-0,01$ & $<0,001$ \\
\hline IMC $\left(\mathrm{kg} / \mathrm{m}^{2}\right)$ & $26,50(3,95)$ & $26,09(4,10)$ & 0,41 & $<0,001$ \\
\hline \multicolumn{5}{|c|}{ Mulheres $(\mathrm{N}=1033)$} \\
\hline Peso (kg) & $68,34(14,26)$ & $67,15(13,77)$ & 1,19 & $<0,001$ \\
\hline Estatura (m) & $1,59(0,06)$ & $1,60(0,07)$ & $-0,01$ & 0,041 \\
\hline IMC $\left(\mathrm{kg} / \mathrm{m}^{2}\right)$ & $27,02(5,34)$ & $26,11(5,08)$ & 0,91 & $<0,001$ \\
\hline
\end{tabular}

A Tabela 18 apresenta as médias de peso, estatura e IMC calculadas a partir de medidas aferidas e referidas/ajustadas conforme os modelos de correção construídos neste estudo. No caso dos homens, com o ajuste, a média das diferenças entre medidas aferidas e referidas aumentou para peso (de $1,07 \mathrm{~kg}$ para $1,5 \mathrm{~kg}$ ), para estatura (de $1 \mathrm{~cm}$ para $2 \mathrm{~cm}$ ) e diminuiu com relação ao IMC (de $0,41 \mathrm{~kg} / \mathrm{m}^{2}$ para $0,26 \mathrm{~kg} / \mathrm{m}^{2}$ ). No caso das mulheres, com o ajuste, a média das diferenças entre medidas aferidas e referidas diminuiu para o peso (de 1,2kg para $0,31 \mathrm{~kg}$ ), aumentou para estatura (de $1 \mathrm{~cm}$ para $2 \mathrm{~cm}$ ) e diminuiu em relação ao IMC (de $0,91 \mathrm{~kg} / \mathrm{m}^{2}$ para $0,65 \mathrm{~kg} / \mathrm{m}^{2}$ ). Em ambos os sexos, houve diferenças estatisticamente significativas $(p<0,0001)$ entre o peso, estatura e IMC aferidos e ajustados (teste t pareado). 
Tabela 18 - Média (desvio-padrão) e média das diferenças de peso, estatura e índice de massa corporal (IMC) segundo medidas aferidas $\mathrm{e}$ referidas/ajustadas, por sexo. Adultos com 40 ou mais anos de idade do Estudo Pró-Saúde, 2003.

\begin{tabular}{l|c|c|c|c}
\hline Sexo/ Medida & $\begin{array}{c}\text { Medidas } \\
\text { aferidas }\end{array}$ & $\begin{array}{c}\text { Medidas referidas/ } \\
\text { ajustadas (modelo } \\
\text { separado por sexo) }\end{array}$ & $\begin{array}{c}\text { Médias das } \\
\text { diferenças }\end{array}$ & Valor p \\
\hline Homens $(\mathrm{N}=775)$ & $78,07(13,91)$ & $76,57(14,16)$ & 1,50 & $<0,001$ \\
Peso $(\mathrm{kg})$ & $1,71(0,06)$ & $1,69(0,06)$ & 0,02 & $<0,001$ \\
Estatura (m) & $26,50(3,95)$ & $26,24(4,32)$ & 0,26 & $<0,001$ \\
IMC $\left(\mathrm{kg} / \mathrm{m}^{2}\right)$ & $68,34(14,26)$ & $68,03(13,50)$ & 0,31 & $<0,001$ \\
Mulheres $(\mathrm{N}=1033)$ & $1,59(0,06)$ & $1,57(0,05)$ & 0,02 & $<0,001$ \\
Peso $(\mathrm{kg})$ & $27,02(5,34)$ & $27,67(5,21)$ & 0,65 & $<0,001$ \\
\hline Estatura $(\mathrm{m})$ & & & & \\
IMC $\left(\mathrm{kg} / \mathrm{m}^{2}\right)$ &
\end{tabular}

A Tabela 19 mostra a distribuição da população adulta com 40 ou mais anos de idade do Estudo Pró-Saúde, segundo estado nutricional calculado com base no peso e estatura aferidos, referidos e referidos/ajustados pelo modelo de correção proposto pelo presente estudo. As equações de correção do peso e estatura referidos "eliminaram" a subestimação da prevalência de obesidade, induzida pelos valores referidos em ambos os sexos. No caso das mulheres, a magnitude do erro na prevalência da obesidade caiu, passando de $-6,0$ pontos percentuais para $+3,0$ pontos percentuais. No caso dos homens, entretanto, a subestimação (-1,3 pontos percentuais) deu lugar à superestimação de maior magnitude $(+3,1$ pontos percentuais). Em ambos os sexos, a prevalência da obesidade aferida diferiu estatisticamente (Teste de McNemar - $p<0,001$ ) daquela obtida a partir dos valores antropométricos referidos $\mathrm{e}$ referidos/ajustados. 
Tabela 19 - Distribuição segundo categorias de IMC calculado a partir de medidas aferidas, referidas e referidas/ajustadas, por sexo. População adulta com 40 ou mais anos de idade do Estudo Pró-Saúde, 2003.

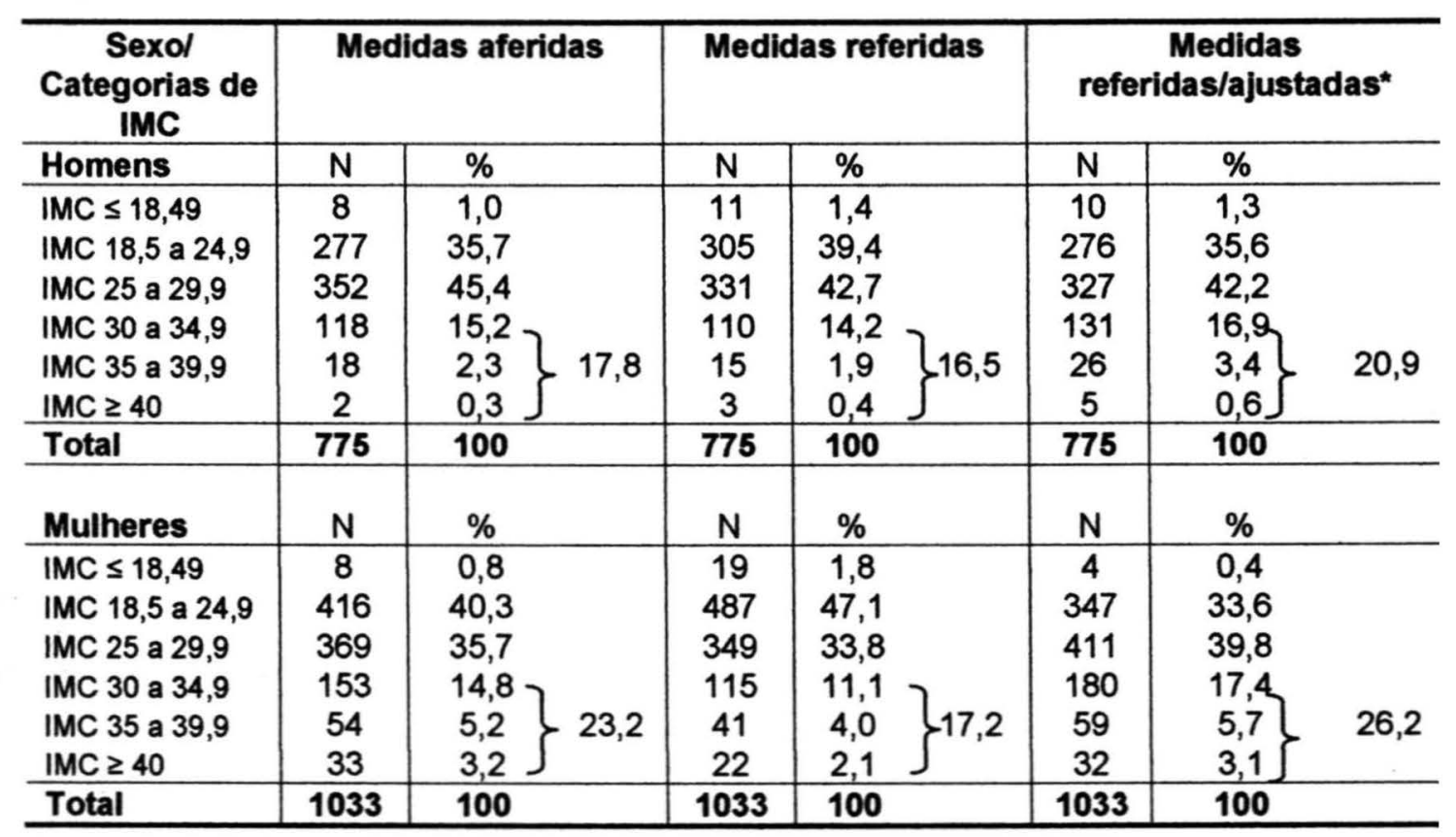

Nota: *refere-se ao peso e estatura referidos, ajustados pelos modelos de correção.

A Tabela 20 mostra a sensibilidade e a especificidade do diagnóstico de obesidade com base em medidas referidas com e sem ajuste, considerando-se os valores aferidos como padrão-ouro. No caso dos homens, a sensibilidade do diagnóstico de obesidade foi extremamente baixa: $26 \%$. Após o ajuste pelo modelo de correção, a sensibilidade aumentou para $33 \%$, valor, evidentemente, ainda muito baixo. No caso das mulheres, a sensibilidade do diagnóstico de obesidade baseada no IMC calculado a partir do peso e estatura referidos também foi extremamente baixa: $29,2 \%$ e, embora este valor tenha aumentado para $44,2 \%$ após o ajuste pelo modelo de correção, ainda continuou sendo 
muito baixo. A especificidade do diagnóstico de obesidade permaneceu muito alta $(>99,0 \%)$ com ou sem 0 ajuste.

Tabela 20 - Sensibilidade (\%) e Especificidade (\%) do diagnóstico de obesidade (IMC $\geq 30 \mathrm{~kg} / \mathrm{m}^{2}$ ) com base em medidas referidas com e sem ajuste ${ }^{*}$, segundo faixa etária e escolaridade, por sexo. População adulta com 40 ou mais anos de idade do Estudo Pró-Saúde, 2003.

\begin{tabular}{l|c|c|c|c|c|c|c|c}
\hline \multirow{2}{*}{ Variáveis } & \multicolumn{4}{|c|}{ Homens } & \multicolumn{4}{c}{ Mulheres } \\
\cline { 2 - 9 } & \multicolumn{2}{|c|}{ Sensibilidade } & Especificidade & Sensibilidade & Especificidade \\
\cline { 2 - 9 } & $\begin{array}{c}\text { sem } \\
\text { ajuste }\end{array}$ & $\begin{array}{c}\text { com } \\
\text { ajuste }\end{array}$ & $\begin{array}{c}\text { sem } \\
\text { ajuste }\end{array}$ & $\begin{array}{c}\text { com } \\
\text { ajuste }\end{array}$ & $\begin{array}{c}\text { sem } \\
\text { ajuste }\end{array}$ & $\begin{array}{c}\text { com } \\
\text { ajuste }\end{array}$ & $\begin{array}{c}\text { sem } \\
\text { ajuste }\end{array}$ & $\begin{array}{c}\text { com } \\
\text { ajuste }\end{array}$ \\
\hline $\begin{array}{l}\text { Faixa etária } \\
\text { (anos) }\end{array}$ & & & & & & & & \\
40 a 49 & 25,4 & 31,8 & 99,5 & 99,5 & 27,7 & 42,2 & 100,0 & 99,4 \\
50 a 59 & 30,1 & 38,8 & 100,0 & 100,0 & 33,3 & 49,7 & 100,0 & 100,0 \\
60 a 69 & 16,7 & 25,0 & 100,0 & 100,0 & 28,1 & 40,6 & 100,0 & 100,0 \\
Escolaridade & & & & & & & & \\
$1^{\circ}$ grau completo & 29,1 & 35,7 & 99,1 & 99,1 & 34,0 & 51,7 & 100,0 & 99,0 \\
$2^{\circ}$ grau completo & 21,7 & 30,7 & 100,0 & 100,0 & 32,2 & 47,7 & 100,0 & 99,1 \\
$3^{\circ}$ grau completo & 26,6 & 31,5 & 100,0 & 100,0 & 20,9 & 33,2 & 100,0 & 100,0 \\
\hline Total & $\mathbf{2 6 , 0}$ & $\mathbf{3 2 , 9}$ & $\mathbf{9 9 , 7}$ & $\mathbf{9 9 , 7}$ & $\mathbf{2 9 , 2}$ & $\mathbf{4 4 , 2}$ & $\mathbf{1 0 0 , 0}$ & $\mathbf{9 9 , 5}$ \\
\hline
\end{tabular}

Nota: *refere-se ao peso e estatura referidos, ajustados pelos modelos de correção.

A Tabela 21 mostra os valores preditivos positivos e negativos, bem como a eficiência do teste em identificar a obesidade com base em medidas referidas com e sem ajuste. No caso dos homens, o valor preditivo positivo foi alto $(>99,0 \%)$ e praticamente não se alterou após o ajuste. $O$ valor preditivo negativo aumentou de $44 \%$ para $46,5 \%$ e a eficiência do teste passou de $53,2 \%$ para $66,9 \%$. No caso das mulheres, o valor preditivo positivo foi alto $(100 \%)$ e praticamente não sofreu alteração após o ajuste. $\mathrm{O}$ valor preditivo negativo aumentou passando de $49,6 \%$ para $55,4 \%$ e a eficiência do teste praticamente não se alterou (de $58,3 \%$ para $57,5 \%$ ). 
Tabela 21 - Valor Preditivo Positivo (\%), Valor Preditivo Negativo (\%) e Eficiência do teste (\%) do diagnóstico da obesidade (IMC $\geq 30 \mathrm{~kg} / \mathrm{m}^{2}$ ) com base em medidas referidas com e sem ajuste*, por sexo. Adultos com 40 ou mais anos de idade do Estudo Pró-Saúde, 2003.

\begin{tabular}{l|c|c|c|c|c|c}
\hline Sexo & \multicolumn{2}{|c|}{ VPP } & \multicolumn{2}{c|}{ VPN } & \multicolumn{2}{c}{ Eficiéncia do teste } \\
\cline { 2 - 7 } & sem ajuste & com ajuste & sem ajuste & com ajuste & sem ajuste & com ajuste \\
\hline Homens & 99,2 & 99,4 & 44,0 & 46,5 & 53,2 & 66,9 \\
Mulheres & 100 & 99,3 & 49,6 & 55,4 & 58,3 & 57,5 \\
\hline
\end{tabular}

Nota: *refere-se ao peso e estatura referidos, ajustados pelos modelos de correção.

A Tabela 22 mostra a sensibilidade e a especificidade do diagnóstico de excesso de peso com base em medidas referidas com e sem ajuste, considerando o diagnóstico segundo medidas aferidas como padrão-ouro. No caso do sexo masculino, a sensibilidade do diagnóstico de excesso de peso já era elevada antes do ajuste pelo modelo de correção (>90\%), não havendo, portanto, ganhos substanciais com a correção. No caso do sexo feminino, após 0 ajuste, a sensibilidade do diagnóstico de excesso de peso apresentou ganho maior, passando de $83 \%$ para $95 \%$. Houve queda da especificidade após o ajuste, sobretudo entre as mulheres. 
Tabela 22 - Sensibilidade (\%) e Especificidade (\%) do diagnóstico de excesso de peso (IMC $\geq 25 \mathrm{~kg} / \mathrm{m}^{2}$ ) com base em medidas referidas com e sem ajuste*, segundo faixa etária e escolaridade, por sexo. Adultos com 40 ou mais anos de idade do Estudo Pró-Saúde, 2003.

\begin{tabular}{l|c|c|c|c|c|c|c|c}
\hline \multirow{2}{*}{ Variáveis } & \multicolumn{4}{|c|}{ Homens } & \multicolumn{4}{c}{ Mulheres } \\
\cline { 2 - 9 } & \multicolumn{2}{|c|}{ Sensibilidade } & \multicolumn{2}{c|}{ Especificidade } & Sensibilidade & \multicolumn{2}{c}{ Especificidade } \\
\cline { 2 - 9 } & $\begin{array}{c}\text { sem } \\
\text { ajuste }\end{array}$ & $\begin{array}{c}\text { com } \\
\text { ajuste }\end{array}$ & $\begin{array}{c}\text { sem } \\
\text { ajuste }\end{array}$ & $\begin{array}{c}\text { com } \\
\text { ajuste }\end{array}$ & $\begin{array}{c}\text { sem } \\
\text { ajuste }\end{array}$ & $\begin{array}{c}\text { com } \\
\text { ajuste }\end{array}$ & $\begin{array}{c}\text { sem } \\
\text { ajuste }\end{array}$ & $\begin{array}{c}\text { com } \\
\text { ajuste }\end{array}$ \\
\hline $\begin{array}{l}\text { Faixa etária } \\
\text { (anos) }\end{array}$ & & & & & & & & \\
40 a 49 & 89,8 & 92,8 & 92,4 & 86,8 & 82,5 & 93,9 & 95,5 & 74,5 \\
50 a 59 & 92,2 & 93,2 & 97,3 & 90,7 & 82,4 & 95,2 & 93,6 & 73,1 \\
60 a 69 & 87,5 & 95,8 & 100,0 & 92,9 & 84,4 & 93,8 & 100,0 & 84,6 \\
Escolaridade & & & & & & & & \\
$1^{\circ}$ grau completo & 87,8 & 90,8 & 92,2 & 87,1 & 83,7 & 96,2 & 90,6 & 65,6 \\
$2^{\circ}$ grau completo & 91,0 & 94,6 & 92,9 & 85,9 & 82,9 & 95,5 & 93,9 & 73,9 \\
$3^{\circ}$ grau completo & 92,7 & 94,4 & 97,5 & 91,4 & 81,1 & 91,8 & 98,1 & 78,9 \\
\hline Total & 90,2 & 93,0 & 94,1 & $\mathbf{8 8 , 1}$ & $\mathbf{8 2 , 6}$ & $\mathbf{9 4 , 3}$ & $\mathbf{9 5 , 0}$ & $\mathbf{7 4 , 5}$ \\
\hline
\end{tabular}

Nota: *refere-se ao peso e estatura referidos, ajustados pelos modelos de correção.

A Tabela 23 mostra os valores preditivos positivos e negativos, bem como a eficiência do teste em identificar o excesso de peso com base em medidas referidas com e sem ajuste. No caso dos homens, o valor preditivo positivo caiu ligeiramente passando de $99 \%$ para $93 \%$, o valor preditivo negativo aumentou de $85 \%$ para $88 \%$ e a eficiência do teste ficou praticamente inalterada, em torno de $91 \%$. No caso das mulheres, o valor preditivo positivo caiu de $96 \%$ para $84 \%$, o valor preditivo negativo aumentou de $79 \%$ para $90 \%$ e a eficiência do teste ficou praticamente inalterada, em torno de $87 \%$. A tendência do estudo Pró-Saúde em detectar melhor o excesso de peso do que a obesidade se manteve após o ajuste pelo modelo de correção. 
Tabela 23 - Valor Preditivo Positivo (\%), Valor Preditivo Negativo (\%) e Eficiência do teste $(\%)$ do diagnóstico de excesso de peso $\left(\mathrm{IMC} \geq 25 \mathrm{~kg} / \mathrm{m}^{2}\right)$ com base em medidas referidas com e sem ajuste*, por sexo. Adultos com 40 ou mais anos de idade do Estudo Pró-Saúde, 2003.

\begin{tabular}{l|c|c|c|c|c|c}
\hline \multirow{2}{*}{ Sexo } & \multicolumn{2}{|c|}{ VPP } & \multicolumn{2}{c|}{ VPN } & \multicolumn{2}{c}{ Eficiência do teste } \\
\cline { 2 - 7 } & sem ajuste & com ajuste & sem ajuste & com ajuste & sem ajuste & com ajuste \\
\hline Homens & 96,3 & 93,0 & 84,9 & 88,1 & 91,6 & 91,2 \\
Mulheres & 96,0 & 84,2 & 79,2 & 90,0 & 87,7 & 86,1 \\
\hline
\end{tabular}

Nota: *refere-se ao peso e estatura referidos, ajustados pelos modelos de correção.

A Tabela 24 mostra os coeficientes de correlação de concordância para peso, estatura e IMC baseados em valores aferidos e referidos e valores aferidos e referidos/ajustados conforme os modelos de correção construídos neste estudo. A análise dos coeficientes de concordância aponta para ganhos pouco substanciais no estudo Pró-Saúde após a correção pelo modelo proposto, uma vez que o coeficiente de correlação de concordância entre o IMC aferido e ajustado sofreu apenas um discreto aumento (passando de 0,915 para $0,933)$, praticamente não se alterou em relação ao peso aferido e ajustado e houve redução do mesmo coeficiente em relação à estatura aferida e ajustada.

Tabela 24 - Coeficientes de correlação de concordância para peso, estatura e IMC aferidos e referidos, e aferidos e referidos/ajustados. Adultos com 40 ou mais anos de idade do Estudo Pró-Saúde, 2003.

\begin{tabular}{l|c|c|c}
\hline \multicolumn{1}{c|}{ CCC } & Peso & Estatura & IMC \\
\hline $\begin{array}{l}\text { Medidas aferidas e referidas } \\
\begin{array}{l}\text { Medidas aferidas e } \\
\text { referidas/ajustadas }\end{array}\end{array}$ & 0,970 & 0,922 & 0,915 \\
\hline
\end{tabular}

Nota: *refere-se ao peso e estatura referidos, ajustados pelos modelos de correção. 


\subsection{Modelos para correção de medidas referidas - II}

Nesta seção foram desenvolvidos modelos com o objetivo de corrigir as medidas de peso e estatura referidas de modo a aproximá-las das medidas reais (aferidas) utilizando, porém, apenas metade da amostra. Posteriormente, as referidas equações foram aplicadas na metade restante da amostra, com o objetivo de indicar a utilidade das mesmas em população semelhante à estudada. As variáveis dependentes deste modelo serão os valores aferidos das medidas e as variáveis explicativas (independentes) serão os valores referidos e outras variáveis que exerçam influências sobre as diferenças existentes entre valores referidos e aferidos. Para cada variável (peso e estatura) foram construídos três modelos: um modelo para o total da amostra e dois modelos específicos segundo sexo. A Tabela 25 mostra os resultados de modelos de regressão para correção do peso referido.

Tabela 25 - Resultados de modelos de regressão para correção do peso referido. População adulta com 40 ou mais anos de idade da área metropolitana de São Paulo, 2003.

\begin{tabular}{l|c|c|c|c}
\hline SEXO/ TERMOS & $\begin{array}{c}\text { Coeficiente } \\
\text { de regressão }\end{array}$ & EP & $\mathbf{p}$ & $\mathbf{R}^{2}$ \\
\hline \multicolumn{5}{|l|}{ AMBOS OS SEXOS } \\
\hline Constante & 2,451 & 1,48 & 0,098 & 0,940 \\
Peso referido (kg) & 0,995 & 0,013 & $<0,001$ & \\
Idade (anos) & $-0,0416$ & 0,020 & 0,037 & \\
\hline MASCULINO & $-2,603$ & 1,531 & 0,091 & 0,941 \\
\hline Constante & 1,031 & 0,020 & $<0,001$ & \\
Peso referido (kg) & \multicolumn{5}{|l}{} \\
\hline FEMININO & 0,738 & 1,178 & 0,531 & 0,945 \\
\hline Constante & 0,991 & 0,017 & $<0,001$ & \\
\hline
\end{tabular}

Nota: $E P=$ erro padrão; valor $=$ nível descritivo referente à hipótese de beta $=0 ; R^{2}=$ coeficiente de determinação. 
Equação geral para correção do peso referido, ambos os sexos:

Peso aferido $=2,45+0,995$ (peso referido, em $\mathrm{kg}$ ) $-0,04$ (idade, em anos)

Equação para correção do peso referido, sexo masculino:

Peso aferido $=-2,60+1,032$ (peso referido, $\mathrm{em} \mathrm{kg}$ )

Equação para correção do peso referido, sexo feminino:

Peso aferido $=0,738+0,991$ (peso referido, $\mathrm{em} \mathrm{kg}$ )

Os três modelos apresentaram um bom ajuste com valores de $R^{2}$ superiores a 0,90 . Nos modelos estratificados por sexo nenhuma outra variável ou termo de interação foi importante para predizer o peso aferido. A Tabela 26 mostra os resultados de modelos de regressão para correção da estatura referida. 
Tabela 26 - Resultados de modelos de regressão para correção da estatura referida. População adulta com $\mathbf{4 0}$ ou mais anos de idade da área metropolitana de São Paulo, 2003.

\begin{tabular}{l|c|c|c|c}
\hline \multicolumn{1}{c|}{ SEXO/ TERMOS } & $\begin{array}{c}\text { Coeficiente } \\
\text { de regressão }\end{array}$ & EP & $\mathbf{p}$ & $\mathbf{R}^{2}$ \\
\hline \multicolumn{5}{|c}{ AMBOS OS SEXOS } \\
\hline Constante & 0,625 & 0,050 & $<0,001$ & 0,803 \\
\hline Estatura referida (m) & 0,648 & 0,029 & $<0,001$ & \\
Sexo & $-0,0054$ & 0,005 & $<0,001$ & \\
Escolaridade (anos) & 0,0018 & 0,000 & $<0,001$ & \\
Idade (anos) & $-0,0011$ & 0,000 & $<0,001$ & \\
\hline MASCULINO & 0,605 & 0,073 & $<0,001$ & 0,689 \\
\hline Constante & 0,670 & 0,042 & $<0,001$ & \\
Estatura referida (m) & $-0,0014$ & 0,000 & $<0,001$ & \\
Idade (anos) & 0,0019 & 0,001 & 0,010 & \\
Escolaridade (anos) & \multicolumn{5}{|c}{} \\
\hline FEMININO & 0,572 & 0,064 & $<0,001$ & 0,622 \\
\hline Constante & 0,651 & 0,038 & $<0,001$ & \\
Estatura referida (m) & $-0,0010$ & 0000 & $<0,001$ & \\
Idade (anos) &
\end{tabular}

Nota: $E P=$ erro padrão; $p$-valor $=$ nível descritivo referente à hipótese de beta $=0 ; R^{2}=$ coeficiente de determinação.

\section{Equação geral para correção da estatura referida, ambos os sexos:}

Estatura aferida $=0,625+0,648$ (estatura referida, em metros) $-0,0054$ (sexo) $+0,0018$ (escolaridade, em anos) - 0,0011 (idade, em anos)

Onde: masculino $=0 ;$ feminino $=1$. 
Equação para correção da estatura referida, sexo masculino:

Estatura aferida $=0,605+0,67$ (estatura referida, em metros) - 0,0014 (idade, em anos) $+0,0019$ (escolaridade, em anos)

\section{Equação para a correção da estatura referida, sexo feminino:}

Estatura aferida $=0,572+0,651$ (estatura referida, em metros) $-0,0010$ (idade, em anos)

A qualidade de ajuste avaliada pelo $R^{2}$ não foi tão boa quanto nos modelos para o peso. No modelo final para o sexo masculino as variáveis estatisticamente significativas foram a estatura referida, a idade e a escolaridade. Para o sexo feminino, foram estatisticamente significativas as variáveis estatura referida e idade.

\subsection{Aplicação dos modelos de correção para peso e estatura referidos, elaborados a partir de metade da amostra, em metade restante da amostra.}

No sentido de verificar a utilidade dos modelos de correção propostos em população semelhante à estudada, as equaçōes de correção das medidas referidas geradas a partir de metade da amostra foram aplicadas na metade restante da amostra. A Tabela 27 apresenta a distribuição da população adulta com 40 ou mais anos de idade da área metropolitana de São Paulo segundo categorias de IMC calculado a partir de medidas aferidas, referidas e referidas/ajustadas. 
As equações de correção do peso e estatura referidos não "eliminaram" a subestimação da prevalência da obesidade, induzida pelos valores referidos em ambos os sexos, porém diminuíram a magnitude do erro na prevalência do problema, passando de $-6,0$ para $-2,6$ pontos percentuais, no caso dos homens e de $-8,5$ para $-1,8$ pontos percentuais, no caso das mulheres, aproximando, portanto, a prevalência da obesidade referida à real prevalência de obesidade. Em ambos os sexos, as prevalências da obesidade e do excesso de peso aferidos diferiram estatisticamente (Teste de McNemar: $p=0,001$ para homens e $<0,001$ para mulheres) daquela obtida a partir dos valores antropométricos referidos, porém, não diferiram estatisticamente (homens: $p=0,533$; mulheres: $p=0,092$ ) daquela obtida a partir dos valores referidos/ajustados.

Tabela 27 - Distribuição da população adulta com 40 ou mais anos de idade da área metropolitana de São Paulo (2003) segundo categorias de IMC calculado a partir de medidas aferidas, referidas e referidas/ajustadas, por sexo.

\begin{tabular}{|c|c|c|c|c|c|c|}
\hline \multirow{2}{*}{$\begin{array}{c}\text { Categorias de } \\
\text { IMC }\end{array}$} & \multicolumn{2}{|c|}{ Medidas aferidas } & \multicolumn{2}{|c|}{ Medidas referidas } & \multicolumn{2}{|c|}{$\begin{array}{c}\text { Medidas } \\
\text { referidas/ajustadas* }\end{array}$} \\
\hline & $\mathrm{N}$ & $\%$ & $\mathrm{~N}$ & $\%$ & $N$ & $\%$ \\
\hline IMC $\leq 18,49$ & 5 & 2,6 & 2 & 1,3 & 3 & 2,0 \\
\hline IMC 18,5 a 24,9 & 53 & 35,1 & 67 & 44,4 & 53 & 35,1 \\
\hline IMC 25 a 29,9 & 66 & 43,7 & 63 & 41,7 & 71 & 47,0 \\
\hline IMC 30 a 34,9 & 23 & 15,2 & 16 & ר 10,6 & 21 & 13,9 \\
\hline IMC 35 a 39,9 & 3 & 18,5 & 2 & $1,3\}$ & 1 & 0,7 \\
\hline$I M C \geq 40$ & 2 & 1,3 & 1 & 0,7 & 2 & 1,3 \\
\hline Total & 151 & 100 & 151 & 100 & 151 & 100 \\
\hline Mulheres & $\mathrm{N}$ & $\%$ & $\mathrm{~N}$ & $\%$ & $\mathrm{~N}$ & $\%$ \\
\hline$I M C \leq 18,49$ & 6 & 2,8 & 14 & 6,6 & 7 & 3,3 \\
\hline IMC 18,5 a 24,9 & 59 & 27,8 & 75 & 35,4 & 64 & 30,2 \\
\hline IMC 25 a 29,9 & 69 & 32,5 & 63 & 29,7 & 67 & 31,6 \\
\hline IMC 30 a 34,9 & 49 & 23,1 & 39 & ר 18,4 & 51 & 24,1 \\
\hline IMC 35 a 39,9 & 19 & $9,0\} 36,8$ & 14 & $6,6\}$ & 15 & 35,0 \\
\hline$I M C \geq 40$ & 10 & $4,7 \mathrm{~J}$ & 7 & $3,3 \mathrm{~J}$ & 8 & 3,8 \\
\hline Total & 212 & 100 & 212 & 100 & 212 & 100 \\
\hline
\end{tabular}

Nota: *refere-se ao peso e estatura referidos, ajustados pelos modelos de correção. 
A Tabela 28 mostra a sensibilidade e a especificidade do diagnóstico de obesidade com base em medidas referidas com e sem ajuste, considerando-se os valores aferidos como padrão-ouro. No caso dos homens, os valores de sensibilidade aumentaram entre aqueles mais velhos e com menor escolaridade e permaneceram inalterados nos demais subgrupos. Neste caso, a sensibilidade do diagnóstico de obesidade baseada no IMC calculado a partir do peso e estatura referidos foi relativamente baixa: $68 \%$, aumentando para $71,4 \%$, após o ajuste pelo modelo de correção. No caso das mulheres, a sensibilidade do diagnóstico de obesidade baseada no IMC calculado a partir do peso e estatura referidos também foi relativamente baixa: $68 \%$, porém, após o ajuste pelo modelo de correção, este valor subiu para $83,3 \%$. A especificidade já era muito elevada (>94,0\%) em ambos os sexos e praticamente não sofreu alteração após o ajuste.

Tabela 28 - Sensibilidade (\%) e Especificidade (\%) do diagnóstico de obesidade (IMC $\geq 30 \mathrm{~kg} / \mathrm{m}^{2}$ ) com base em medidas referidas com e sem ajuste, segundo faixa etária e escolaridade, por sexo. População adulta com 40 ou mais anos de idade da área metropolitana de São Paulo, 2003.

\begin{tabular}{l|c|c|c|c|c|c|c|c}
\hline \multirow{2}{*}{ Variáveis } & \multicolumn{4}{|c|}{ Homens } & \multicolumn{4}{c}{ Mulheres } \\
\cline { 2 - 9 } & \multicolumn{2}{|c|}{ Sensibilidade } & \multicolumn{2}{c|}{ Especificidade } & \multicolumn{2}{c}{ Sensibilidade } & \multicolumn{2}{c}{ Especificidade } \\
\cline { 2 - 9 } & $\begin{array}{c}\text { sem } \\
\text { ajuste }\end{array}$ & $\begin{array}{c}\text { com } \\
\text { ajuste }\end{array}$ & $\begin{array}{c}\text { sem } \\
\text { ajuste }\end{array}$ & $\begin{array}{c}\text { com } \\
\text { ajuste }\end{array}$ & $\begin{array}{c}\text { sem } \\
\text { ajuste }\end{array}$ & $\begin{array}{c}\text { com } \\
\text { ajuste }\end{array}$ & $\begin{array}{c}\text { sem } \\
\text { ajuste }\end{array}$ & $\begin{array}{c}\text { com } \\
\text { ajuste }\end{array}$ \\
\hline $\begin{array}{l}\text { Faixa etária } \\
\text { (anos) }\end{array}$ & & & & & & & & \\
40 a 49 & 72,7 & 72,7 & 99,5 & 98,8 & 75,0 & 89,3 & 97,6 & 97,6 \\
50 a 59 & 60,0 & 60,0 & 100,0 & 97,6 & 66,7 & 81,5 & 93,0 & 90,7 \\
60 a 69 & 71,6 & 85,7 & 100,0 & 97,0 & 60,9 & 78,3 & 93,9 & 91,8 \\
& & & & & & & & \\
Escolarida- & & & & & & & & \\
de (anos de & & & & & & & & \\
estudo) & 66,7 & 73,3 & 100,0 & 94,2 & 63,0 & 76,1 & 92,3 & 90,8 \\
0 a 4 & 66,7 & 66,7 & 100,0 & 100,0 & 73,3 & 93,3 & 92,9 & 89,3 \\
5 a 8 & 66,7 & 66,7 & 100,0 & 92,3 & 75,0 & 100,0 & 100,0 & 100,0 \\
12 e mais & 75,0 & 75,0 & 100,0 & 100,0 & 75,0 & 87,5 & 100,0 & 100,0 \\
\hline Total & $\mathbf{6 7 , 9}$ & $\mathbf{7 1 , 4}$ & $\mathbf{1 0 0 , 0}$ & $\mathbf{9 6 , 7}$ & $\mathbf{6 7 , 9}$ & $\mathbf{8 3 , 3}$ & $\mathbf{9 4 , 8}$ & $\mathbf{9 3 , 3}$ \\
\hline
\end{tabular}


A Tabela 29 mostra os valores preditivos positivos e negativos, bem como a eficiência do teste em identificar a obesidade com base em medidas referidas (antes e após ajuste pelos modelos de correção propostos). No caso dos homens, o valor preditivo positivo e a eficiência do teste praticamente não sofreram alteração após o ajuste; o valor preditivo negativo caiu cerca de 10 pontos percentuais. No caso das mulheres, após o ajuste, o valor preditivo positivo praticamente não se alterou. $O$ valor preditivo negativo aumentou passando de $83,6 \%$ para $90,6 \%$ e a eficiência do teste aumentou de $85 \%$ para $89,6 \%$.

Tabela 29 - Valor Preditivo Positivo (\%), Valor Preditivo Negativo (\%) e Eficiência do teste (\%) do diagnóstico de obesidade (IMC $\geq 30 \mathrm{~kg} / \mathrm{m}^{2}$ ) com base em medidas referidas com e sem ajuste, por sexo. População adulta com 40 ou mais anos de idade da área metropolitana de São Paulo, 2003.

\begin{tabular}{l|c|c|c|c|c|c}
\hline \multirow{2}{*}{ Sexo } & \multicolumn{2}{|c|}{ VPP } & \multicolumn{2}{c|}{ VPN } & \multicolumn{2}{c}{ Eficiência do teste } \\
\cline { 2 - 7 } & $\begin{array}{c}\text { sem } \\
\text { ajuste }\end{array}$ & $\begin{array}{c}\text { com } \\
\text { ajuste }\end{array}$ & $\begin{array}{c}\text { sem } \\
\text { ajuste }\end{array}$ & $\begin{array}{c}\text { com } \\
\text { ajuste }\end{array}$ & $\begin{array}{c}\text { sem } \\
\text { ajuste }\end{array}$ & $\begin{array}{c}\text { com } \\
\text { ajuste }\end{array}$ \\
\hline Homens & 100,0 & 93,7 & 93,2 & 83,3 & 94,0 & 92,0 \\
Mulheres & 88,3 & 87,8 & 83,6 & 90,6 & 84,9 & 89,6 \\
\hline
\end{tabular}


A Tabela 30 mostra a sensibilidade e a especificidade do diagnóstico do excesso de peso com base em medidas referidas com e sem ajuste. No caso dos homens, após o ajuste, houve aumento da sensibilidade do diagnóstico de excesso de peso entre os homens mais novos e mais velhos e entre aqueles com maior e menor escolaridade. No caso das mulheres, após o ajuste, a sensibilidade do mesmo diagnóstico apresentou ganho maior, em média 10 pontos percentuais, em todas as categorias, exceto para aquelas com escolaridade entre 5 a 8 anos de estudo. A especificidade do diagnóstico do excesso de peso caiu em ambos os sexos, sobretudo entre os homens.

Tabela 30 - Sensibilidade (\%) e Especificidade (\%) do diagnóstico de excesso de peso (IMC $\geq 25 \mathrm{~kg} / \mathrm{m}^{2}$ ) com base em medidas referidas com e sem ajuste, segundo faixa etária e escolaridade, por sexo. População adulta com 40 ou mais anos de idade da área metropolitana de São Paulo, 2003.

\begin{tabular}{l|c|c|c|c|c|c|c|c}
\hline Variáveis & \multicolumn{4}{|c|}{ Homens } & \multicolumn{4}{c}{ Mulheres } \\
\cline { 2 - 9 } demográficas & \multicolumn{2}{|c|}{ Sensibilidade } & \multicolumn{2}{c|}{ Especificidade } & \multicolumn{2}{c}{ Sensibilidade } & Especificidade \\
\cline { 2 - 8 } & $\begin{array}{c}\text { sem } \\
\text { ajuste }\end{array}$ & $\begin{array}{c}\text { com } \\
\text { ajuste }\end{array}$ & $\begin{array}{c}\text { sem } \\
\text { ajuste }\end{array}$ & $\begin{array}{c}\text { com } \\
\text { ajuste }\end{array}$ & $\begin{array}{c}\text { sem } \\
\text { ajuste }\end{array}$ & $\begin{array}{c}\text { com } \\
\text { ajuste }\end{array}$ & $\begin{array}{c}\text { sem } \\
\text { ajuste }\end{array}$ & $\begin{array}{c}\text { com } \\
\text { ajuste }\end{array}$ \\
\hline Faixa etária & & & & & & & & \\
(anos) & & & & & & & & \\
40 a 49 & 80,6 & 83,3 & 95,7 & 91,3 & 79,2 & 87,5 & 95,5 & 95,5 \\
50 a 59 & 96,9 & 88,9 & 93,8 & 81,3 & 85,4 & 91,7 & 95,5 & 95,5 \\
60 a 69 & 77,3 & 95,5 & 83,3 & 61,1 & 80,4 & 94,1 & 95,2 & 76,2 \\
& & & & & & & & \\
Escolaridade & & & & & & & & \\
(anos de & & & & & & & & \\
estudo) & & & & & & & \\
0 a 4 & 81,8 & 95,5 & 87,0 & 65,2 & 85,2 & 92,6 & 93,3 & 80,0 \\
5 a 8 & 90,0 & 85,0 & 100,0 & 90,0 & 92,3 & 92,3 & 94,1 & 94,1 \\
9 a 11 - & 80,0 & 80,0 & 83,3 & 83,3 & 66,7 & 88,9 & 100,0 & 100,0 \\
12 e mais & 75,0 & 80,0 & 87,5 & 87,5 & 66,7 & 85,7 & 100,0 & 100,0 \\
\hline Total & $\mathbf{8 1 , 5}$ & $\mathbf{8 8 , 3}$ & $\mathbf{9 1 , 2}$ & $\mathbf{7 8 , 9}$ & $\mathbf{8 1 , 6}$ & $\mathbf{9 1 , 2}$ & $\mathbf{9 5 , 4}$ & $\mathbf{8 9 , 2}$ \\
\hline
\end{tabular}


A Tabela 31 mostra os valores preditivos positivos e negativos, bem como a eficiência do teste em identificar o excesso de peso com base em medidas referidas (antes e após ajuste pelos modelos de correção propostos). No caso dos homens, após o ajuste, o valor preditivo positivo caiu de $94 \%$ para $87,4 \%$; O valor preditivo negativo aumentou de $75 \%$ para $80,4 \%$ e a eficiência do teste ficou praticamente inalterada, em torno de $85 \%$. No caso das mulheres, o valor preditivo negativo aumentou de $69,7 \%$ para $81,7 \%$ e a eficiência do teste aumentou passando de $85,8 \%$ para $90,6 \%$, após o ajuste.

Tabela 31 - Valor Preditivo Positivo (\%), Valor Preditivo Negativo (\%) e Eficiência do teste (\%) do diagnóstico do excesso de peso (IMC $\geq 25 \mathrm{~kg} / \mathrm{m}^{2}$ ) com base em medidas referidas com e sem ajuste, por sexo. População adulta com 40 ou mais anos de idade da área metropolitana de São Paulo, 2003.

\begin{tabular}{l|c|c|c|c|c|c}
\hline \multirow{2}{*}{ Sexo } & \multicolumn{2}{|c|}{ VPP } & \multicolumn{2}{c|}{ VPN } & \multicolumn{2}{c}{ Eficiência do teste } \\
\cline { 2 - 7 } & sem ajuste & com ajuste & sem ajuste & com ajuste & sem ajuste & com ajuste \\
\hline Homens & 93,9 & 87,4 & 75,2 & 80,4 & 85,4 & 84,8 \\
Mulheres & 97,6 & 95,0 & 69,7 & 81,7 & 85,8 & 90,6 \\
\hline
\end{tabular}




\section{DISCUSSÃO}

Esse estudo investigou a validade da informação de peso e estatura obtida por entrevista telefônica, em uma amostra probabilística da população de indivíduos com $\mathbf{4 0}$ ou mais anos de idade residentes na área metropolitana de São Paulo em 2003, comparada às informações fornecidas pela mensuração direta dos indivíduos logo após a entrevista.

O razoável grau de acurácia na informação do peso pode ser depreendido a partir da diferença média entre as medidas referidas e aferidas $(0,5 \mathrm{~kg})$ e da proporção de $63 \%$ dos indivíduos que informaram seu peso com uma diferença máxima de $2 \mathrm{~kg}$ (para mais ou para menos) com relação ao seu peso real. As informações referidas de peso e o IMC calculado com base em valores referidos apresentaram boa concordância quando comparadas às suas respectivas aferições ( $C C C=0,95$ para peso e $C C C=0,87$ para $I M C$ ). A estatura auto-referida, entretanto, mostrou-se menos confiável ( $C C C=0,75$ para homens e $\mathrm{CCC}=0,60$ para mulheres) quando comparada à estatura aferida. De fato, mais da metade da população $(53 \%)$ referiu a estatura com diferença superior a $3 \mathrm{~cm}$. A validade das medidas referidas, avaliada a partir da alta sensibilidade ( $71 \%$ ) e especificidade ( $96 \%$ ) do diagnóstico de obesidade (e excesso de peso), mostrou que a entrevista telefônica é um método viável para diagnosticar a prevalência de obesidade nesta população. Entretanto, nossos resultados sugerem cautela ao se utilizar dados auto-referidos de peso e estatura, devido aos erros sistemáticos encontrados. Esses erros (superestimativa da estatura e subestimativa do peso) levam à subestimativa da prevalência de obesidade e excesso de peso e à diminuição da sensibilidade do diagnóstico desses problemas na população. O grau de obesidade foi um dos fatores mais importantes para as diferenças entre peso aferido e referido, em ambos os sexos, sendo influentes ainda, a escolaridade, no caso dos homens, e a idade, 
no caso das mulheres. A idade e escolaridade foram preditores do erro em informar a estatura, em ambos os sexos.

Os modelos de regressão desenvolvidos para predizer os verdadeiros valores do peso e da estatura a partir de valores referidos apresentaram desempenho apenas razoável quando aplicados em população diferente daquela que gerou os referidos modelos. No entanto, as equações de peso e estatura desenvolvidas em metade da amostra (PLATINO), quando aplicadas no restante da amostra, foram úteis em aproximar a prevalência de obesidade referida da verdadeira prevalência de obesidade, bem como em melhorar a sensibilidade do diagnóstico de obesidade e excesso de peso.

A seguir, serão comparados nossos principais achados com a literatura nacional e internacional existente sobre o tema.

No caso do peso, encontramos superestimação entre os homens (cerca de $0,5 \mathrm{~kg}$ ) e subestimação entre as mulheres (também cerca de $0,5 \mathrm{~kg}$ ), resultado similar ao encontrado por SCHMIDT et al., (1993) no Brasil (RS) e por dois outros estudos realizados nos Estados Unidos (KUCZMARSKI et al., 2001 e VILLANUEVA, 2001), porém diferente do encontrado por SILVEIRA et al., (2005) no Rio Grande do Sul, que observaram superestimação do peso em ambos e sexos. Nossos resultados também foram diferentes de outros estudos que observaram subestimativa do peso em ambos os sexos, dois dos quais realizados no Rio de Janeiro por CHOR et al., (1999) e FONSECA et al. (2004) e de outros estudos realizados nos Estados Unidos (TELL et al., 1987; NIETOGARCIA et al., 1990; DEL PRETE et al., 1992; BOWLIN et al., 1993; BOWLIN et al., 1996), Europa (BÖSTROM e DIDERICHSEN, 1997; NIEDHAMMER et al., 2000; BOLTON-SMITH et al., 2000; GUNNELL et al., 2000; PACCAUD et al., 
2001; SPENCER et al., 2002) e Austrália (FLOOD et al., 2000; WANG et al., 2002).

A tendência em informar um peso maior que o real por parte dos homens e menor por parte das mulheres, pode refletir diferenças entre os sexos no que concerne aos padrões culturais de peso culturalmente aceitáveis. Segundo SCHMIDT et al. (1993), independentemente da regularidade ou acurácia com que o indivíduo se pesa, ele forma uma idéia errônea do seu peso, de acordo com uma imagem corporal desejada internamente. Assim, mesmo aquele indivíduo com conhecimento acurado de seu peso, pode ser levado a relatá-lo erroneamente ao entrevistador por necessidade psicológica pessoal como, por exemplo, o desejo de ser mais saudável ou por fatores culturais. Este viés no peso referido, aparentemente para seguir um padrão culturalmente ideal, é consistente com a literatura existente sobre o tema (JALKANEN et al., 1987; PALTA et al., 1982; PIRIE et al., 1981; STUNKARD e ALBAUM 1981).

LARSON (2000) examinou a relação entre discrepâncias no peso (atual vs referido) e o desejo de adaptar-se ao padrão estético imposto pela sociedade utilizando um questionário capaz de avaliar tendências em pensar ou comportar-se dentro de um padrão desejável socialmente. Após ajustes estatísticos para peso atual, o estudo encontrou relação significativamente positiva entre o erro em informar o peso e os escores obtidos por mulheres. Aquelas que obtiveram maiores escores (maior tendência de agir na escala socialmente desejável) tinham maior probabilidade de subestimar o peso, sugerindo, portanto, que as discrepâncias em referir o peso podem ser diretamente influenciadas pelo desejo de adaptar-se às regras da sociedade entre mulheres jovens e não obesas. Esta relação não foi significativa no caso dos homens. 
Observamos, ainda, que as diferenças entre o peso aferido e referido foram influenciadas pelo peso e IMC reais dos indivíduos, em ambos os sexos, e ainda pela idade, nível de escolaridade e estatura real, entre as mulheres. ROWLAND (1989) também encontrou em seu estudo que o peso medido foi o preditor mais forte da discrepância no peso referido, em ambos os sexos.

A tendência à subestimação do peso acentuou-se entre os indivíduos com sobrepeso e obesos, em ambos os sexos; já os indivíduos com peso adequado ou situados nos dois primeiros quartis da distribuição do peso, tenderam a informar um peso superior ao real. Esses resultados foram semelhantes aos encontrados por SCHMIDT et al. (1993) no Brasil e outros estudos realizados em países desenvolvidos (STEWART, 1982; PALTA et al., 1982; KUSKOWSKA-WOLK et al., 1989; ROWLAND, 1990; JEFFERY, 1996; GUNNELL et al., 2000; VILLANUEVA, 2001). Nossos achados, porém, foram diferentes dos encontrados por FONSECA et al. (2004) no Rio de Janeiro que não encontraram maior tendência à subestimação do peso em indivíduos com maior peso.

Observamos também que a idade esteve associada com discrepâncias no peso referido apenas entre mulheres. Em nosso estudo, a tendência de subestimação do peso diminuiu com a idade e, na faixa etária mais velha (70 a 99 anos) houve menor tendência a superestimar o peso, resultados semelhantes aos encontrados em populações de países desenvolvidos (KUCZMARSKI et al., 2001; VILLANUEVA, 2001). De acordo com KUCZMARSKI et al. (2001), a superestimativa do peso, ao invés de subestimativa, talvez indique uma menor pressão social sofrida pelas mulheres de idades mais avançadas. Outros estudos realizados no Brasil não apresentaram associação entre a idade e o erro no peso referido, talvez por estudarem indivíduos de faixa etária inferior à nossa. 
A acurácia em informar o peso também esteve associada com a estatura real apenas no caso das mulheres. Assim, aquelas de menor estatura tenderam a superestimar o peso referido e as mais altas a subestimá-lo. No estudo de SCHMIDT et al. (1993) a influência da estatura real no erro do peso referido apresentou pequena magnitude.

Não houve associação entre a qualidade na informação do peso e escolaridade no caso dos homens. Já entre as mulheres, o nível de escolaridade mostrou-se inversamente relacionado à acurácia na informação do peso, observando-se maior tendência à subestimação entre mulheres com maior escolaridade. Estes resultados são semelhantes aos de um estudo finlandês (JALKANEN et al., 1987), o qual demonstrou que, entre mulheres, o aumento da renda e da escolaridade elevaram as chances de informações incorretas sobre o peso. Outros estudos norte-americanos também demonstraram que quanto maior a escolaridade, maiores eram as diferenças entre o peso aferido e referido, em ambos os sexos (PIRIE et al., 1981; PALTA et al., 1982; NIETO-GARCIA et al., 1990).

É importante entender as potenciais causas das diferenças entre o peso aferido e referido. Se por um lado, espera-se que o indivíduo com menor escolaridade informe o peso de forma menos precisa, devido a ter menor conhecimento sobre seu próprio peso (menos acesso a consultas médicas e balanças domésticas ou comerciais) (JEFFERY, 1996), por outro, o indivíduo com maior escolaridade pode intencionalmente subestimar seu peso movido por uma necessidade psicológica pessoal, seja para melhor enquadrar-se às normas culturais ou pela maior consciência sobre os riscos do excesso de peso (NIETO-GARCIA et al., 1990). Uma possível explicação para associação entre maior escolaridade e maior erro no peso referido pode estar no fato de que a 
imagem corporal e o peso desejável são culturalmente determinados. Assim, quanto maior o nível sócio-econômico e cultural, maior a preocupação com o excesso de peso.

$\mathrm{Na}$ análise de regressão linear múltipla para o sexo masculino, apenas a escolaridade apareceu associada ao erro do peso, explicando $90,8 \%$ da variabilidade do erro médio do peso $(p=0,033)$ no modelo final. Assim, aqueles com maior escolaridade superestimaram menos o peso. Na mesma análise para o sexo feminino, apenas a idade apareceu associada ao erro do peso, explicando $93 \%$ da variabilidade do erro médio do peso $(p<0,001)$ no modelo final. Portanto, as mulheres mais velhas tenderam a subestimar menos o peso.

SHAPIRO e ANDERSON (2003) realizaram análise de regressão múltipla hierárquica para verificar a influência de comportamentos de restrição alimentar (restrained eaters) sobre a acurácia das medidas referidas de peso. A análise revelou que o comportamento de restrição alimentar colaborou com uma proporção significativa da variabilidade na subestimativa do peso (em torno de $4 \%$ ), de forma que os maiores escores de restriçăo alimentar associaram-se com o maior grau de subestimação do peso. Uma possível explicação pode estar no fato de que comedores moderados são altamente preocupados com seu peso e com o padrão cultural para um corpo "ideal", o que os levaria a subestimar o peso. Os autores alertam ainda para o fato de que, em pesquisas cuja população inclua grande proporção de indivíduos com restrição alimentar, o peso referido provavelmente pode estar enviesado.

Em nosso estudo, as discrepâncias entre peso aferido e referido foram inferiores a $2 \mathrm{~kg}$ em $63,2 \%$ dos indivíduos. Estes achados estão de acordo com dois estudos realizados na região Sul do Brasil: um por SILVEIRA et al. (2005) em Pelotas, outro por SCHMIDT et al. (1993) em Porto Alegre, onde $61 \%$ e 
$62 \%$ dos indivíduos estudados referiram peso com um erro inferior a $2 \mathrm{~kg}$, respectivamente. Proporção menor de informações satisfatórias - $52 \%$ - foi encontrada por um estudo norte-americano que também empregou entrevista telefônica (BOWLIN et al., 1993).

A análise do gráfico de concordância de BLAND e ALTMAN confirmou a tendência à subestimativa do peso referido entre as mulheres e superestimativa do peso entre os homens e a tendência de maior subestimação entre os indivíduos com maior peso. Achados semelhantes foram encontrados por CHOR et al. (1999) no Rio de Janeiro e em estudos realizados em países desenvolvidos (NAKAMURA et al., 1999; NIEDHAMMER et al., 2000; PACCAUD et al., 2001; SPENCER et al., 2002; GUNNELL et al., 2000; LARSON 2000; FLOOD etal., 2000).

A alta correlação entre o peso aferido e referido observada em nosso estudo $(r=0,95)$ coincide com os valores elevados $(0,96-0,98)$ observados em outros estudos realizados em população de adultos da França, Espanha e Estados Unidos, tendo este último também empregado entrevistas telefônicas (NIEDHAMMER et al., 2000; ALVAREZ-TORICES et al., 1993; BOWLIN et al., 1996).

O coeficiente de correlação intraclasse entre peso aferido e referido também foi alto em nosso estudo $(0,91)$, porém ligeiramente inferior aos resultados encontrados por CHOR et al. (1999) $(0,98)$ e FONSECA et al. (2004) $(0,97)$ no Brasil e por BOWLIN et al. $(1996)(0,97)$ nos Estados Unidos.

Observou-se, ainda, alto coeficiente de correlação de concordância entre peso aferido e referido, tanto entre as mulheres $(0,95)$ quanto entre os homens $(0,94)$, próximo ao observado no estudo brasileiro de SILVEIRA et al. (2005): 
0,98 . Outros estudos sobre validade de pesos referidos não têm empregado este coeficiente.

Podemos aventar como hipóteses prováveis para a relativa acurácia em reportar o peso, o uso bastante difundido de balanças em drogarias, a posse comum de balanças domésticas ou ainda, numa extensão menor, o acesso da população a serviços de saúde.

No caso da estatura, encontramos superestimação nas informações referidas tanto entre os homens (em média cerca de $2 \mathrm{~cm}$ ) quanto entre as mulheres (em média cerca de $4 \mathrm{~cm}$ ). A tendência de superestimação da estatura em ambos os sexos foi consistente com os achados de outros estudos realizados no Brasil (CHOR et al., 1999, FONSECA et al., 2004 e SILVEIRA et al., 2005). Esta tendência de superestimação da estatura também foi consistente com outros estudos realizados em países desenvolvidos cuja entrevista também foi realizada por telefone (BOWLIN et al., 1993; BOWLIN et al., 1996; BÖSTROM e DIDERICHSEN, 1997; FLOOD et al., 2000; PACCAUD et al., 2001 e DEL PRETE et al., 1992) ou por inquérito domiciliar (STEWART et al., 1987; KUSKOWSKA-WOLK et al., 1989; NIETO-GARCIA et al., 1990; FORTENBERRY, 1992; ROBERTS, 1995; NIEDHAMMER et al., 2000; GUNNELL et al., 2000; SPENCER et al., 2002; STEWART, 1982; PALTA et al., 1982; MILLAR, 1996; ROWLAND, 1990; VILLANUEVA, 2001; WANG ET AL., 2002) e pode ser parcialmente explicada pelo fato de que, na sociedade ocidental onde a obesidade é uma condição menos desejável, é natural que indivíduos possam tender a relatar valores de estatura e peso que estes acreditem estar de acordo com as normas vigentes (KUSKOWSKA-WOLK et al., 1989). 
A maior magnitude de superestimação da estatura que observamos entre mulheres também foi encontrada por dois estudos realizados no Brasil (SILVEIRA et al.; 2005 e FONSECA et al.; 2004) e dois outros estudos realizados por telefone na Suécia (BOSTRÖM e DIDERICHSEN, 1997) e Suíça (PACCAUD et al., 2001). Um terceiro estudo realizado no Brasil não encontrou diferenças relevantes entre estatura informada e medida (CHOR et al., 1999).

Observamos ainda, que as diferenças entre a estatura aferida e referida foram influenciadas pela idade e pelo valor da estatura aferida, em ambos os sexos. A tendência de superestimação da estatura acentuou-se entre os indivíduos mais baixos. Estes resultados foram consistentes com os resultados de CHOR et al. (1999) e de outros estudos realizados em países desenvolvidos (PALTA et al., 1982; TIENBOON et al., 1992; BOSTRÖM e DIDERICHSEN, 1997; NAKAMURA et al., 1999; FLOOD et al., 2000; LARSON, 2000; GUNNELL et al., 2000; NIEDHAMMER et al., 2000; PACCAUD et al., 2001 e SPENCER et al., 2002).

Observou-se também que a tendência de superestimação da estatura foi maior entre os indivíduos mais velhos, em ambos os sexos. $\mathrm{O}$ aumento da superestimativa da estatura de acordo com aumento da idade foi consistente com a literatura de vários países desenvolvidos (ROWLAND, 1990; STEWART, 1982; PALTA et al., 1982; BOSTRÖM e DIDERICHSEN, 1997; KUCZMARSKI et al., 2001; BOWLIN et al., 1993). Sabe-se que a medida da estatura tende a diminuir com o avanço da idade (WHO, 1995) e a taxa de declínio pode variar de $1 \mathrm{a} 2 \mathrm{~cm}$ por década como resultado da compressão vertebral, perda de tônus muscular e declínio postural (WHO, 1998; ALVAREZ-TORICES et al., 1993). Portanto, a superestimativa da estatura parece ter bases fisiológicas, podendo ser explicada, em parte, pelos efeitos da idade (ROWLAND, 1990; KUSKOWSKA-WOLK et al., 1989). 
A análise do gráfico de concordância de BLAND e ALTMAN confirma os achados da análise de variância, sugerindo tendência de superestimação da estatura, em ambos os sexos, sobretudo entre as mulheres.

Após a análise de regressão linear múltipla, as variáveis que estiveram associadas com a estatura relatada incorretamente foram idade e escolaridade, para ambos os sexos, explicando $70 \%$ da variabilidade do erro médio da estatura no modelo final masculino e $59,3 \%$ no modelo final feminino. Assim, quanto mais velho o indivíduo, maior a superestimativa da estatura e quanto maior a escolaridade, menor a superestimativa da estatura. NIEDHAMMER et al. (2000) e STEWART (1982) também encontraram menores diferenças entre a estatura aferida e referida em indivíduos com maior escolaridade, em ambos os sexos. ROWLAND (1989) também encontrou que a idade foi o preditor mais forte da discrepância entre estatura aferida e referida.

Em média, a população do presente estudo referiu menos satisfatoriamente a estatura do que a população de Pelotas (RS). No estudo de SILVEIRA et al. (2005), $43 \%$ dos homens e $27 \%$ das mulheres referiram a estatura com uma diferença de até $1 \mathrm{~cm}$ em relação à estatura aferida, enquanto, em nosso estudo apenas $21,8 \%$ dos homens e $19,7 \%$ das mulheres referiram a estatura neste intervalo. Esta diferença talvez possa ser explicada pela maior escolaridade observada na população de Pelotas em comparação com a nossa.

O coeficiente de correlação de Pearson entre valores aferidos e referidos foi menor para estatura do que para o peso ( $r=0,82$ contra 0,95 ), em ambos os sexos. Nossos achados foram inferiores aos encontrados por NIEDHAMMER et al. $(2000)(r=0,98)$ em amostra de indivíduos com 40 anos ou mais de idade e 
inferiores a três outros estudos norte-americanos, cujos coeficientes de correlação foram 0,96, 0,92 e 0,89, respectivamente (STEWART et al., 1987, ROWLAND, 1990 e BOWLIN et al., 1993).

Situação semelhante à do coeficiente de correlação de Pearson foi encontrada pelo coeficiente de correlação intraclasse entre a estatura aferida e referida $(0,74)$, em ambos os sexos. Nossos resultados foram inferiores aos encontrados por FONSECA et al. $(2004)(0,94)$ no Brasil e BOWLIN et al. $(1996)(0,98)$ nos Estados Unidos. Esta diferença talvez possa ser explicada pela maior escolaridade observada na população destes dois estudos.

Em nosso estudo, observamos menor coeficiente de correlação de concordância entre a estatura aferida e referida do que entre o peso aferido e referido, tanto para homens $(0,75)$ quanto para mulheres $(0,60)$. SILVEIRA et al. (2005) também encontraram menor concordância entre a estatura referida e aferida do que entre o peso referido e aferido, sobretudo entre mulheres, porém os valores do coeficiente de correlação de concordância encontrados por este autor foram superiores aos do nosso estudo $(0,93$ e 0,71 para homens e mulheres, respectivamente), possivelmente devido à maior escolaridade na população de Pelotas.

A informação mais satisfatória sobre estatura por parte dos homens pode ser devido à lembrança da estatura da época do alistamento militar. BAILEY et al. (2000) relataram que apenas $25 \%$ das mulheres com idade superior a 35 anos tinham sua estatura medida em visitas médicas de rotina. Desta forma, mesmo mulheres que recebam cuidado médico regular podem não ter suas estaturas medidas regularmente. Não se pode, entretanto, descartar a possibilidade de que o desejo de ser mais alta e/ou mais saudável determine a superestimativa da estatura entre as mulheres. 
De acordo ZIEBLAND et al. (1996), a superestimativa da estatura se deve, provavelmente, ao fato de que a maioria dos adultos não é medida com freqüência. Por outro lado, em relação ao peso, LARSON (2000), que estudou a relação entre o erro do peso e desejo de adaptar-se às normas impostas pela sociedade, afirma que o peso referido provavelmente é influenciado por normas socialmente impostas para que o indivíduo seja magro. Isto ajudaria a explicar a tendência de a mulher obesa ou com sobrepeso subestimar seu peso mais do que homens na mesma condiçăo, bem como o fato de mulheres mais jovens subestimarem seu peso mais do que as mulheres mais velhas, já que a expectativa da sociedade para magreza é mais evidente para mulheres do que para homens e para mulheres mais jovens do que para mulheres mais velhas (ROWLAND, 1990).

As mulheres, em média, subestimaram seu IMC em aproximadamente $1,5 \mathrm{~kg} / \mathrm{m}^{2} \mathrm{e}$ os homens em $0,40 \mathrm{~kg} / \mathrm{m}^{2}$. A diferença média entre o IMC aferido e referido foi superior àquela encontrada em Pelotas por SILVEIRA et al. (2005), tanto para homens $\left(-0,17 \mathrm{~kg} / \mathrm{m}^{2}\right)$ quanto para mulheres $\left(-1,0 \mathrm{~kg} / \mathrm{m}^{2}\right)$. Subestimativa do IMC em ambos os sexos também foi observada em outros estudos realizados no Rio de Janeiro (CHOR et al., 1999), na França (NIEDHAMMER et al., 2000), Inglaterra (SPENCER et al., 2002) e Nova Zelândia (STEWART et al., 1987). A subestimação do IMC entre mulheres excedeu aquela encontrada entre os homens, também nos estudos de KUCZMARSKI et al. (2001), PACCAUD et al. (2001) e BÖSTROM e DIDERICHSEN (1997).

Em nosso estudo, observamos, ainda, que as diferenças entre o IMC calculado com base nos valores referidos e aferidos foram influenciadas pelo peso e IMC reais. Houve tendência de subestimação do IMC, especialmente 
entre as mulheres e, nos dois sexos, foi maior em indivíduos com IMC igual ou superior a $25 \mathrm{~kg} / \mathrm{m}^{2}$.

A análise do gráfico de concordância de BLAND e ALTMAN confirma os achados da análise de variância, sugerindo maior subestimação do IMC entre as mulheres, tendência que cresce conforme o IMC aumenta.

Neste estudo, as discrepâncias entre o IMC calculado com base nos valores referidos e aferidos foram inferiores a $0,5 \mathrm{~kg} / \mathrm{m}^{2}$ em $47,7 \%$ dos homens e $67,9 \%$ das mulheres. A maior frequeencia de discrepâncias em mulheres deveu-se essencialmente à informação menos acurada de estatura pelas mesmas.

Em nosso estudo, o efeito combinado da subestimação do numerador com a superestimação do denominador na composição do IMC levou a distorções na distribuição do IMC e na prevalência da obesidade, especialmente entre as mulheres, o que poderia prejudicar 0 estudo de associações envolvendo o diagnóstico de obesidade feito a partir de peso e estatura referidos.

Em nosso estudo, as prevalências de obesidade baseadas nas medidas aferidas para homens e mulheres foram, respectivamente, 1,16 e 1,25 vezes maiores do que as prevalências baseadas nos valores referidos. Outros autores relataram efeitos similares considerando a distribuição do IMC (MILLAR, 1986; STEWART et al., 1987; KUSKOWSKA-WOLK et al., 1989; NIETO-GARCIA et al., 1990; ROWLAND, 1990; DEL PRETE et al., 1992; ALVAREZ-TORICES et al., 1993; BOWLIN et al., 1993; WEAVER et al., 1996; BÖSTROM e DIDERICHSEN, 1997; HILL e ROBERTS, 1998 e NIEDHAMMER et al., 2000) ou a prevalência da obesidade e excesso de peso (MILLAR, 1986; BOWLIN et 
al., 1993; ROBERTS, 1995; ALVAREZ-TORICES et al., 1993; KUCZMARSKI et al., 2001).

A alta correlação entre os valores de IMC calculados com base em medidas aferidas e referidas observada em nosso estudo $(0,87$ e 0,90, para homens e mulheres, respectivamente) foi próxima aos valores $(0,94-0,97)$ observados em outros estudos realizados em população de adultos dos Estados Unidos (BOWLIN et al., 1993; NIEDHAMMER et al., 2000) e em população neozelandesa (STEWART et al., 1987). O coeficiente de correlação intraclasse entre os valores de IMC calculados com base em valores aferidos e referidos foi menos elevado que o coeficiente de Pearson $(0,79$ para homens $e$ 0,83 para mulheres), ficando abaixo dos valores encontrados por CHOR et al. (1999) em amostra de funcionários públicos no Rio de Janeiro $(0,95)$. Finalmente, o coeficiente de correlação de concordância entre os valores de IMC calculados com base em valores aferidos e referidos foi também bastante alto entre homens $(0,86)$ e mulheres $(0,87)$, apenas ligeiramente inferiores àqueles observados no estudo brasileiro de SILVEIRA et al. (2005) em ambos os sexos $(0,91)$.

\subsection{Validade do diagnóstico de obesidade}

$\mathrm{Na}$ análise da validade do diagnóstico da obesidade calculada com base nos valores referidos de peso e estatura, foram observados valores razoáveis de sensibilidade ( $78 \%$ e $71,3 \%$ entre homens e mulheres, respectivamente) e elevados de especificidade (98,1\% e $96 \%$ ). As estimativas de sensibilidade situaram-se acima de $70 \%$ para todos os subgrupos estudados, com exceção dos homens com escolaridade entre 5 a 8 anos de estudo $(62,5 \%)$ e mulheres acima de 70 anos de idade $(53,8 \%)$ ou com escolaridade entre 9 e 11 anos de estudos $(61,5 \%)$. A menor sensibilidade no grupo dos homens com baixa 
escolaridade talvez possa ser devido ao desconhecimento ou não disponibilidade de informações atualizadas sobre seu peso e estatura. No caso das mulheres mais velhas, a menor preocupação com padrão estético ou mesmo a falta de informações mais atualizadas sobre peso e estatura também podem ter levado a valores de sensibilidade menores. Já no caso das mulheres com maior escolaridade, os valores de sensibilidade mais baixos talvez possam ser atribuídos ao desejo de ser mais saudável ou à preocupação maior com o excesso de peso.

O valor da sensibilidade do diagnóstico da obesidade a partir de medidas referidas (em torno de $74,5 \%$ ) encontrado neste estudo foi semelhante ao encontrado por FONSECA et al. (2004) no Rio de Janeiro (74\%), NIETOGARCIA et al., (1990) nos Estados Unidos (74\%) e BOWLIN et al. (1996) (74\%) em sua pesquisa também realizada por telefone nos Estados Unidos. Nossos valores foram bem mais altos do que os encontrados por ALVAREZ-TORICES et al. (1993) na Espanha (55\% entre mulheres e $61 \%$ entre os homens), por BOSTRÖM e DIDERICHSEN (1997) na Suécia (55-61\%) e por STEWART et al. (1987) na Nova Zelândia (63\%), porém foi inferior ao encontrado por BOLTONSMITH et al. (2000) na Escócia (83\% e $89 \%$ entre homens e mulheres, respectivamente).

A sensibilidade para o diagnóstico do excesso de peso $\left(\geq 25 \mathrm{~kg} / \mathrm{m}^{2}\right)$ situou-se acima de 81,5\%, com exceção dos homens entre 60 e 69 anos, mulheres mais jovens ( 40 a 49 anos) e mais velhas ( 70 a 99 anos), e mulheres e homens com maior escolaridade. Estes valores de sensibilidade (em torno de $81 \%)$ são semelhantes aos encontrados por um estudo realizado na França (NIEDHAMMER et al., 2000), cuja amostra também era composta por adultos com 40 anos ou mais ( $81,5 \%$ e $80 \%$ para homens e mulheres, respectivamente) e são superiores aos encontrados por FONSECA et al. (2004) no Rio de Janeiro 
(76,6\%), ALVAREZ-TORICES et al. (1993) na Espanha (68\%) e STEWART et al. (1987) na Nova Zelândia (70\%).

Ao se usar um teste diagnóstico pretende-se identificar a presença de uma determinada doença na população. Os testes sensíveis também são úteis no rastreamento (screening) de doenças em grupos populacionais. Neste sentido, a entrevista telefônica mostrou-se mais confiável em detectar indivíduos com excesso de peso $\left(\geq 25 \mathrm{~kg} / \mathrm{m}^{2}\right)$ do que indivíduos obesos $(\geq$ $30 \mathrm{~kg} / \mathrm{m}^{2}$ ).

A especificidade do diagnóstico de obesidade ficou em torno de $97 \%$, valor semelhante ao encontrado por FONSECA et al. (2004) (98\%) e SCHMIDT et al. (1993) (99\%) no Brasil e outros estudos realizados em países desenvolvidos como NIETO-GARCIA et al. (1990) (99\%), BOLTON-SMITH et al. (2000) (97\%), STEWART et al. (1987) (99,6\%) e BOWLIN et al. (1993) (99\%). A alta especificidade indica que é mínima (cerca de $3 \%$ ) a probabilidade de um indivíduo não obeso ser classificado como obeso.

A especificidade do diagnóstico de excesso de peso, em torno de $92 \%$, foi superior aos valores encontrados por FONSECA et al. (2004) $(90,8 \%)$ e STEWART et al. (1987) $(90,1 \%)$, porém foi inferior ao valor encontrado por NIEDHAMMER et al. (2000) em amostra de adultos com 40 anos ou mais $(98,4 \%)$.

O valor preditivo positivo do diagnóstico a partir de medidas referidas foi maior para o excesso de peso do que para obesidade, sobretudo entre as mulheres. Já o valor preditivo negativo do diagnóstico de obesidade (95,2\% para homens e $87,7 \%$ para mulheres) foi maior que do diagnóstico de excesso de peso $(77,6 \%$ e $71,4 \%$, para homens e mulheres, respectivamente). Dentre 
todos os testes realizados, houve maior eficiência em diagnosticar a proporção de testes corretos para obesidade $(91 \%)$ do que para o excesso de peso (cerca de $85 \%$ ).

Vale ressaltar que, enquanto a população deste estudo incluiu adultos de 40 anos ou mais, outros estudos avaliaram peso e estatura referidos em amostras com idade inferior a 40 anos. Talvez parte das diferenças encontradas quanto à qualidade da informação do peso e estatura referida entre esta população e populações de outros países, possa ser explicada pelas diferenças etárias e de escolaridade.

\subsection{Desempenho dos modelos para correção das medidas referidas}

As equações para peso e estatura desenvolvidas com o objetivo de predizer o verdadeiro valor de peso e estatura a partir dos valores referidos, quando aplicadas na amostra do estudo Pró-Saúde, não tiveram utilidade no caso da população masculina e tiveram utilidade apenas modesta no caso da população feminina.

No caso dos homens, o uso das equações de correção não aproximou a prevalência de obesidade referida da verdadeira prevalência de obesidade, ao contrário, aumentou a magnitude do erro na prevalência (de 1,3 para 3,1 pontos percentuais). Além disso, o aumento da sensibilidade do diagnóstico da obesidade foi modesto após a correção. No caso das mulheres, as equações de correção aproximaram a prevalência de obesidade referida da prevalência de obesidade real e aumentaram a sensibilidade do diagnóstico da obesidade em 15 pontos percentuais. 
Encontramos na literatura nove estudos que construíram equações que pudessem predizer verdadeiro valor de peso e/ou estatura a partir dos valores referidos (STEWART, 1982; TELL et al., 1987; KUSKOWSKA-WOLK et al., 1989; ROWLAND, 1990; PIRIE et al., 1981; BOLTON-SMITH et al., 2000; KUCZMARSKI et al., 2001; ÁVILA-FUNES et al., 2005; OSUNA-RAMíREZ et al., 2006). Entretanto, em apenas quatro dos estudos (KUSKOWSKA-WOLK et al., 1989; ROWLAND, 1990; SPENCER et al., 2002; OSUNA-RAMÍREZ et al., 2006) a eficiência das referidas equações foi testada em subamostra da população estudada ou subamostra diferente da estudada.

ROWLAND (1990) também testou equaçōes de regressão e verificou um aumento da sensibilidade do diagnóstico do sobrepeso e da obesidade, porém não mais do que 10 pontos percentuais. A sensibilidade do diagnóstico do baixo peso não foi melhorada. De acordo com este autor, o erro residual em classificar O IMC após o ajuste para vieses pode refletir em erro aleatório, ou seja, não confiabilidade. Nosso estudo verificou, após o ajuste, um aumento na sensibilidade do diagnóstico de obesidade de 7 pontos percentuais, no caso dos homens, e de 15 pontos percentuais, no caso das mulheres.

KUSKOWSKA-WOLK e RÖSSNER (1992) usaram dados de um estudo transversal cuja amostra era representativa da população sueca, no qual tinha sido realizada entrevista pessoal em 7065 homens e 7484 mulheres, com idades entre 16 e 84 anos. Primeiramente os autores calcularam O IMC baseado no peso e estatura referidos e em seguida corrigiram o IMC "referido" de acordo com as equações de regressão derivadas do estudo de validade (KUSKOWSKA-WOLK et al., 1989). Na maioria das comparações houve melhor concordância entre os valores medidos e calibrados do que entre os medidos e referidos, quando as equações foram aplicadas numa população com faixaetária diferente ( $n=295$; entre 25 e 64 anos) (KUSKOWSKA-WOLK e 
RÖSSNER, 1989). De acordo com os autores, a notável concordância entre medido e calibrado demonstrou que as equaçōes de regressão foram confiáveis para a estimação da "real" prevalência de obesidade na população estudada. Não foi possível, no entanto, comparar rigorosamente estes resultados com os de nosso estudo, pois os autores utilizaram equações de regressão que descreveram a relação entre o IMC "aferido" e "referido", enquanto nosso estudo utilizou-se das equações de regressão para peso e estatura referido e aferido.

SPENCER et al. (2002) em seu estudo para avaliar a validade do peso e estatura referidos e determinar a extensão do erro em classificar o IMC a partir de medidas referidas, desenvolveram modelos de regressão utilizando $10 \%$ da população de 35 a 76 anos de idade $(n=480)$ e aplicaram nos $90 \%$ restantes $(n=4328)$. Após correção dos valores referidos usando as equações preditivas, o erro na classificação do IMC caiu 15,2\% em homens e 13,8\% em mulheres. Os autores concluíram que em análises onde os fatores antropométricos são variáveis primárias de interesse, pode-se desenvolver e testar equaçőes de calibração em uma amostra representativa da população a ser estudada a fim de melhorar a acurácia das estimativas de peso, estatura e IMC.

OSUNA-RAMÍREZ et al. (2006) em seu estudo para avaliar a precisão do IMC "referido" e da percepção da imagem corporal auto-referida como indicadores do grau de sobrepeso em população adulta mexicana, desenvolveram modelos de regressão utilizando uma parte da amostra $(n=506)$ e aplicaram no restante da amostra $(n=428)$. Os autores verificaram que houve aumento da sensibilidade do diagnóstico de sobrepeso, obesidade e, sobretudo, do diagnóstico do excesso de peso, além do aumento da correlação entre IMC "medido" e IMC "referido" corrigido. Este estudo, no entanto, não 
explora a concordância entre os valores medidos, referidos e referidos ajustados.

Em nosso estudo, as equações preditoras para peso e estatura desenvolvidas em metade da amostra quando aplicadas na metade restante, foram úteis em aproximar a prevalência de obesidade referida da verdadeira prevalência de obesidade, em ambos os sexos. A sensibilidade do diagnóstico da obesidade e excesso de peso foi melhorada após o ajuste, especialmente entre as mulheres (15 pontos percentuais e 9,6 pontos percentuais, respectivamente).

\subsection{Diferenças entre entrevista telefônica e entrevista pessoal ou questionário de auto-preenchimento}

Os valores informados de peso e estatura, nos diversos estudos por nós revisados, foram obtidos por entrevista pessoal (PIRIE et al., 1981; PALTA et al., 1982; STEWART et al., 1987; NIETO-GARCIA et al., 1990; ROWLAND, 1990; FORTENBERRY, 1992; ALVAREZ-TORICES et al., 1993; SCHMIDT et al., 1993; STRAUSS, 1999; KUCZMARSKI et al., 2001; VILLANUEVA, 2001; WANG et al. 2002; ÁVILA-FUNES et al., 2004; NG et al., 2005), por questionário de auto-preenchimento (STUNKARD e ALBAUM, 1981; STEWART, 1982; JALKANEN et al., 1987; KUSKOWSKA-WOLK et al., 1989; TIENBOON et al., 1992; ZHANG et al., 1993; TROY et al., 1995; ROBERTS, 1995; WEAVER et al., 1996; HILL e ROBERTS, 1998; CHOR et al., 1999; NAKAMURA et al., 1999; BOLTON-SMITH et al., 2000; GUNNELL et al., 2000; NIEDHAMMER et al., 2000; SPENCER et al., 2002; LAWLOR et al., 2002; FONSECA et al., 2004; WADA et al., 2005; ELGAR et al., 2005; SILVEIRA et al., 2005) ou por entrevista telefônica (MILLAR, 1986; TELL et al., 1987; DEL PRETE et al., 1992; SMITH et al., 1992; BOWLIN et al., 1993; BOWLIN et al., 
1996; JEFFERY, 1996; FLOOD et al., 2000; NAWAZ et al., 2001; PACCAUD et al., 2001).

Nenhum dos estudos usou mais do que um dos métodos para obter os dados referidos, exceto BÖSTROM e DIDERICHSEN (1997) que utilizaram entrevista telefônica para completar os dados que não retornaram via correio (questionário). Uma observação mais cuidadosa da magnitude do erro entre valores aferidos e referidos (Tabela 1 ) nos permitiu verificar que a magnitude destas diferenças médias é, geralmente, maior nos estudos que se utilizam de pesquisas telefônicas quando comparados àqueles que se utilizam de entrevista pessoal ou questionários de auto-preenchimento, seguidos por pesagem direta. A comparação da magnitude do erro entre valores aferidos $e$ referidos nos diferentes estudos foi obtida por meio do cálculo da média destes erros (valores referidos menos aferidos). Nos estudos que utilizaram entrevista telefônica verificou-se, em média, subestimação do peso de $-1,03 \mathrm{~kg}$ para homens e -2,33kg para mulheres e superestimação da estatura de $2,28 \mathrm{~cm}$ e $1,52 \mathrm{~cm}$, para homens e mulheres, respectivamente. $O$ mesmo cálculo feito para os valores encontrados nos estudos que utilizaram entrevista pessoal ou questionários de auto-preenchimento resultou em subestimação do peso, em média, de $-0,49 \mathrm{~kg}$ e $-0,96 \mathrm{~kg}$ para homens e mulheres, respectivamente e superestimação da estatura de $+0,94 \mathrm{~cm}$ para homens e $+0,68 \mathrm{~cm}$ para mulheres. Uma possível explicação para estas discrepâncias pode estar no fato de que, em entrevistas telefônicas, o participante não pode ser visto pelo entrevistador, gerando, portanto, uma menor expectativa de avaliação. Desta forma, o participante estaria mais à vontade para informar valores que fossem mais convenientes com a imagem corporal desejada internamente. 
PACCAUD et al. (2001) compararam valores médios e a prevalência de obesidade obtidos em duas pesquisas conduzidas simultaneamente na mesma população (uma por telefone, outra por exame clínico). Apesar das duas pesquisas utilizarem amostras independentes, o que inviabiliza a análise da relação entre medidas aferidas e referidas para o mesmo indivíduo, os autores chamam atenção para o fato de que as prevalências de obesidade e sobrepeso de acordo com pesquisa telefônica foram grosseiramente menores do que aquelas obtidas pelo exame clínico. Os autores argumentam ainda que é improvável que estas discrepâncias sejam devido ao efeito de seleção, ou seja, que o estudo telefônico tenha selecionado participantes mais obesos do que 0 estudo por exame físico e que, ao contrário, há evidências de que pessoas obesas participem menos de pesquisas que tenham exame físico. Embora 0 grupo etário e o delineamento do estudo não sejam exatamente comparáveis com o presente estudo, isto sugere um padrão similar de diferenças entre estudos que utilizam entrevistas telefônicas e entrevistas pessoais.

Se compararmos nossos resultados àqueles provenientes de estudos realizados também por entrevista telefônica encontramos discrepâncias, em relação ao peso, de menor magnitude em ambos os sexos, ainda que em direção oposta no caso dos homens $(+0,54 \mathrm{~kg}$ e $-0,48 \mathrm{~kg}$ para homens e mulheres, respectivamente). Em relação à estatura, encontramos discrepâncias maiores e na mesma direção $(1,98 \mathrm{~cm}$ e $3,97 \mathrm{~cm}$ para homens e mulheres, respectivamente).

\subsection{Limitações do estudo}

5.4.1. Validade interna: $A$ melhor forma de avaliar a validade de um instrumento é comparando-se os resultados obtidos com este instrumento com 
os resultados obtidos usando um instrumento que, por definição, é perfeito (padrão-ouro). Uma importante fonte de erro seria a utilização de um padrăoouro inadequado, ou seja, que não refletisse o "verdadeiro" valor do fenômeno estudado. No entanto, devido ao fato das medidas antropométricas serem realizadas por entrevistadores previamente treinados e coletadas em duplicata de cada indivíduo, acreditamos que esta não tenha sido uma fonte de erro relevante.

Altos percentuais de respostas em branco ou inválidas e recusas podem representar fontes de erro em potencial. No caso deste estudo, as perdas representaram $18,2 \%$ do total da amostra; no entanto, a população excluída não apresentou diferenças estatisticamente significativas em relação à população estudada quanto a gênero, peso, estatura, IMC e escolaridade.

Outra importante fonte de erro dos nossos resultados seria o conhecimento pelos entrevistados sobre nosso interesse em estudar a acurácia de informações referidas de peso e estatura e, em particular, sobre o fato de que seriam pesados e medidos após a entrevista telefônica. Tais circunstâncias foram evitadas uma vez que o objetivo do estudo era o diagnóstico de DPOC na população. Assim, acreditamos que esta não tenha sido uma fonte de erro importante, sendo pouco provável que os participantes tivessem razões específicas para subestimar ou superestimar suas medidas.

O tempo decorrido entre a visita domiciliar (ocasião em que peso e a estatura foram mensurados) e a entrevista telefônica poderia resultar em alguma variação no peso informado (ganho ou perda de alguns quilos). Todavia, se tal variação ocorreu, foi, provavelmente, de pequena magnitude, pois o intervalo de tempo nunca foi superior a 15 dias. 
Em nosso estudo, não dispusemos de informação sobre o tempo decorrido desde a última mensuração de peso e estatura. Espera-se que indivíduos que monitorem seu peso regularmente tendam a referir o peso com maior precisão. De acordo com VILLANUEVA (2001), entre as mulheres, o tempo decorrido desde a última visita médica foi associado ao grau de discrepância do peso referido. No estudo de PACCAUD et al. (2000), as mulheres que se pesavam pelo menos uma vez ao mês (comparadas com aquelas cuja freqüência era de poucas vezes ao ano ou menos) apresentaram um erro menor no valor referido, porém, entre os homens, as diferenças não foram significativas. De acordo com DEL PRETE et al. (1992) a pesagem recente (uma semana) contribuiu com $7 \%$ da variância entre peso aferido e referido. Portanto, encorajar as pessoas a se pesarem antes de informar o peso pode melhorar a acurácia dos dados. Já no caso da estatura, não foram encontradas evidências de que medidas de estatura tomadas recentemente melhorassem significativamente a acurácia dos valores referidos, embora houvesse uma pequena melhora na precisão da informação da estatura, principalmente no caso de pessoas mais velhas (GUNNELL et al., 2000).

Também não dispusemos de informações sobre outros fatores que possivelmente pudessem interferir na magnitude de subestimação do peso como "indivíduo estar tentando perder peso", "estar sob cuidados médicos para perder peso", "auto-percepção sobre o peso atual" (normal, acima ou abaixo do adequado) e "desejo de mudar de peso". Segundo VILLANUEVA (2001), o desejo de mudar de peso está associado ao grau de discrepância do peso referido. De acordo com este autor, há duas vezes mais chance de o participante subestimar seu peso durante a entrevista quando o mesmo refere $o$ desejo de pesar menos ou quando este se percebe como obeso. No estudo de JEFFERY (1996), a participação em programas de perda de peso e histórico de dietas influenciaram a magnitude da subestimativa de peso. 
5.4.2. Validade externa: A população participante foi selecionada de forma probabilística e representativa da população adulta residente no município de São Paulo com 40 anos ou mais de idade; portanto, os resultados observados neste estudo rigorosamente seriam extrapolados apenas para esta população. Entretanto, a alta proporção de cobertura telefônica no município de São Paulo (cerca de $85 \%$ - MONTEIRO et al., 2005) sugere que os resultados poderiam ser extrapolados para o conjunto de população de meia idade e idosa do município de São Paulo e, com alguma calibração, para a população de mesma idade de outros centros urbanos brasileiros com características demográficas, socioeconômicas e de estado nutricional semelhantes à São Paulo.

Apesar destas limitações, o presente estudo é o primeiro no Brasil a verificar a validade de medidas antropométricas auto-referidas através de entrevista telefônica e tem importantes achados e implicações para futuras pesquisas.

\subsection{Implicações dos resultados}

O peso e estatura auto-referidos podem ser usados para calcular o índice de massa corporal, amplamente utilizado em estudos de epidemiologia descritiva e aplicações clínicas, provendo medidas categóricas de obesidade. Assim, os valores auto-referidos de peso e estatura podem ter aplicação no monitoramento da distribuição do IMC na população. Desta forma, dados obtidos continuamente podem ter utilidade na comparação de medidas referidas ao longo tempo. Devido ao fato de a obesidade e excesso de peso serem problemas de saúde pública relevantes no Brasil, um monitoramento regular é importante para avaliar se o tamanho do erro varia e para monitorar a tendência e freqüência da obesidade ao longo do tempo, na população ou em subgrupos vulneráveis. 
As medidas antropométricas auto-referidas também podem ser usadas para estimar prevalência de obesidade. Entretanto, nossos resultados e os demais estudos sobre o tema, sugerem cautela na utilização destes dados, devido aos erros sistemáticos encontrados. Se as medidas de peso e estatura referidas forem usadas para estimar prevalência de obesidade em nível populacional, é provável que os erros (superestimativa da estatura e subestimativa do peso) levem à subestimativa da prevalência de obesidade e excesso de peso gerando falsas conclusões sobre a magnitude do problema de saúde e, consequentemente, a sua menor prioridade para a saúde pública.

Na prática clínica (nível individual), onde maior acurácia do peso e estatura é requerida ou em análises onde os fatores antropométricos são as variáveis primárias de interesse, erros na classificação resultam em indivíduos com sobrepeso ou obesidade sendo classificados como normais, o que poderia levar a vieses na associação entre doenças. Um estudo realizado no México, por exemplo, evidenciou diminuição substancial da associação entre obesidade e asma quando o diagnóstico da obesidade era feito a partir de medidas referidas e não aferidas (SANTILLAN e CAMARGO JR, 2003). Desta forma, uma avaliação apropriada da saúde, bem como medidas de intervenção e educação podem não ser oferecidas a estes indivíduos.

A medida de peso e estatura auto-referida por telefone é um método válido para obter informações sobre a prevalência da obesidade e, devido ao baixo custo e rapidez na obtenção dos dados, pode ser usado em estudos epidemiológicos de larga escala quando os valores reais não puderem ser diretamente obtidos. No entanto, devido aos vieses sistemáticos mencionados, o pesquisador deve estar ciente da necessidade de se corrigir estes erros. 
A fim de melhorar a acurácia das medidas referidas, fatores de correção que pudessem predizer os verdadeiros valores a partir dos valores referidos foram sugeridos e testados pelo presente estudo. $O$ estudo do desempenho destes modelos preditivos evidenciou que a aplicação dos fatores de correção em população diferente daquela que gerou os modelos apresentou utilidade apenas razoável. Entretanto, a aplicação dos fatores de correção (derivados de metade da mostra) na metade restante, foi útil em aproximar a prevalência de obesidade referida da verdadeira prevalência de obesidade, bem como em melhorar a sensibilidade do diagnóstico de obesidade e excesso de peso.

Se o propósito for estimar peso e estatura de grupos de indivíduos semelhantes aos do presente estudo, recomenda-se o estudo do desempenho das medidas referidas de peso e estatura e que sejam desenvolvidas e testadas equações de calibração em uma subamostra da população a ser estudada no sentido de melhorar a acurácia destas medidas. 


\section{CONCLUSÃO}

- As informações referidas de peso através de entrevistas telefônicas apresentaram boa validade e concordância quando comparadas a sua aferição, no entanto, a estatura referida mostrou-se menos acurada e menos confiável quando comparada à estatura real.

- A validade do IMC calculado com base nos valores referidos, avaliada a partir da alta sensibilidade $(71 \%)$ e especificidade $(96 \%)$ do diagnóstico de obesidade (e excesso de peso, $81 \%$ e $92 \%$, respectivamente), mostrou que o uso do peso e estatura obtidos através de entrevista telefônica é um método válido para diagnosticar a prevalência de obesidade na população estudada. Houve alta concordância entre o IMC "referido" e o IMC "aferido" (CCC=0,87; CCIC=0,81).

- O grau de obesidade foi um dos fatores mais importantes para as diferenças entre peso aferido e referido, em ambos os sexos, sendo influentes ainda, a escolaridade, no caso dos homens, e a idade, no caso das mulheres.

- A idade e escolaridade mostraram-se associadas com o erro em informar a estatura, em ambos os sexos.

- Os erros sistemáticos encontrados na informação do peso e estatura autoreferidos (superestimativa da estatura e subestimativa do peso) influenciaram a acurácia na estimativa da prevalência de obesidade e excesso de peso. Para minimizar este problema, recomenda-se a elaboração de equações de calibração. 
- As equações preditivas de peso e estatura desenvolvidas em metade da amostra, quando aplicadas no restante da amostra, foram úteis em aproximar a prevalência de obesidade referida da verdadeira prevalência de obesidade, bem como em melhorar a sensibilidade do diagnóstico de obesidade e excesso de peso.

- As equações preditivas desenvolvidas para predizer os verdadeiros valores do peso e da estatura a partir de valores referidos apresentaram desempenho apenas razoável quando aplicados em população diferente daquela que gerou os referidos modelos. Por isso, recomenda-se o estudo do desempenho das medidas referidas de peso e estatura em subamostra da população a ser estudada, bem como o desenvolvimento e teste de equações de calibração a fim de melhorar a acurácia destas medidas. 


\section{REFERÊNCIAS BIBLIOGRÁFICAS}

Abalkhail BA, Shawky S, Soliman NK. Validity of self-reported height and weight among Saudi School children and adolescents. Saudi Med J. 2000;23(7):831-837.

Abramson JH. Survey Methods in community medicine. An introduction to epidemiological and evaluative studies. London, Churchill Livingstone. Third edition, 1984.

Ajlouni K, Jaddou H, Batieha A. Obesity in Jordan. Int J Obes Relat Disord. 1998; 22: 624-628.

Alvarez-Torices JC, Franch-Nadal J, Alvarez-Guisasola F, Hernandez-Mejia R, CuetoEspinar A. Self-reported height and weight and prevalence of obesity. Study in a Spanish population. Int J Obes Relat Metab Disord. 1993; Nov; 17(11):663-7.

Anjos LA. Índice de massa corporal como indicador do estado nutricional de adultos: revisão de literatura. Rev Saúde Pública. 1992;26(6):431-436.

Avila-Funes JA, Gutierrez-Robledo LM, Ponce De Leon Rosales S. Validity of height and weight self-report in Mexican adults: results from the national health and aging study. J Nutr Health Aging. 2004; 8(5):355-61.

Bailey K, Combs MC, Rogers LJ, Stanley KL. Measuring up. Could this simple nursing intervention help prevent osteoporosis? Association of Women's Health, Obstetrics and Neonatal Nurses Lifelines. 2000; Apr-May; 4(2):41-4.

Bartko JJ, Carpenter WT Jr. On the methods and theory of reliability. J Nerv Ment Dis. 1976; Nov; 163(5):307-17.

Bell AC, Ge K, Popkin BM. Weight gain and its predictors in Chinese adults. Int J Obes Relat Disord. 2001; 25(7):1079-86.

Bell AC, Ge K, Popkin BM. The road to obesity or the path to prevention? Motorized transportation and obesity in China. Obesity Research. 2002; 10:277-83.

Bergamaschi DP. Correlação intraclasse de Pearson para pares repetidos - comparação entre dois estimadores [Tese de Doutorado]. São Paulo: Faculdade de Saúde Pública da USP; 1999.

Black DR, Taylor AM, Coster DC. Accuracy of self-reported body weight: Stepped Approach Model component assessment. Health Education Research. 1998; 13(2);301307. 
Bland JM, Altman DG. Statistical methods for assessing agreement between two methods of clinical measurements. The Lancet. 1986; 8:307-310.

Bland JM, Altman DG. Measuring agreement in method comparison studies. Statistical Methods in Medical Research. 1999; 8:135-160.

Bolton-Smith C, Woodward M, Tunstall-Pedoe H, Morrison C. Accuracy of the estimated prevalence of obesity from self reported height and weight in an adult Scottish population. J Epidemiol Community Health. 2000; 54:143-148.

Boström G, Diderichsen F. Socioeconomic differentials in Misclassification of height, weight and body mass index based on questionnaire data. Int J Epidemiol. 1997; 26(4):860-866.

Bowlin SJ, Morril BD, Nafziger AN, Jenkins PL, Lewis C, Pearson TA. Validity of cardiovascular disease risk factors assessed by telephone survey: The Behavioral Risk Factor Survey. J Clin Epidemiol. 1993; 46(6):561-571.

Bowlin SJ, Morril BD, Nafziger AN, Jenkins PL, Lewis C, Pearson TA. Reliability and changes in Validity of self-reported cardiovascular disease risk factors using dual response: The Behavioral Risk Factor Survey. J Clin Epidemiol. 1996; 49 (5); 511-517.

Burton BT, Foster WR, Hirsch J, Van-Itallie TB. Health implications of obesity. NIH consensus development conference. Int J Obes Relat Metab Disord. 1985; 9:155-69.

Carmines EG, Zeller RA. Reliability and validity assessment. Series: Quantitative applications in the social sciences. SAGE University paper,1979.

Centers for Disease Control and Prevention (CDC) [homepage na internet]. BRFSS in action: tracking health objectives. Atlanta, Georgia: U.S. Department of Health and Human Services, CDC, National Center for Chronic Disease Prevention and Health Promotion. [acesso em maio de 2002]. Disponível em: http://www.cdc.gov/brfss/dataused.htm.

Centers for Disease Control and Prevention (CDC). Public health surveillance for behavioral risk factors in a changing environment: recommendations from the BRFSS Team. MMWR, 2003; 52 (No RR-9).

Chor D, Coutinho ESF, Laurenti R. Reliability of self-reported weight and height among state bank employees in Rio de Janeiro. Rev Saúde Pública. 1999; 33(1):16-23. 
Coitinho DC, Leão MM, Recine E, Sichieri R. Condições nutricionais da população brasileira: adultos e idosos. Pesquisa Nacional sobre Saúde e Nutrição. Ministério da Saúde-INAN, Brasília, 1991.

Del Prete LR, Caldwell M, English C, Banspach SW, Lefebvre C. Self-reported and measured weights and heights of participants in community-based weight loss programs. J Am Diet Assoc. 1992; 92;1483-1486.

Drewnowski A, Popkin BM. The nutrition transition: new trends in the global diet. Nutrition Reviews. 1997; 55:31-43.

Elgar FJ, Roberts C, Tudor-Smith C, Moore L. Validity of self-reported height and weight and predictors of bias in adolescents. Journal of Adolescent Health. 2005; 37: 371-375.

Engstrom JL. Assessment of the Reliability of Physical Measures. Research in Nursing \& Health. 1988; 11:383-389.

Filozof C, Gonzalez C, Sereday M, Mazza C, Braguinsky J. Obesity prevalence and trends in Latin American countries. Obesity Reviews. 2001;2:99-106.

Flegal KM, Carroll MD, Kuczmarski RJ, Johnson CL. Overweight and obesity in the United States: prevalence and trends 1960-1994. Int J Obes Relat Disord. 1998; 22:3947.

Flegal KM, Carroll MD, Ogden CL, Johnson CL. Prevalence and trends in obesity among US adults, 1999-2000. JAMA. 2002; Oct 9;288(14):1723-1727.

Fletcher HR, Fletcher WS, Wagner HE. Epidemiologia Clínica. 2a edição. Porto Alegre: Artes Médicas, 1991.

Flood V, Webb K, Lazarus R, Pang G. Use of self-report to monitor overweight and obesity in populations: some issues for consideration. Aust N Z J Public Health. 2000; Feb(1);96-99.

Fonseca MJM. Índice de massa corporal de funcionários públicos do Rio de Janeiro: Validade da informação referida e associação com posição socioeconômica no Estudo Pró-Saúde. Rio de Janeiro [Tese de Doutorado]. Rio de Janeiro: Universidade do Estado do Rio de Janeiro; 2003.

Fonseca MJM, Faerstein E, Chor D, Lopes CS. Validade de peso e estatura informados e indice de massa corporal: Estudo Pró-Saúde. Rev Saúde Pública. 2004; 38(3):392-398. 
Fortenberry JD. Reliability of adolescents reports of height and weight. Journal of Adolescent Health. 1992;13:114-117.

Galuska DA, Serdula M, Pamuk E, Siegel PZ, Byers T. Trends in overweight among US adults from 1987 and 1993: a Multistate Telephone Survey. Am J Public Health. 1996; 86:1729-1735.

Garrow JS, Webster Y. Quetelet's index as a measure of fatness. Int Obes. 1985;9:147153.

Gigante DP, Barros FC, Post CLA, Olinto MTA. Prevalência de obesidade em adultos e seus fatores de risco. Rev Saúde Pública. 1997;31(3):236-246.

Gunnell D, Berney L, Holland P, Maynard M, Blane D, Frankel S, Smith GD. How accurately are height, weight and leg length reported by the elderly, and how closely are they related to measurements recorded in childhood? Int J Epidemiol. 2000; 29: 456464.

Gutiérrez-Fisac JL, Regidor E, Banegas JR, Rodriguez C. Increasing prevalence of overweight and obesity among Spanish adults, 1987-1997. Int J Obes. 2000; 24:16771682.

Hill A, Roberts J. Body mass index: a comparison between self-reported and measured height and weight. J Publ Health Med. 1998;20(2):206-210.

Himes JH, Faricy A. Validity and reliability of self-reported stature and weight of US adolescents. Am J Human Biol. 2001; Mar-Apr;13(2):255-260.

Hortobagyi T, Israel RG, O'Brien KF. Sensitivity and specificity of the Quetelet index to assess obesity in men and women. Eur J Clin Nutr 1994; 48: 369-75.

Jackson M, Ball K, Crawford D. Beliefs about the causes of weight change in the Australian population. Int J Obes. 2001; 25:1512-1516.

Jalkanen L, Tuomilehto J, Tanskanen A, Puska P. Accuracy of self-reported body weight compared to measured body weight. Scand J Soc Med. 1987; 15: 191-98.

Jeffery RW. Bias in reported body weight as a function of education, occupation, health and weight concern. Addictive Behaviors. 1996;21(2);217-222.

Jeffery RW. Public Health strategies for obesity treatment and prevention. Am J Health Behav. 2001; May-Jun; 25(3):252-9. Review 
Keys A, Fidanza F, Karvonen MJ, Kimura N, Taylor HL. Indices of relative weight and obesity. J Chron Dis. 1972;25:329-43.

Kuczmarski RJ, Flegal KM, Campbell SM, Johnson CL. Increasing prevalence of overweight among US adults. JAMA. 1994; July 20;272(3);205-211.

Kuczmarski MF, Kuczmarski R, Najjar M. Effects of age on validity of self-reported height, weight, and body mass index: findings from the third National Health and Nutrition Examination Survey, 1988-1994. J Am Diet Assoc. 2001;101:28-34.

Kuskowska-Wolk A, Karlson P, Stolt M, Rössner S. The predictive reported weight and height. Int J Obes. 1989;13: 441-453.

Kuskowska-Wolk A, Rossner S. The "true" prevalence of obesity. A comparison of objective weight and height measures versus self-reported and calibration data. Scand J Prim Health Care. 1989;7 79-82.

Kuskowska-Wolk A, Rossner S. Self-reported weight and height considerably affect the weight distribution of a population. Scand J Soc Med. 1992; Sep;20(3):188-9

Kuskowska-Wolk A, Bergström R. Trends in body mass index and prevalence of obesity in Swedish men 1980-89. Journal of Epidemiology and Community Health. 1993a; 47:103-108.

Kuskowska-Wolk A, Bergström R. Trends in body mass index and prevalence of obesity in Swedish women 1980-89. Journal of Epidemiology and Community Health. 1993b; 47:195-199.

Lanningham-Foster L, Nysse LJ, Levine JA. Labor saved, calories lost: the energetic impact of domestic labor-saving devices. Obesity Research. 2003;11: 1178-81.

Larson MR. Social desirability and self-reported weight and height. Int J Obes. 2000; 24:663-665.

Lawlor DA, Bedford C, Taylor M, Ebrahim S. Agreement between measured and selfreported weight in older women. Results from the British Women's Heart and Health Study. Age and Ageing. 2002; 31:169-174.

Lessa I. O adulto brasileiro e as doenças da modernidade: epidemiologia das doenças crônicas não-transmissíveis. São Paulo; Hucitec/ABRASCO; 1998. 284 p. (Saúde em Debate, 114).

Lin LI. A concordance correlation coefficient to evaluate reproductibility. Biometrics. $1989 ; 45: 255-268$. 
Maillard G et al. Trends in the prevalence of obesity in the French population between 1980 and 1991. Int J Obes Relat Metab Disord. 1999;23:389-394.

Manson JE, Willet W, Stampfer MJ, Colditz GA, Hunter DJ, Hankinson SE, Hennekens $\mathrm{CH}$, Speizer FE. Body weight and mortality among women. $\mathrm{N}$ Engl J Med. 1995;333(11):677-685.

Marini A, Gragnolati M. Malnutrition and poverty in Guatemala. Paper 2967 [acesso em 10 de novembro de 2003]. Disponível em http://www.econ.workbank.org/files/24031_wps2967.pdf.

Martorell R, Khan Kettel, Hughes ML, Grummer-Strawn LM. Obesity in women from developing countries. Eur J Clin Nutr. 2000;54:247-252.

Mendez MA, Monteiro CA, Popkin BM. Overweight now exceeds underweight among women in most developing countries. Am J Clin Nutr. 2005;81:714-21.

Menezes AMB, Victora CG, Perez-Padilla R, PLATINO Team. The Platino project: methodology of a multicenter prevalence survey of chronic obstructive pulmonary disease in major Latin American cities. BMC Med Res Methodol. 2004; Jun17;4(1):15.

Millar WJ. Distribution of body weight and height: comparison of estimates based on self-reported and observed measures. J Epidem Commun Health. 1986;40:319-323.

Monteiro CA, Mondini L, de Souza AL, Popkin BM. The nutrition transition in Brazil. European Journal of Clinical Nutrition. 1995;49(2):105-13.

Monteiro CA, Benício MHD'A, Conde WL, Popkin BM. Shifting obesity trends in Brazil. European Journal of Clinical Nutrition. 2000; Apr; 54(4):342-6.

Monteiro CA, Conde WL, Popkin BM. Independent effects in income and education on the risk of obesity in the Brazilian adult population. J Nutr. 2001; 131(3):881S-6S.

Monteiro CA, Conde WL, Popkin BM. Is obesity replacing or adding to undernutrition? Evidence from different social classes in Brazil. Public Health Nutrition. 2002;5:105112.

Monteiro CA, Conde WL, Popkin BM. The burden of disease from undernutrition and overnutrition in countries undergoing rapid nutrition transition: a view from Brazil. Am J Public Health. 2004a; Mar; 94(3):433-4. 
Monteiro CA, Moura EC, Conde WL, Popkin BM. Socioeconomic status and obesity in adult populations of developing countries: a review. Bull World Health Organ. 2004b; Dec; 82(12): 940-6. Review.

Monteiro CA, Moura EC, Jaime PC et al. Monitoramento de fatores de risco para doenças crônicas por entrevistas telefônicas. Rev Saúde Pública. 2005; Fev; 39(1):47-57.

Nakamura K, Hoshino Y, Kodama K, Yamamoto M. Reliability of self-reported body height and weight of adult Japanese women. J Biosoc Sci. 1999;31:555-558.

National Institute of Health Consensus. Health implications of obesity. Ann Intern Med. 1985; Dec.;103(6 - part 2):1073-7.

Nawaz H, Chan W, Abdulrahman M, Larson D, Katz DL. Self-reported weight and height. Implications for obesity research. Am J Prev Med. 2001;20(4):294-298.

Niedhammer I, Bugel I, Bonenfant S, Goldberg M, Leclerc A. Validity of self-reported weight and height in the French Gazel cohort. Int J Obes Metab Disord. 2000; Sep (9):1111-18.

Nielsen SJ, Siega-Riz AM, Popkin BM. Trends in energy intake in the US between 1977 and 1996: similar shifts seen across age groups. Obesity Research. 2002;10:370-8.

Nieto-García FJ, Busch TL, Keyl PM. Body Mass Definitions of Obesity: Sensivity and Specificity using self-reported weight and height. Epidemiology. 1990;1:146-152.

Ng SA, Naidu RS, Tan SLA, Deurenberg-Yap M. Validation of self-reported versus measured height and weight among adult Singaporeans. Int Journal of Body Composition Research. 2005;3(2):43-47.

Oliveira AF; Gadelha AMJ, Leal MC, Szwarcwald CL. Estudo da validação das informações de peso e estatura em gestantes atendidas em maternidades municipais no Rio de Janeiro, Brasil. Cadernos de Saúde Pública. 2004; 20 (Supl 1): 92-100.

Osuna-Ramírez I, Hernandez-Prado B, Campuzano JC, Salmeron J. Body mass index and body image perception in mexican adult population: the accuracy of self-reporting. Salud Publica Mex. 2006; Mar-Apr;48(2):94-103.

Paccaud F, Wietlisbach V, Rickenbach M. Body mass index: comparing mean values and prevalence rates from telephone and examination surveys. Rev Epidemiol Sante Publique. 2001; Feb (1): 33-40. 
Paeratakul S, Popkin BM, Keyou G, Adair LS, Stevens J. Changes in diet and physical activity affect the body mass index of Chinese adults. Int J. Obes Relat Disord. 1998; 22:424-31.

Palta M, Prineas RJ, Berman R, Hannan P. Comparison of self-reported and measured height and weight. Am J Epidemiol. 1982;115:223-230.

Pena M, Bacallao J, editors. Obesity and Poverty: A new Public Health Challenge. Washington, DC: Pan American Health Organization (PAHO), 2000.

Pereira MA, Kartashov AI, Ebbeling CB, Van Horn L, Slattery ML, Jacobs DR Jr, Ludwig DS. Fast-food habits, weight gain, and insulin resistance (the CARDIA study): 15-year prospective analysis. Lancet. 2005; Jan 1-7; 365(9453):36-42.

Pereira RA. Avaliação antropométrica do estado nutricional. In: Epidemiologia da obesidade. Rio de Janeiro: Editora UERJ. pp 44-64, 1998.

Perry GS, Byers TE, Mokdad AH, Serdula MK, Williamson DF. The validity of selfreported of past body weights by US adults. Epidemiology. 1995; Jan, 6(1):61-66.

Pinheiro ARO, Freitas SFT, Corso, ACT. Uma abordagem epidemiológica da obesidade. [homepage na internet] Rev Nutr. 2004; Oct./Dec., 17(4): 523-533. Disponível em http://www.scielo.br/scielo.

Pirie P, Jacobs D, Jeffery R, Hannan P. Distortion in self-reported heigh and weight data. Research. 1981; June,Vol 78: 601-06.

Popkin BM. Nutritional patterns and transitions. Popul Dev Rev. 1993;19:138-157.

Popkin BM. The nutrition transition in low-income countries: an emerging crisis. Nutr Reviews. 1994;52(9):285-298.

Popkin BM. The nutrition transition and its health implication in lower-income countries. Public Health Nutrition. 1998;1:5-21.

Popkin BM. The shift in stages of the nutrition transition in the developing world differs from past experiences. Public Health Nutrition. 2002;5(1A):205-14.

Popkin BM. The nutrition transition in the developing world. Development Policy Review. 2003;21;581-97.

Popkin BM. Using research on the obesity pandemic as a guide to a unified vision of nutrition. Public Health Nutr. 2005;Sep; 8(6A):724-9. Review. 
Popkin BM, Lu B, Zhai F. Understanding the nutrition transition: measuring rapid dietary changes in transitional countries. Public Health Nutrition 2002;5:947-53.

Popkin BM, Zizza C, Siega-Riz AM. Who is leading the change? United States dietary trends 1965-96. Am J Prevent Med. 2003;25:1-8.

Prentice MA. The emerging epidemic of obesity in developing countries. Int J Epidemiol. 2006;35:93-99.

Quiles-Izquierdo J, Vioque J. Validity of notified anthropometric data for determining the prevalence of obesity. Med Clin (Barc). 1996;May 18;106(19): 725-729.

Reed DR, Price RA. Estimates of the heights and weights of family members: accuracy of informant reports. Int J Obes Relat Metab Disord. 1998;Sep; 22(9):827-35.

Remington PL, Smith MY, Williamson DF, Anda RF, Gentry EM, Hogelin GC. Design, Characteristics and Usefulness of State-based Behavioral Risk Factor Surveillance: 1981-87. Public Health Reports. 1988, July-August, 103(4):366-75. Disponível em http://www.cdc.gov/nccdphp/brfss.

Roberts RJ. Can self-reported data accurately describe the prevalence of overweight? Public Health. 1995; Jul;109(4):275-84.

Rowland ML. Reporting bias in height and weight data. Stat Bull Metrop Insur Co. 1989; Apr-Jun;70(2):2-11.

Rowland ML. Self-reported weight and height. Am J Clin Nutr. 1990;52:1125-33.

Santillan AA, Camargo Jr CA. Body mass index and asthma among Mexican adults: the effect of using self-reported vs measured weight and height. Int J Obes. 2003;27:14301433.

Schmidt MI, Duncan BB, Tavares M, Polanczyk CA, Pellanda L, Zimmer PM. Validity of self-reported weight - a study of urban brazilian adults. Rev Saúde Pública. 1993; 27(4):271-6.

Schutz Y, Woringer V. Obesity in Switzerland: a critical assessment of prevalence in children and adults. Int J Obes. 2002; 26(Suppl 2): S3-S11.

Seidell JC. Time trends in obesity: an epidemiological perspective. Horm Metab Res. 1997;29:155-158.

Seidell JC. Obesity: a growing problem. Acta Paediatrica. 1999; Supl. 88(428):46-50. 
Shapiro JR, Anderson DA. The effects of restraint, gender, and body mass index on the accuracy of self-reported weight. Int J Eat Disord. 2003;Jul;34(1):177-80.

Silveira EA, Araújo CL, Gigante DP, Barros AJD, Lima MS. Validação do peso e altura referidos para o diagnóstico do estado nutricional em uma população de adultos no Sul do Brasil. Cad. Saúde Pública. 2005; Fev; 21(1):235-245.

Skodova Z, Pisa Z, Emrova R, Vorlicek J, Vojtisek P, Berka L, Pikhartova J, Cicha Z, Wiesner E, Grafnetter D, et al. Cardiovascular risk factors in the Czech population. Cor Vasa. 1991;33(2):114-22.

Smith GT, Hohlstein LA. Accuracy of self-reported weight: covariation with binger or restrainer status and eating disorder symptomatology, Addictive Behaviours. 1992;17:18.

Solomon CG, Manson JE. Obesity and mortality: a review of the epidemiologic data. Am J Clin Nutr. 1997;66(Suppl):1044-50.

Spencer EA, Appleby PN, Davey GK, Key TJ. Validity of self-reported height and weight in 4808 EPIC-Oxford participants. Public Health Nutr. 2002;5(4): 561-565.

Stevens J, Keil JE, Waid LR, Gazes PC. Accuracy of current 4-year and 28-year selfreported body weight in an elderly population. Am J Epidemiology. 1990; 132:1156-64.

Stewart AL. The reliability and validity of self-reported weight and height. J Cron Dis. $1982 ; 35: 295-309$.

Stewart AW, Jackson RT, Ford MA, Beaglehole R. Underestimation of relative weight by use of self-reported weight and height. Am J Epidemiol. 1987;125 (1):123-6.

Strauss RS. Comparison of measured and self-reported weight and height in a crosssectional sample of young adolescents. Int J Obes. 1999;23:904-908.

Stunkard AJ, Albaum JM. The accuracy of self-reported weight. Am J Clin Nutr. 1981; 34:1593-99.

Swinburn BA, Ley SJ, Carmichael HE, Plank LD. Body size and composition in Polynesians. Int J Obes Relat Disord. 1999; 23(11):1178-83.

Swinburn BA, Caterson I, Seidell JC, James WPT. Diet, nutrition and the prevention of excess weight gain and obesity. Public Health Nutrition. 2004; 7(1A):123-146. 
Tell GS, Jeffery RW, Kramer FM, Snell MK. Can self-reported body weight be used to evaluate long-term follow-up of a weight-loss program? J Am Diet Assoc. 1987; 87(9):1198-1201.

Tienboon P, Wahlqvist ML, Rutishauser IHE. Self-reported weight and height in adolescents and their parents. Journal of Adolescent Health. 1992;13:528-532.

Troy LM, Hunter DJ, Manson JE, Colditz GA, Stampfer MJ, Willet WC. The validity of recalled weight among younger women. Int $\mathrm{J}$ Obes Relat Metabol Disord. 1995;19(8):570-572.

Villanueva EV. The validity of self-reported weight in US adults: a population based cross-sectional study. BMC Public Health. 2001;1 (1):11.

Zhang J, Feldblum PJ, Fortney JA. The validity of self-reported height and weight in perimenopausal women. m J Public Health. 1993; Jul;83(7):1052-3.

Ziebland S, Thorogood M, Fuller A, Muir J. Desire for the body normal: body image and discrepancies between self reported and measured height and weight in a British population. J Epidemiol Community Health. 1996; 50:105-106.

Wada K, Tamakoshi K, Tsunekawa T, Otsuka R, Zhang H, Murata C, Nagasawa N, Matsushita K, Sugiura K, Yatsuya H, Toyoshima H. Validity of self-reported height and weight in a Japanese workplace population. Int J Obes (Lond). 2005; Sep;29(9):1093-9.

Walker ARP, Adam F, Walker BF. World pandemic of obesity: the situation in Southern African populations. Public Health. 2001;115:368-372.

Wang Z, Patterson CM, Hills AP. A comparison of self-reported and measured height, weight and BMI in Australian adolescents. Aust N Z J Publ Health. 2002; 26(5):473478.

Wang Y, Monteiro AC, Popkin BM. Trends of overweight and underweight in children and adolescents in the United States, Brazil, China and Russia. Am J Clin Nutr. 2002;75:971-7.

Weaver TW, Kushi LH, McGovern PG, Potter JD, King RA, Whitbeck J, Greenstein J, Sellers TA. Validation study of self-reported measures of fat distribution. Int. J. Obesity. 1996;20:644-50.

WHO (World Health Organization). Diet, nutrition and the prevention of chronic diseases. Report of a WHO Study Group. WHO Technical Report Series, 797. Geneva, WHO, 1990. 
WHO (World Health Organization). Physical status: The use and interpretation of anthropometry. WHO Technical Report Series, 854. Geneva, WHO, 1995.

WHO (World Health Organization). Life in the $21^{\text {st }}$ century: a vision for all. The world health report. Geneva, WHO, 1998a.

WHO (World Health Organization). Expert Subcommittee on the Use and Interpretation of Anthropometry in the Elderly. Uses and Interpretation of Anthropometry in the Elderly for the assessment of physical status.: report to the nutrition unit of the World Health Organization. J Nutr Health Ageing. 1998b; 2:5-17.

WHO (World Health Organization) Obesity: preventing and managing the global epidemic. Report of a WHO consultation. WHO Technical Report Series, 894. Geneva, Switzerland. WHO, 2000a.

WHO (World Health Organization). WHO Regional Office for the Western Pacific. The Asia-Pacific Perspective: Redefining obesity and its treatment. Manila, Philippines, $2000 \mathrm{~b}$.

WHO (World Health Organization). The world health report 2002: Reducing risks, promoting healthy life. Geneva, WHO, 2002.

WHO/FAO. Diet, nutrition and the prevention of chronic diseases. [Report of the joint WHO/FAO expert consultation]. Geneva, World Health Organization, 2003.

Willet WC. Anthropometric measures and body composition. In: Nutritional Epidemiology. $2^{\text {nd }}$ ed. Oxford University Press, 1998.

Yoshike N, Matsumura Y, Zaman MM, Yamaguchi M. Descriptive epidemiology of body mass index in Japanese adults in a representative sample from the National Nutrition Survey 1990-1994. Int J Obes Relat Metab Disord. 1998; 22:684-687. 